

\section{DISCLAIMER}

This report was prepared as an account of work sponsored by an agency of the United States Government. Neither the United States Government nor any agency Thereof, nor any of their employees, makes any warranty, express or implied, or assumes any legal liability or responsibility for the accuracy, completeness, or usefulness of any information, apparatus, product, or process disclosed, or represents that its use would not infringe privately owned rights. Reference herein to any specific commercial product, process, or service by trade name, trademark, manufacturer, or otherwise does not necessarily constitute or imply its endorsement, recommendation, or favoring by the United States Government or any agency thereof. The views and opinions of authors expressed herein do not necessarily state or reflect those of the United States Government or any agency thereof. 


\section{DISCLAIMER}

Portions of this document may be illegible in electronic image products. Images are produced from the best available original document. 
The facilities of Argonne National Laboratory are owned by the United States Government. Under the terms of a contract (W-31-109-Eng-38) between the U. S. Atomic Energy Commission, Argonne Universities Association and The University of Chicago, the University employs the staff and operates the Laboratory in accordance with policies and programs formulated, approved and reviewed by the Association.

\section{MEMBERS OF ARGONNE UNIVERSITIES ASSOCIATION}

The University of Arizona Carnegie-Mellon Univer sity

Case Western Reserve University

The University of Chicago

University of Cincinnati

Illinois Institute of Technology

University of Illinois

Indiana University

Iowa State University

The University of Iowa
Kansas State University The University of Kansas Loyola University Marquette University Michigan State University The University of Michigan University of Minnesota University of Missouri Northwestern University University of Notre Dame
The Ohio State University Ohio University

The Pennsylvania State University Purdue University

Saint Louis University

Southern Illinois Univer sity

University of Texas

Washington University

Wayne State University

The University of Wisconsin

\section{LEGAL NOTICE}

This report was prepared as an account of Government sponsored work. Neither the United States, nor the Commission, nor any person acting on behalf of the Commission:

A. Makes any warranty or representation, expressed or implied, with respect to the accuracy, completeness, or usefulness of the information contained in this report, or that the use of any information, apparatus, method, or process disclosed in this report may not infringe privately owned rights; or

B. Assumes any liabilities with respect to the use of, or for damages resulting from the use of any information, apparatus, method, or process disclosed in this report.

As used in the above, "person acting on behalf of the Commission" includes any employee or contractor of the Commission, or employee of such contractor, to the extent that such employee or contractor of the Commission, or employee of such contractor prepares, disseminates, or provides access to, any information pursuant to his employment or contract with the Commission, or his employment with such contractor.

Printed in the United States of America

Available from

Clearinghouse for Federal Scientific and Technical Information

National Bureau of Standards, U. S. Department of Commerce

Springfield, Virginia 22151

Price: Printed Copy $\$ 3.00 ;$ Microfiche $\$ 0.65$ 


\section{ARGONNE NATIONAL LABORATORY \\ 9700 South Cass Avenue \\ Argonne, Illinois 60439}

THE EFFECTS OF

\section{AN OVER - COOLED STAINLESS STEEL REFLECTOR}

ON THE EBR-II POWER COEFFICIENT

by

R. R. Smith, T. R. Bump,* R. A. Cushman, R. W. Hyndman, F. S. Kirn, W. B. Loewenstein, J. K. Long, J. T. Madell, P. J. Persiani,** and W. R. Wallin

\section{EBR-II Project}

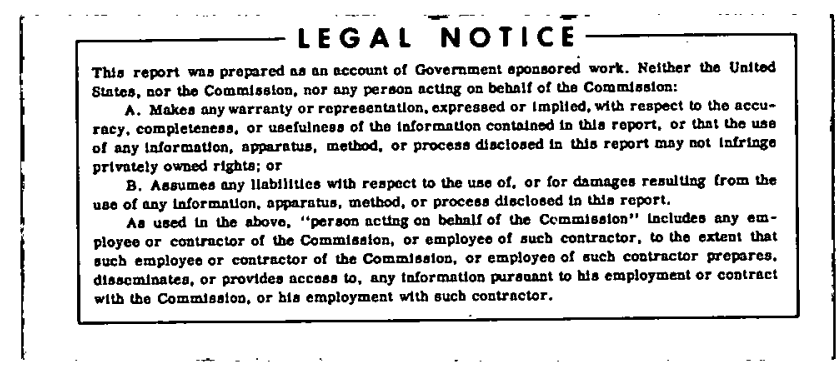

May 1969

*Reactor Engineering Division

**Reactor Physics Division 
TABLE OF CONTENTS

$\underline{\text { Page }}$

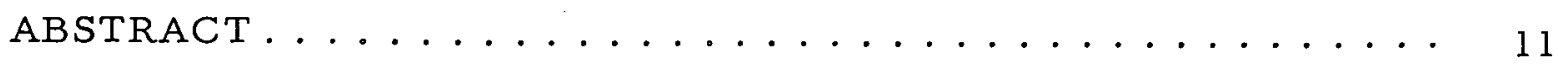

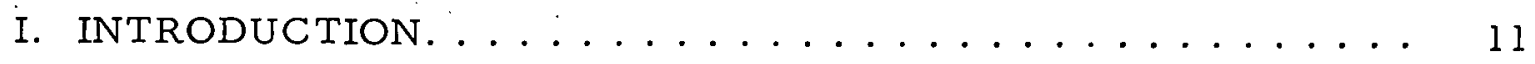

II. REVIEW OF PREVIOUS POWER-COEFFICIENT BEHAVIOR . . 15

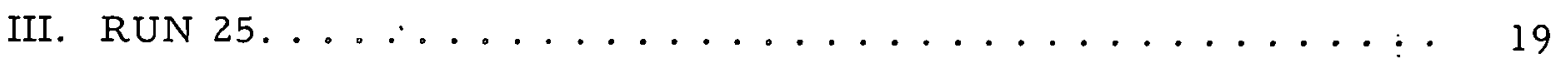

A. Loading Changes Implemented prior to Run-25 Startup ... 19

B. Run-25 Startup . . . . . . . . . . . . . . 22

C. Special Physics Tests ................. 23

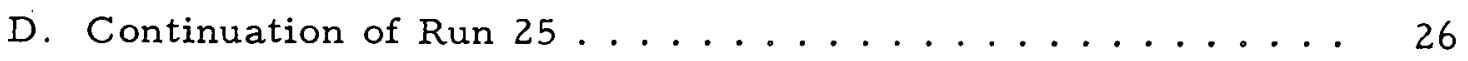

E. Fission-product Release of May 24, 1967. . . . . . . 26

F. Rod-bank Effect . . . . . . . . . . . . . . . 28

G. Randomization of Clearance Systems . . . . . . . . 33

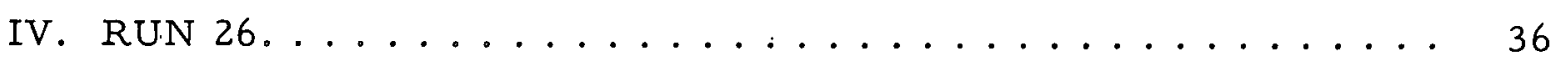

A. Powier-coefficient Measurements during Run-26A Startup. . 36

B. Experimental Investigation of the Banked-control-rod Effect........................ 38

C. Continuation of Run 26 (Run 26B) ............ 41

D. Continuation of Run $26(\operatorname{Run} 26 \mathrm{C}) \ldots \ldots \ldots \ldots \ldots$

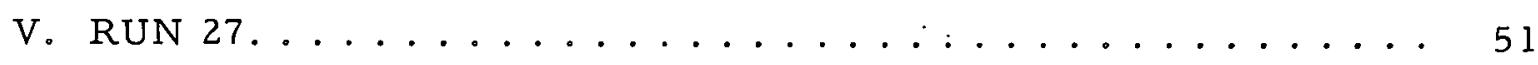

A. Damage to the No.-12 Control-rod Guide Thimble...... 51

B. Reactivity Anomaly of January 29, 1968. . . . . . . . . 53

C. Run-27A Startup ...................... 55

D. Fission-product Release of March 5, 1968......... 57

E. Search for the Origin of the March 5, 1968 Fissionproduct Release .................. 57 
TABLE OF CONTENTS

Page

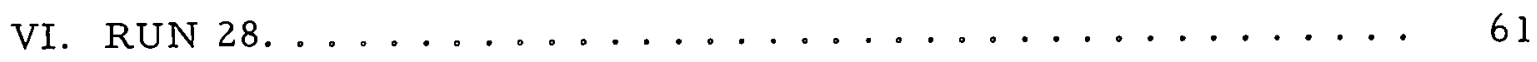

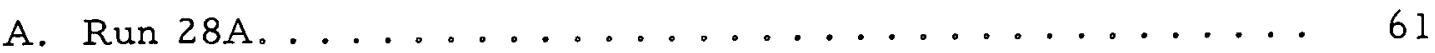

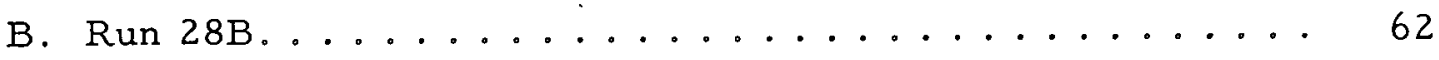

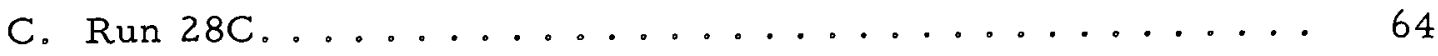

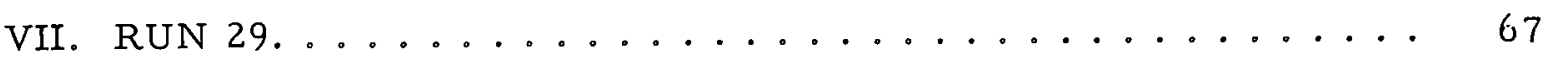

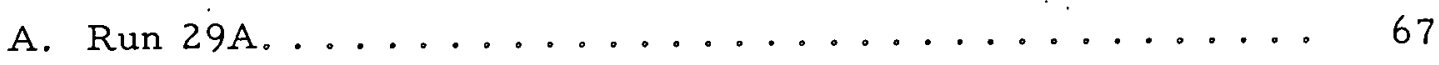

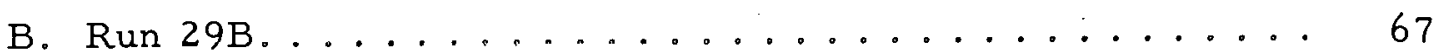

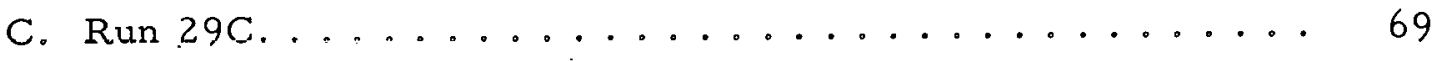

D. Relative Reactivities of Depleted Uranium and

Stainless Steel in the Reflector ............. 71

E. Summary of Startup Power-coefficient Data........ 71

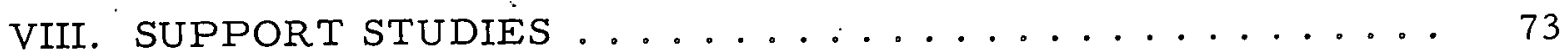

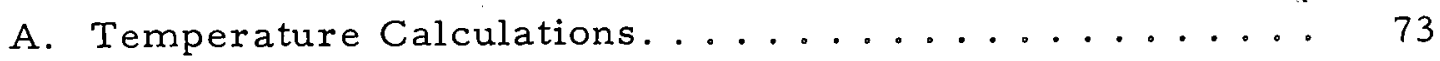

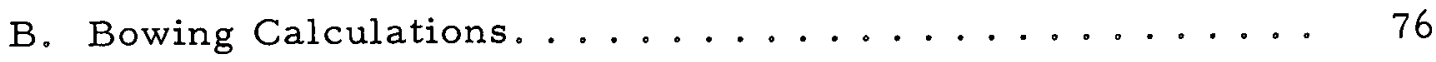

C. Deformation of Subassemblies during Runs 25 and 26... 81

D. Effects of Changes in Core Radius on Reactivity...... 82

E. Separation of Nonlinear Feedback Effects ........ 83

F. Constant- $\Delta T$ Experiments. . . . . . . . . . . 84

G. Flow-coefficient Measurements............ 85

H. The Effects of Core Size and Composition on Power

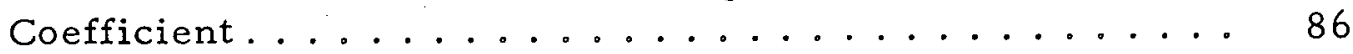

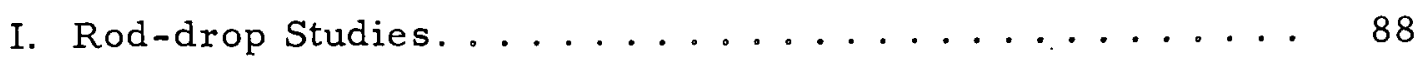

J. Transfer-function Measurements ............. 95

K. Trapezoidal Reactivity-insertion Technique........ 99

L. Monitoring of Subassembly Outlet Temperatures. .... 101

M. Synthesis of a Feedback Model.............. 103 


\section{TABLE OF CONTENTS}

Page

IX. PHYSICAL FEEDBACK MODEL .............. 106

A. The Effects of Subassembly Bowing ........... 106

B. Consistency of the Model with Experimental

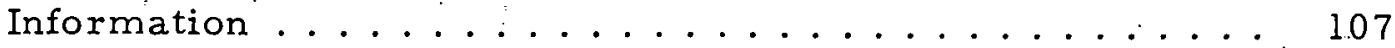

C. Other Power-coefficient Anomalies . . . . . . . 108

1. Deterioration of the Power Coefficient during Run 26: . 108

2. Reactivity Anomaly on January 29, $1968 \ldots \ldots 9$

3. The Increase in PRD during Runs 27 through $29 \ldots 110$

4. Long-term Changes in Power Coefficient ........ 110

X. THE EFFECT OF REINSTALLING A URANIUM REFLECTOR ON THE POWER COEFFICIENT ................. 112

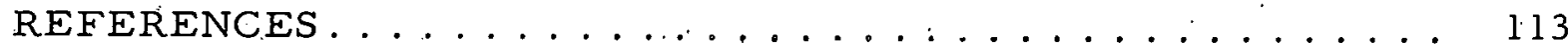




\section{LIST OF FIGURES}

No.

Title

Page

1. Power-coefficient Data from Run 16, Taken 4/18/66 . . . . . . 18

2. EBR-II Experimental Loading for Run 24, December 1966; 81 -subassembly Core .................... 20

3. EBR-II Experimental Loading for Run 25, April 17, 1967;

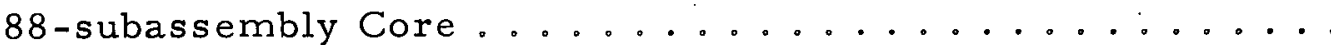

4. Power-coefficient Data for Run 24, December 10, 1966, and Run-25 Startup, April 21, $1967 \ldots \ldots \ldots \ldots$

5. Power-coefficient Data for Run 24, December 10, 1966 , and Run 25, April 26 and 27, $1967 \ldots \ldots \ldots 24$

6. Power-coefficient Data for Run 25, May 19, 1967 ....... 27

7. Run-25 Power-coefficient Data with Rod Bank of 11.4 and

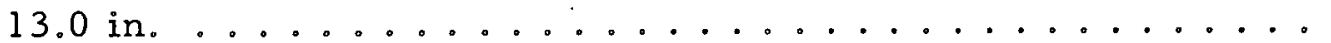

8. Run-25 Power-coefficient Data, Normalized to a Rod Bank of 11.00 in

9. Run-25 Power-coefficient Data, Uncorrected for Banked-

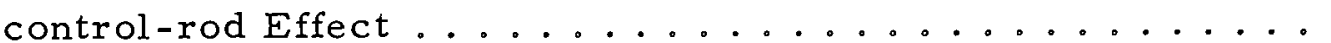

10. Run-25 Power-coefficient Data, Corrected for Banked-

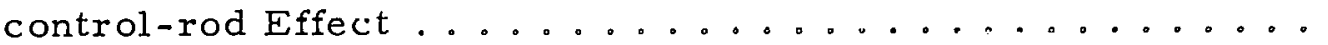

11. The Effect of Clearance Randomization on Ruli-25 Powcr Coefficient; Data Normalized to Rod Bank of 11.00 in.

12. Power-coefficient Data from Run 26A and the End of Run 25, Normalized to a Rod Bank of 11.00 in. ........ 37

13. Run-26A Power-coefficient Data for Increasing and Decreasing Power Modes and Normalized to a Rod Bank of $11.00 \mathrm{in}$.

14. Run-26B Power-coefficient Data Taken on October 14, 1967, Normalized to a Rod Bank of 11.00 in. . . . . . . . . .

15. Run-26B Power-coefficient Data, Normalized to a Rod Bank

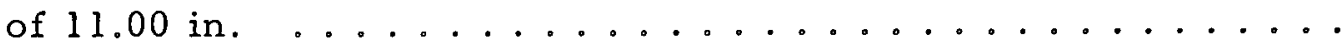

16. Run-26C Power-coefficient Data Taken on November 25 and 30, Normalized to a Rod Bank of 11.00 in. . . . . . . . . .

17. Run-26C Power-coefficient Data Taken on December 11, 1967, Normalized to a Rod Bank of 11.00 in. . . . . . . . .

18. ${ }^{133} \mathrm{Xe}$ and ${ }^{135} \mathrm{Xe}$ Activities in Cover Gas, December 1-13,.1967. 


\section{LIST OF FIGURES}

No. Title

Page

19. Damage at Top of No.-12 Control-rod Thimble ........ 52

20. Dimensions of Deformation of No.-12 Control-rod Thimble . . 52

21. Run-27A Power-coefficient Data Taken on February 5, 1968, Normalized to a Rod Bank of 11.00 in. ........... 55

22. Run-27A Power-coefficient Data Taken on February 8, 23, and 28, 1967, Normalized to a Rod Bank of 11.00 in. . . . . 56

23. Power-coefficient Data for Runs 27D and 27E, Normalized to

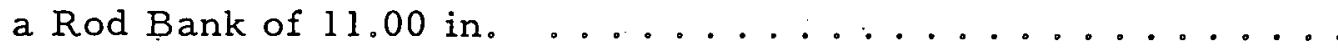

24. Power-coefficient Data for Runs $27 \mathrm{~F}$ through 27I, Normalized

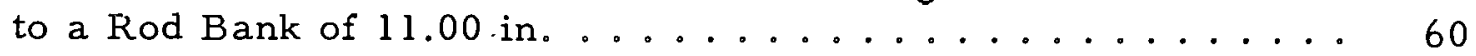

25. EBR-II Loading Pattern for Run 28A ............. 6 I

26. Run-28A Power-coefficient Data, Normalized to a Rod Bank

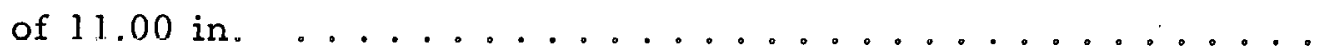

27. Run-28B Power-coefficient Data, Normalized to a Rod Bank of 11.00 in.

28. EBR-II Loading Pattern for Run 28C ............. 65

29. Run-28C Power cocfficient Datd, Nurmalized to a Rod Bank

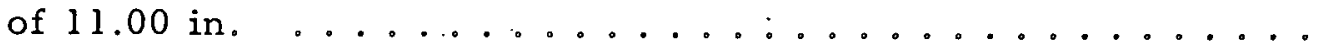

30. Run-29A Power-coefficient Data, Normalized to a Rod Bank

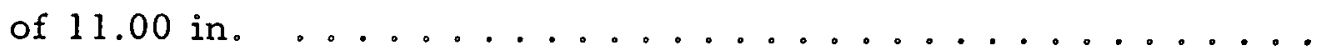

31. Run-29B Power-coefficient Data, Normalized to a Rod Bank

32. Run-29C Power-coefficient Data Taken on July 16; 1968, Normalized to a Rod Bank of 11.00 in.

33. Run-29C Power-coefficient Data Taken July 17, 1968, Normalized to a Rod Bank of 11.00 in.

34. Comparison of Power-coefficient Data for Runs 29A, 29B,

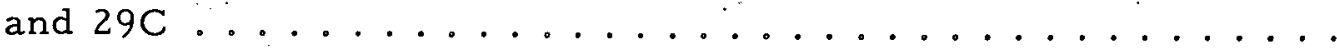

35. Comparison of Startup Power-coefficient Data for Runs 24 through 29C, Normalized to a Rod Bank of 11.00 in.

36. Variation in PRD with Time during Runs 25 through 29C;

All Values Normalized to a Rod Bank of 11.00 in. ........

37. Gamma-heat Production in Rows 7 through $9 \ldots \ldots$ 


\section{LIST OF FIGURES}

No

Title

Page

38. Fission Distribution in Row 9 for ${ }^{235} \mathrm{U},{ }^{238} \mathrm{U}$, and ${ }^{239} \mathrm{Pu} \ldots \ldots$

39. Unrestrained Thermal-bowing Deflections for Runs 17-24;

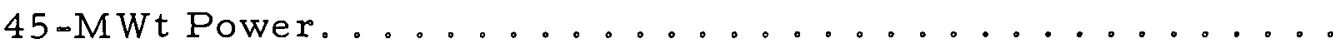

40. Unrestrained Thermal-bowing Deflections for Run 25;

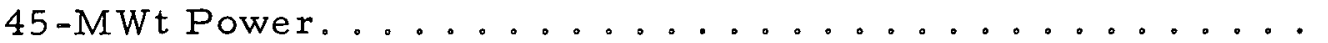

41. Comparison of Calculated and Experimentally Based Nonlinear Reactivity Feedbacks for Runs 24 and $25 \ldots$

42. Effect of Size of Hypothetical EBR-II Core on PRD........

43. Power Trace Following Rod Drop on May 17, 1967;

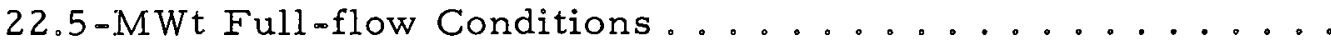

44. Reactivity Recovery under Various Conditions of Power

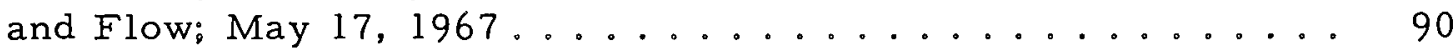

45. Reactivity Recovery at $500-\mathrm{kW}$ Power ............. 91

46. Reactivity Feedback to System as a Function of Time;

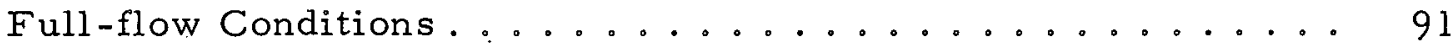

47. Reactivity Recovery under Full-flow Conditions; July $23,1967 \ldots \ldots \ldots \ldots \ldots$

48. Reactivity Feedback to System as a Function of Time;

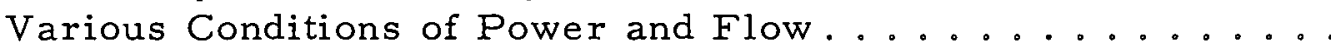

49. Comparison of Reactivity Recoveries Measured at $30 \mathrm{MWt}$ and $100 \%$ Flow on May 17 and July 23, 1967..........

50. Comparison of Reactivity Recoveries Measured at 41.5 MWt

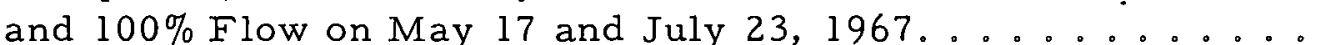

51. Results of Rod-drop Experiments at 22.5 MWt during Run 26A. 93

52. Results of Rod-drop Experiments at $30.0 \mathrm{MWt}$ during Run 26B . 94

53. Results of Rod-drop Experiments at 41.4 MWt during Run 26B.

54. Feedback as Determined from Oscillator-rod Data Obtained at 22.5 MWt on October 23, 1967, during Run 26B; Rod-bank Position 11.5 in.

55. Feedback as Determined from Oscillator-rod Data Obtained at $30 \mathrm{MWt}$ on October 18, 1967, during Run 26B; Rod-bank

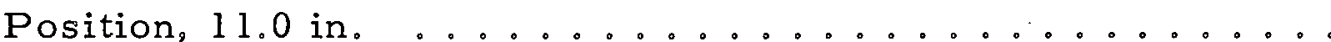

56. Feedback as Determined from Oscillator-rod Data Obtained at $41.5 \mathrm{MWt}$ on October 18, 1967, during Run 26B; Rod-bank Position, 11.0 in. 


\section{LIST OF FIGURES}

No.

57. Response of Power to Trapezoidal Reactivity Change . . . . . . 99

58. Thermocouple Locations in EBR-II . . . . . . . . . . . . 102

59. Fit of Mathematical Feedback Models to Data from Roddrop Experiment at $22.5 \mathrm{MWt}$ in Run 26B . . . . . . . . . . 104

60. Fit of Mathematical Models to Nyquist Plot of Oscillator Feedback Function at $22.5 \mathrm{MWt}$ in Run 26B . . ....... 105 


\section{LIST OF TABLES}

No.

$\underline{\text { Title }}$

$\underline{\text { Page }}$

I. PRD Data for Different Banked Pósitions of Control Rods . . 38

II. PRD Normalized to Nominal Banked Position of 11.0 in. . . 40

III. PRD for Hypothetical EBR-II Core. without Control Rods . . . 40

IV. Comparison of Measured and Calculated Reactivity Changes for Shifts in the Banked Position......... 40

V. Reactivity Drift on November 7 and $8,1967 \ldots \ldots 44$

VI. Reactivity Drift on October 23 and 24, 1967......... 44

VII. Effects of a Scram on Reactivity Balance,

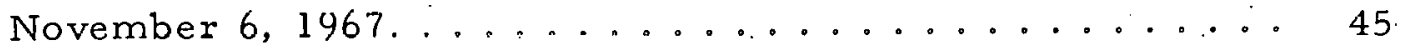

VIII. Reactivity Balance from 0800 on $11 / 29 / 67$ to 0600 on

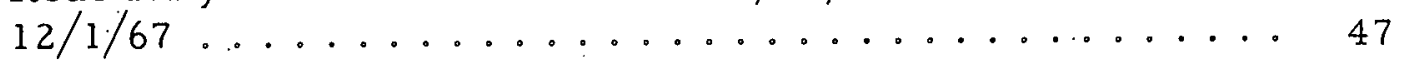

IX. Reactivity Balance from 1400 on $12 / 9 / 67$ to 1000 on

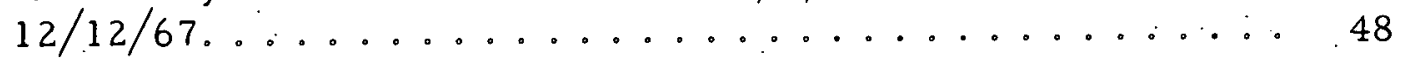

X. Transfer of Experiments between Runs $26 \mathrm{C}$ and $27 \mathrm{~A} \ldots . . .53$

XI. Calculated $\mathrm{k}_{\mathrm{ex}}$ for Run $27 \mathrm{~A} \ldots \ldots \ldots . \ldots . \ldots . . \ldots 54$

XII. Estimated and Measured Values for $k_{\text {ex }}$, Run 27A ..... 54

XIỊ̇. Loading Changes prior to Run-28B Startup . . . . . . . . 63

XIV. Loading Changes prior to Run-28C Startup . . . . . . . 64

$\mathrm{XV}$. Thermal-hydraulic Information on Rows $6-9$ in Run $25 \ldots 74$

XVI. Hex Temperatures as a Function of Radius and Elevation . 74

XVII. Expansion and Compaction Reactivity Coefficients . . . . 82

XVIII. Calculated Power-coefficient Components for Runs 24

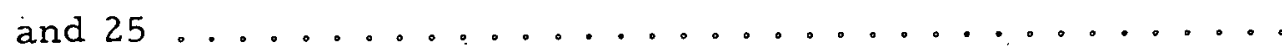

XIX. Average Fuel and Coolant Temperatures as a Function

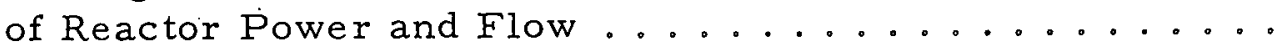

XX. Reactivity Changes under Constant-power and Reduced-

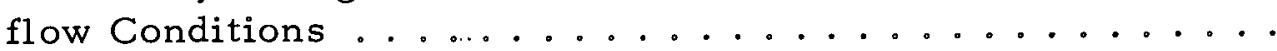




\title{
THE EFFECTS OF \\ AN OVER-COOLED STAINLESS STEEL REFLECTOR ON THE EBR-II POWER COEFFICIENT
}

\author{
by \\ R. R. Smith, T. R. Bump, R. A. Cushman, \\ R. W. Hyndman, F. S. Kirn, W. B. Loewenstein, \\ J. K. Long, J. T. Madell, \\ P. J. Persiani, and W. R. Wallin
}

\begin{abstract}
During a routine startup for EBR-II Run 25 on April 21, 1967, significant changes were noted in the basic behavior of the power coefficient. The magnitude of the integral power coefficient decreased by a factor of approximately two while the magnitude of the differential power coefficient in the midpower region decreased by a factor of approximately four.

As the result of considerable analytical effort, the change in the power coefficient has been identified with thermomechanical deformation effects in a stainless steel reflector that was installed before the startup. Keversed thermal gradients in the outer row of the two-row reflector were manifested by mechanical action that, in turn, modified the power coefficient by re-: stricting the normal outward "flowering" of the core at upper elevations while augmenting the normal inward bowing of fuel subassemblies at core midplane. The two effects, both nonlinear with respect to power, affected the power coefficient by decreasing the negative (flowering) component and increasing the positive (inward-bowing) component.
\end{abstract}

\section{INTRODÜCTION}

Up to and during Run 24, the power coefficient of EBR-II was characteristic of a system in which the various feedback components were relatively prompt, strongly negative, and reasonably predictable over a considerable period of time. While a long-term tendency towards weakening was noted, most changes were small and were attributed to gradual changes in core size, fuel concentration, and power distribution as irradiation subassemblies. were added. Also noted was a consistent tendency towards lower integral power coefficients near the end of a fuel cycle. Such changes were also.small and were correctly identified with differences in the initial and final positions of control rods during a given run. 
During the startup for Run 25, however, significant changes were noted in the basic behavior of the power coefficient. The overall magnitude of the integral power coefficient decreased by a factor of approximately two, and the behavior of the differential power coefficient in the midpower region changed markedly. Since such changes implied significant changes in mechanically coupled reactivity feedback effects, concern was expressed for the operational stability of the system, particularly in the midpower range where the differential power coefficient was unusually weak. Also considered a source of concern was the possibility that the change might have been associated with a strong decrease in the magnitude of the prompt component of the power coefficient. Such a change would have affected the ability of the system to limit the consequences of inadvertent reactivity insertions or loss-of-flow incidents.

Since the origin of the power-coefficient decrease was not understood and since stability and safety consideralions were conceivably involved, much analytical and experimental effort was devoted to studies intended to explain the decrease and to recommend any necessary remedial action. To benefit those who may be concerned with similar problems in the design of sodiumcooled fast breeder reactors, a comprehensive summary of events and conclusions relevant to the problem will be presented here.

In preparing a report of this nature, it is difficult to present the detailed results of all experimental and analytical effort and at the same time convey to the reader a concise overall understanding of the problem and its solution. The approach considered the most beneficial, to casual and detailed readers alike, is one in which specific areas of effort, along with pertinent experimental and analytical data, have been treated in individual reports. Information documented in this manner has been abstracted and used in this report to present a more comprehensive view of the overall problem. Hopefully, this approach will provide sufficiently detailed information for those who may wish to examine the information in depth and for those who are mainly interested in what the problem was and how it was treated. A brief review of the problem and the remedial action taken has been given by Smith et al.

Specific areas of the overall power coefficient problem have been examined by numerous investigators. Historical events leading up to the Run- 25 core configuration, the results of actual measurements of power coefficient during Run 25, and a suggested model for the change in power coefficient have been discussed by Kirn, et al. ${ }^{2}$ In his presentation, Kirn called attention to the reversal of temperature gradients across the stainless steel subassemblies in Row 8 and described a physical feedback model based on reversed bowing attitudes.

Detailed calculations, utilizing an extensively modified HECTIC-II program, were made by Cushman to determine temperature distributions in 
the 7 th, 8 th, and 9 th rows of the radial blanket. ${ }^{3,4,5}$ As the result of these calculations, Cushman showed that whereas the temperature gradients across subassemblies in Row 7 were normal, i.e.; higher temperatures on the inboard surface, the gradients across the subassemblies in Row 8 were reversed.

Using Cushman's results as input information, Bump developed a program, BOW, 6,7 with which he estimated the thermomechanical deflections' for each row of subassemblies and showed that the principal manifestation of reversed temperature gradients in the subassemblies in Row 8 would be a reversal of the normal subassembly bowing attitude. Bump also calculated the resultant forces. on bearing. points between subassemblies and concluded that the forces from bowing were suffiçient to cause both elastic and inelastic compressional effects.

The results of dimensional checks across the spacer pads of all subassemblies discharged from Runs 25 and 26 have been reported by Smith and Mitchell, ${ }^{8}$ who found an average decrease of $0.00 l_{2}$ in. These results indicate that the deformational effects postulated by Bump very likely existed.

A physical feedback model based on reversed bowing effects was rapidly developed. In attempts to correlate the physical model with experimental results, Persiani and others ${ }^{9-14}$ used the results of reduced-flow studies to evaluate the component of the power coefficient associated with fuel expansion. By combining this measured fuel component with other linear compunents (primarily sodium expansion), Hersiani was able to evaluate the nonlinear feedback by subtracting the sum of all linear components from the measured feedback. The results of similar and auxiliary studies have been described in detail by Madell and Jarka. ${ }^{15}$

Using Bump's ${ }^{6,7}$ computed values for subas'sembly movement and Madell's ${ }^{15,20}$ values for the effects of small changes in core radius on reactivity, Persiani 9,10 evaluated the reactivity change caused by compressional movements of the core and showed that the power-dependent deformational effects described by Bump were qualitatively and quantitatively consistent with those established experimentally.

The effects of a decrease in the thermal conductivity of fuel (with burnup) on the power coefficient have been studied by Long ${ }^{16,17}$ and Persiani. 90 Both investigators found that whereas the results of reducedflow measurements indicated that the power coefficient increased as a function of burnup, the results of actual power coefficient measurements indicated no significant change. To explain the difference, Long and Persiani suggested that the expected increase in the power coefficient was cancelled by a comparable change in the positive feedback, which presumably increased as the fuel subassemblies became compressed during a given run. 
The effect of core size and composition on the power coefficient has been investigated by Blomberg, ${ }^{18,19}$ Madell, and others. ${ }^{20-724}$ Using different theoretical approaches, these investigators concluded that the decrease noted in the Run- 25 power coefficient could not be attributed to the replacement of depleted uranium with stainless steel.

A compilation of all power-coefficient data for Runs 24-29 has been assembled by Long. ${ }^{25}$ Included in that report are summaries of pertinent time-power histories, a description of the various loadings, and complete summaries of power-coefficient data in tabular form.

A resolution of the net power coefficient into individual feedback components was provided by a comprehensive series of transfer-function and rod-drop measurements. A description of the technique for measuring the transfer function has been given by Hyndman, et al. ${ }^{26-27}$ The rod-drop method along with the synthesis of a matherratical feedback model have been discussed by Hyndman and Nicholson, ${ }^{28}$ and a report summarizing the actual results of all transfer-function and rod-drop studies conducted during . Runs 25-30A has been prepared by Engen and Hyndman. ${ }^{29}$ Additional effort in feedback synthesis has been described by DeShong. ${ }^{30}$

Insofar as possible the structure of this report will be based on a chronological review of pertinent events and the results of power-coefficient measurements. To avoid disturbing chronological continuity, the results of various experimental and analytical efforts will be discussed separately. Finally, a physical model for the decrease in power coefficient will be described and will be shown to be consistent with the bulk of all experimental and analytical information. 


\section{REVIEW OF PREVIOUS POWER-COEFFICIENT BEHAVIOR}

In assessing the stability characteristics of a new reactor system in its initial startup phase or in monitoring the day-to-day kinetic behavior of an operating system, valuable diagnostic information may be inferred from measurements of the static or steady-state power coefficient. Such measurements are simple to conduct, require only existing reactor instrumentation, and are acceptably reliable and accurate. Because such measurements are usually conducted over a period of time long enough for all reactivity feedback effects to be sensed by the system, the static power coefficient is simply the algebraic sum of all feedback amplitudes.

If it is necessary to understand how individual feedback processes behave in the time and frequency domains, resort must be made to much more sophisticated techniques. Usually such techniques involve disturbing the reactivity balance of the system, observing the resultant changes in neutron level (power), and interpreting such changes, through the neutron kinetic equations, in terms of time- or frequency-dependent feedback components. In the ultimate all feedback information, whether static or kinetic, must be mutually consistent since at infinite time or at zero frequency the amplitudes of time-dependent or frequency-dependent feedback components must sum algebraically to the value established through static measurements. It follows that a complete description of reactivity feedback for a given reactor system must rely on the implementation and use of both static and dynamic techniques.

In the startup phases of EBR-II (July through October 1964), powercoefficient measurements were used to establish the asymptotic feedback. These measurements were made by changing reactor powerby moving a carefully calibrated control rod and dividing the resultant reactivity change by the asymptotic change in reactor power. Dynamic information was obtained by use of a technique that involved the sinusoidal insertion of reactivity with a reciprocating oscillator rod and a Fourier analysis of the fundamental wave of the oscillating power output. ${ }^{31}$

With the mechanical failure of the Mark-I reciprocating oscillator rod in October 1964, routine stability monitoring was based almost entirely on the results of static-power-coefficient measurements usually made at the beginning of each $r$ un. In the absence of a mechanical oscillator rod, attention was focused on two other techniques which at the time seemed capable of yielding useful information. One of these--the trapezoidal reactivity insertion method--was based on an analysis of the power response following the programmed insertion and withdrawal of a control rod over a fixed distance (approximately 0.2 in.). Because of power drifts during measurements and the presence of extraneous noise, this method was never implemented as a routine stability-monitoring technique. The other method considered as an interim measure involved an analysis of the power wave 
during a steep-ramp withdrawal of reactivity (approximately 12 Ih over a period of 280 milliseconds). ${ }^{32}$ Development of this approach, which yielded reactivity in the system as a function of time, proceeded uneventfully until the method was perfected and implemented successfully during Runs 25 and 26. Thus, until December 1966, when a second rotary oscillator rod (Mark IIA) was installed during Run 24, the bulk of stability-monitoring information essentially originated from routine measurements of the static power coefficient. Throughout the period between the initial startup in July 1964 and the completion of Run 24 in December 1966 nothing in the results of routine power-coefficient monitoring implied a significant change in the nature of physical processes which affected reactivity feedback. The failure of the second oscillator rod during the final portions of Run 24, however, intensified the interest in perfecting the rod-drop technique.

As the consequerice of a largc number of power-coefficient measurements taken between Runs 1 and 24, a reasonably consistent rcactivity feedback model was beginning to emerge. In brief, the model involved the following components: the prompt axial expansion of fuel, bond sodium, and cladding; the slightly delayed expansion of primary coolant, and the slightly delayed outward movement of individual fuel elements in a subassembly. All of these components were assumed not only to be negative, but to be linear with respect to power. The model was also based on the existence of relatively delayed positive and negative feedback components originating from bowing effects in fuel and blanket subassemblies. Such effects were then and still are assumed to be highly nonlinear with respect to power.

A simple illustration of the nonlinear nature of such cormpontuls is given by the following considerations. At zero power (i.e., from 50 to $500 \mathrm{~kW}$ ) the configuration of the core and blanket consists of a collection of subassemblies, each of which is separated from its neighbors by a more or less random system of clearances. As the power increases, temperature gradients across fuel and blanket subassemblies increase. Inner surfaces are preferentially heated, and the subassemblies begin assuming the form of a bow, the form of which tends to move lower and upper ends outward. At lower levels of power, the clearances between the pole pieces and the outer edges of the sockets gradually close until the pole pieces are preferentially bearing on the outer edges of the sockets. Similarly, the upper ends of the subassemblies tend to blossom outward until they contact the tops of outlying neighbors. At this point, stresses set up by thermal gradients across the subassemblies are manifested in the form of an inward bowing at midplane elevation. Such effects are positive because fuel material is displaced from a lower- to a higher-worth region.

The limiting constraint for inward bowing effects is a complete closure of clearances between subassemblies at midplane. ${ }^{33,34}$. Each face of a subassembly is equipped with a raised pad, $3 / 8 \mathrm{in}$. in diameter and $0.014 \mathrm{in}$. in height. Although the nominal clearance between subas semblies 
is 0.030 in., the clearance between pads is only 0.002 in. Upon the closure of clearances between adjacent pads, forces resulting from the effects of thermal deformation (bowing) and the thermal expansion of subassemblies are manifested in two ways: by a slight inward deformation of the subassembly walls (a positive reactivity effect), and by further closure of the clearances between outlying subassemblies (a negative reactivity effect). The net result of such effects is an increase in the effective radius of the core and a loss in reactivity since the negative effects predominate.

Complicating attempts to interpret the above model in mathematical terms is the statistical nature of bowing phenomena. For any given power level up to about $30 \mathrm{MWt}$, clearance systems between midplane spacer pads and between the tops of subassemblies are in various stages of ordering. While the tops of some subassemblies have made contact with the tops of neighboring subassemblies, others are still in the process of engagement. The differential power coefficient under these conditions reflects a continuously changing competition between negative and positive reactivity feedback over this power region.

If the above model is qualitatively correct, the expected dependency of power coefficient on power should be reasonably predictable. In the lower power range (0-20 MWt) the power coefficient should be relatively strong because the feedback originates from predominantly negative effects such as axial and radial fuel expansion, coolant expansion and expulsion, and the movement of subassemblies outward at upper and lower ends. Inward bowing components exist, but since only a limited number of subassemblies are in contact at the upper ends, the associated positive effects are small.

In the power range from 20 to $30 \mathrm{MWt}$, clearances between the lower adapters of subassemblies and grid-plate holes and between the tops of subassemblies become increasingly closed. As the collection of subassemblies becomes increasingly ordered, the freedom for blossoming decreases and affects the feedback in two ways: by reducing the negative feedback from blossoming and by increasing the positive feedback from inward bowing. While the overall result is still negative, the increased influence of positive coefficients is reflected by a decrease in the power coefficient.

Eventually the core bows inward to maximum mechanical compaction, i.e. all clearances between spacer pads become closed. For power levels greater than $30 \mathrm{MWt}$, the power coefficient increases as inward bowing effects diminish and as core subassemblies tend to be forced outwardly in a radially contiguous manner.

The consistency between the physical model described above and actual experimental results may be assessed from an inspection of Fig. 1 , which illustrates typical behavior of the power coefficient observed during Run 16. From 0 to $20 \mathrm{MWt}$, the power coefficient is linear with respect to power. Between 20 and $30 \mathrm{MWt}$, a slight decrease in the magnitude of the 
differential power coefficient may be noted. For power levels greater than $30 \mathrm{MWt}$, the differential power coefficient increases and once again appears to be linear with respect to power. While not proving the validity of the models, the agreement between anticipated behavior and actual behavior is excellent. Obviously, a power coefficient dependence illustrated by that measured for Run 16 posed no operational problems. The slight weakening in the range from 20 to $30 \mathrm{MW}$ was never regarded with concern. Its existence was predicted and considered in detail in the original Hazards Summary Report ${ }^{33,34}$ and little or no significant change was ever noted in its behavior until the beginning of Run 25 .

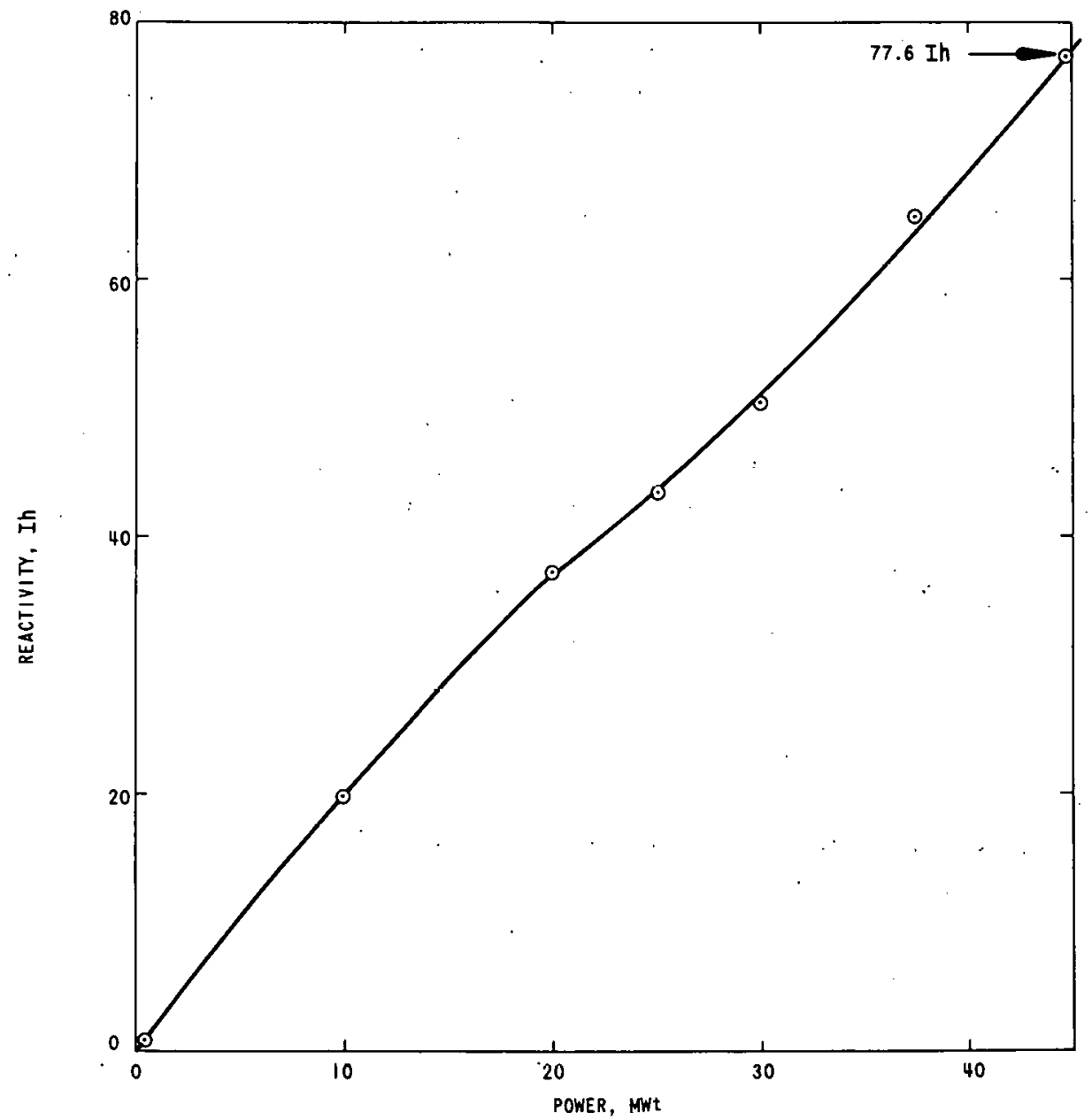

ID-103-K-5775 Rev. 1

Fig. 1. Power-coefficient Data from Run 16, Taken 4/18/66 
III. RUN 25

A. Loading Changes Implemented prior to Run-25 Startup

During the startup for Run 25, marked changes in the nature of the power coefficient were noted. The amplitude of the integral power coefficient decreased by a factor of approximately two, and the differential power coefficient in the midpower range decreased by a factor of approximately four. Because such changes were unprecedented and unanticipated, the need for a definitive understanding of the changes was evident.

Full appreciation of the power-coefficient problem of Run 25 may be gained by reviewing those events that led directly and indirectly to the Run-25 configuration. Fundamental to the problem was the increasing use of EBR-II as an irradiation facility. Up to and including Run 24, increasingly more irradiation subassemblies were added to the core. Because the worth of a typical experiment amounted to approximately one-half the worth of the driver subassembly it replaced, the result was, on balance, a core which gradually increased in effective radius. As a consequence, the power distribution was continually changing. With the operating power level fixed at $45 \mathrm{MWt}$ while the core size increased, previously installed irradiation experiments were being irradiated under lower flux conditions. To remedy this undesirable effect and to avoid the frequent remapping of the flux, it was considered advisable to enlarge the core to some fixed reference condition that would remain relatively invariant with time. To implement this feature, six special subassemblies were fabricated. Each was filled with 46 Mark-IA driver elements and 45 stainless steel dummy rods. As demonstrated by subsequent measurements, each was equivalent in reactivity worth to an average irradiation subassembly containing prototypal fuel.

The objective at that time was the enlargement of the core to 88-91 subassemblies ( 91 completing the sixth row). The addition of future experiments would simply involve replacing an already installed half-fueled subassembly with the experiment without affecting the core outline. As it turned out, the actual change in loading involved an increase to 88 subassemblies from the 81 present in Run 24 .

A more significant change implemented in Run 25 concerned the inner two rows of the depleted-uranium reflector. Because the results of surveillance measurements conducted on depleted-uranium blanket material indicated potential swelling problems, it was considered advisable to replace the inner two rows ( 7 and 8 ) with subassemblies filled with stainless steel rods. The latter were superficially identical with their depleteduranium counterparts. Illustrations of the loadings for Runs 24 and 25 are given in Figs. 2 and 3 , respectively. 
KEY: D - DRIVER FUEL

B - U BLANKET

S - SAFETY ROD

NOTE: CONTROL ROD NO. 8 CONTAINS

C - CONTROL ROD

OSCILLATOR ROD

$X$ - EXPERIMENTAL SUBASSEMBLY

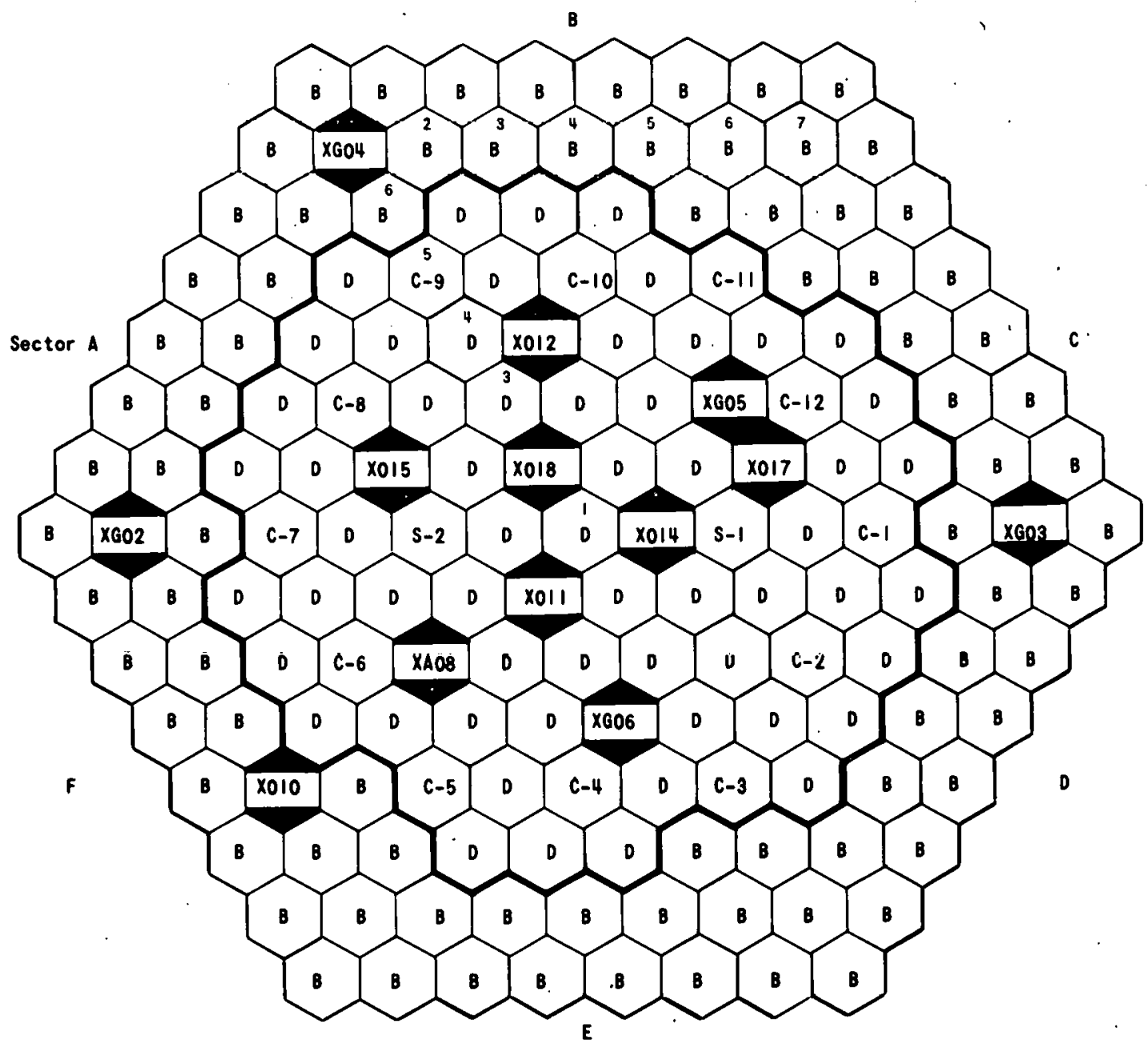

ID-103-J-5538 Rev. 1

Fig. 2. EBR-II Experimental Loading for Run 24, December 1966; 81 -subassembly Core 
NOTE: CONTROL ROD NO. I CONTAINS SS ONLY
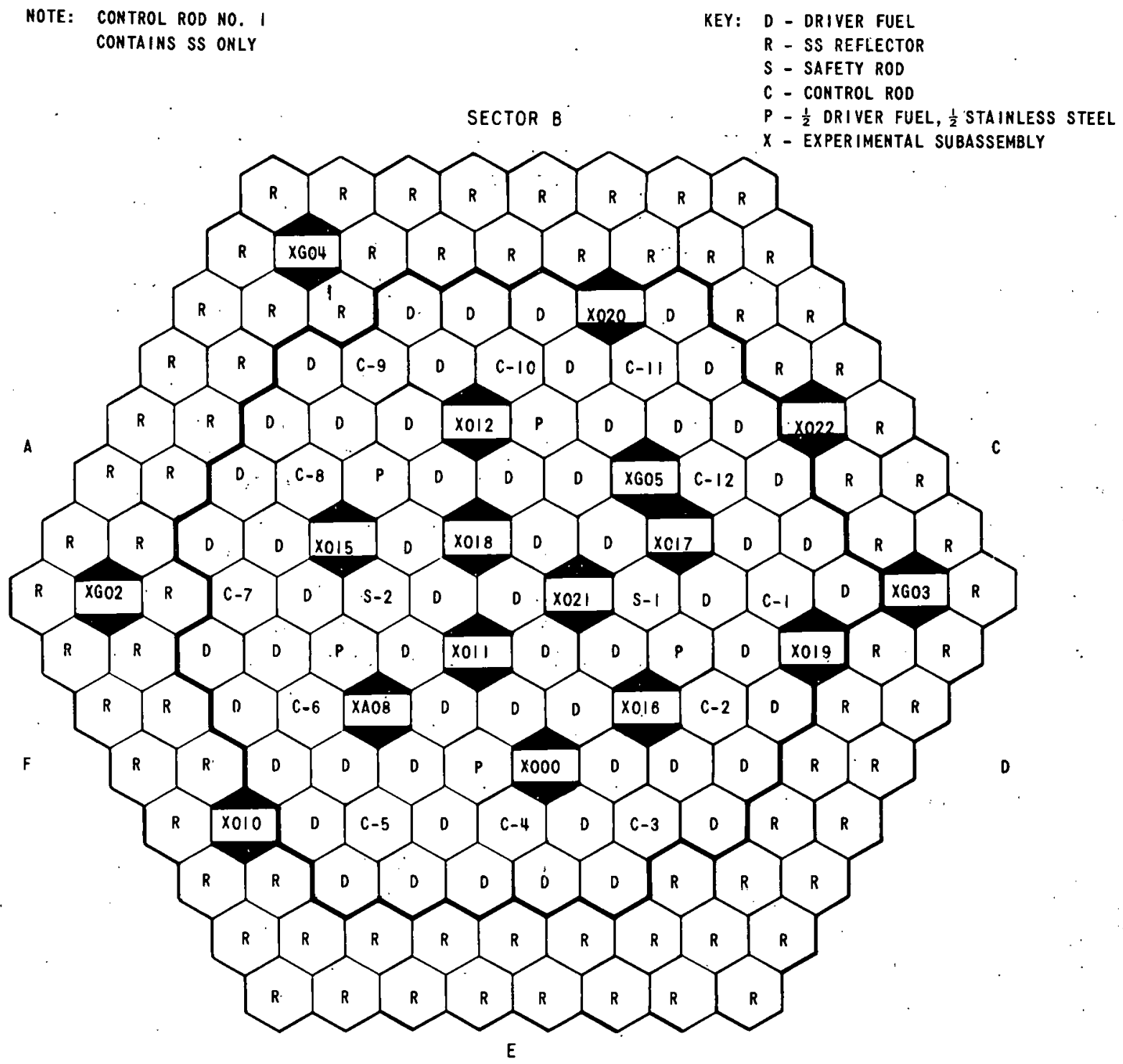

ID-103-J-5536 Rev. 1

Fig. 3. EBR-II Experimental Loading for Run 25, April 17, 1967; 88-subassembly Core

The Run-25 loading was also characterized by other features which differed from much earlier loadings. These were a reduction in fuel-pin length from 14.22 to 13.50 in., an increase in the enrichment of ${ }^{235} \mathrm{U}$ from 48.5 to $52.4 \mathrm{w} / \mathrm{o}$, and the replacement of depleted uranium with stainles $s$ steel in the upper and lower axial reflectors. Such changes resulted from. the replacement of Mark I.with Mark IA fuel elements. However, because the fuel changeover occurred gradually (primarily during Runs 13 through 23), such changes could not logically be associated with the Run-25 powercoefficient problem. 
B. Run-25 Startup

Upon completion of the loading changes described above, the reactor was started up on April 21, 1967. In accordance with standard operating procedures, the power was increased incrementally to establish the magnitude of the power coefficient and its dependence on power. In the range from 0 to $10 \mathrm{MWt}$ nothing unusual was noted. The differential power coefficient was negative and averaged approximately $-1.6 \mathrm{Ih} / \mathrm{MWt}$, a value about the same as that established from earlier loadings. At power levels. above $10 \mathrm{MWt}$, however, a definite decrease was noted. This trend continued as the power increased, with the lowest value of the differential power coefficient reached in the vicinity of $25 \mathrm{MWt}$. In reaching $25 \mathrm{MWt}$ from $50 \mathrm{~kW}$, only 23.6 Ih of reactivity were required. Because the overall average value of the power coefficient at this point $(-0.95 \mathrm{Ih} / \mathrm{MWt})$ fell below the normal operating limit of $-1.00 \mathrm{Ih} / \mathrm{MWt}$, the systern was shut down. A graphical summary of the April 21 data is compared with earlier Run 24 data in Fig. 4. In all cases, corrections have been applied for changes in bulk sodium temperature and for fuel burnup effects during the measurements. As part of the program of investigation, the isothermal temperature coefficient was remeasured on April 22 by noting changes in the position of the regulating rod at $50 \mathrm{~kW}$ when the bulk sodium temperature was reduced from 700 to $650^{\circ} \mathrm{F}$. The data resulted in a value of $-1.04 \mathrm{Ih} /{ }^{\circ} \mathrm{F}$, essentially the same value as $-1.01 \mathrm{Ih} /{ }^{\circ} \mathrm{F}$ established for earlier loadings.

Permission to lower the operating limits to $-0.5 \mathrm{Ih} / \mathrm{MWt}$ was received on April 25, and the power level was increased to $30 \mathrm{MWt}$ in the following eteps: $500 \mathrm{~kW}, 25,27.5$, and $30 \mathrm{MWt}$. The power level was held at $30 \mathrm{MWt}$ for approximately 18 hours and then reduced to $50 \mathrm{kWt}$ to test the reproducibility of critical positions. As a result of these experiments, the following observations were made: (1) the data obtained during the power increases to 25 and $30 \mathrm{MW}$ verified the original power-coefficient data taken on April 21; (2) no evidence of reactivity drift was noted during the 18 hours of 30-MWt operation; and (3) critical positions were reproducible within a range of $\pm 2-3$ Ih.

Additional confirmatory measurements were conducted over the range from 0 to $45 \mathrm{MWt}$ on two successive occasions, one on April 26 and 27, and the other on April 28. Power-coefficient data taken during these tests are summarized in Fig. 5. For convenience, corresponding data for Run 24 have also been plotted. In all cases, corrections have been applied for changes in bulk sodium temperatures and for the effects of burnup during the course of the measurements.

C. Special Physics Tests

In the period immediately following the initial startup, essentially all that was known was the fact that marked changes had occurred in the 
shape and the amplitude of the power-coefficient curve as indicated by the results of static measurements. Although a tendency for extremely lowfrequency power oscillation was noted, the short-term kinetic behavior of the system appeared to be governed by a power-coefficient component that was prompt and negative. For example, when the regulating rod was driven out a small distance (a few tenths of an inch) the power decreased rapidly at first and eventually approached a steady-state value consistent with the measured power coefficient. No evidence of strong competing prompt positive components was noted.

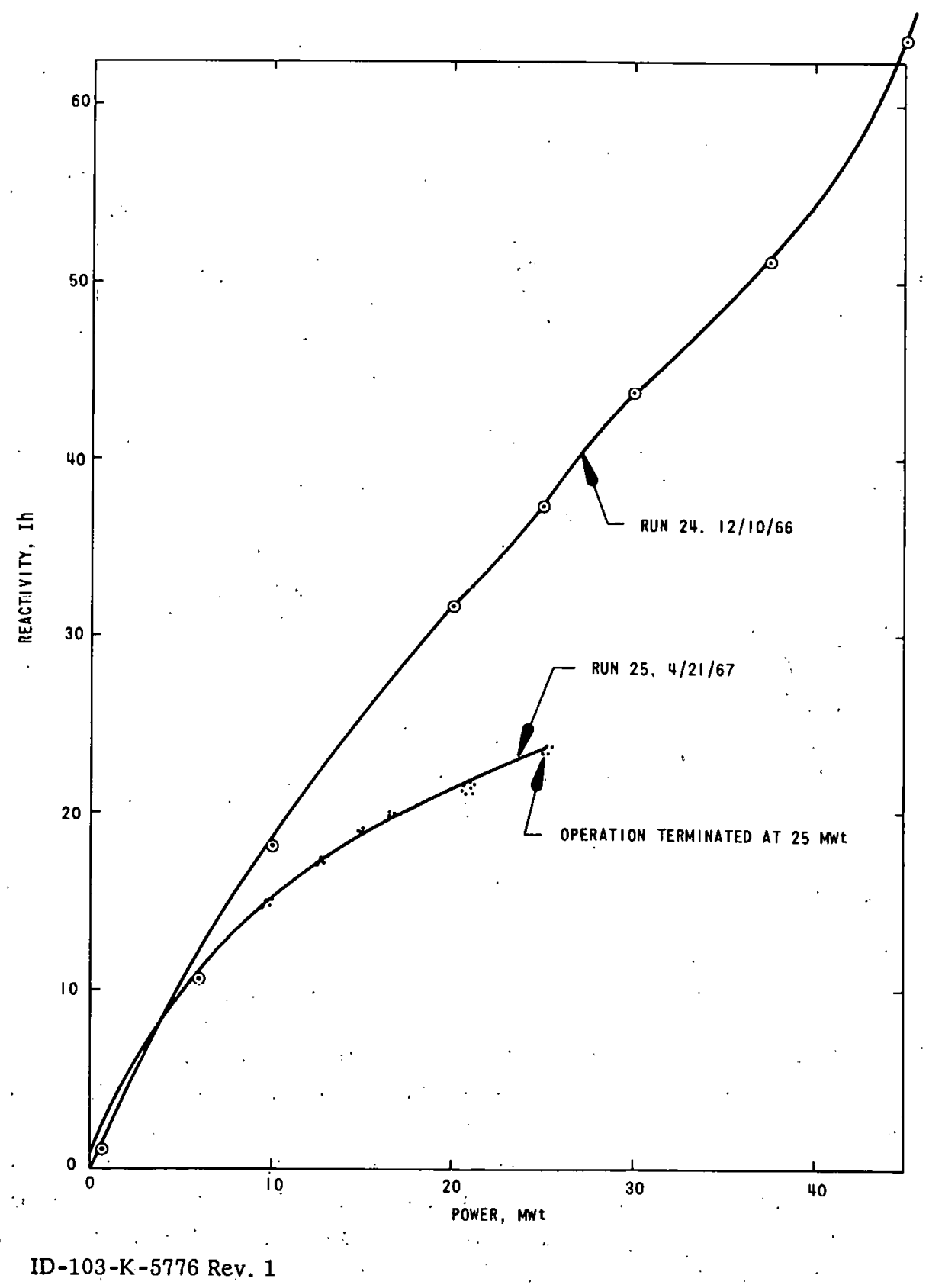

Fig. 4. Power-coefficient Data for Run 24, December 10, 1966, and Run-25 Startup, April 21, 1967 


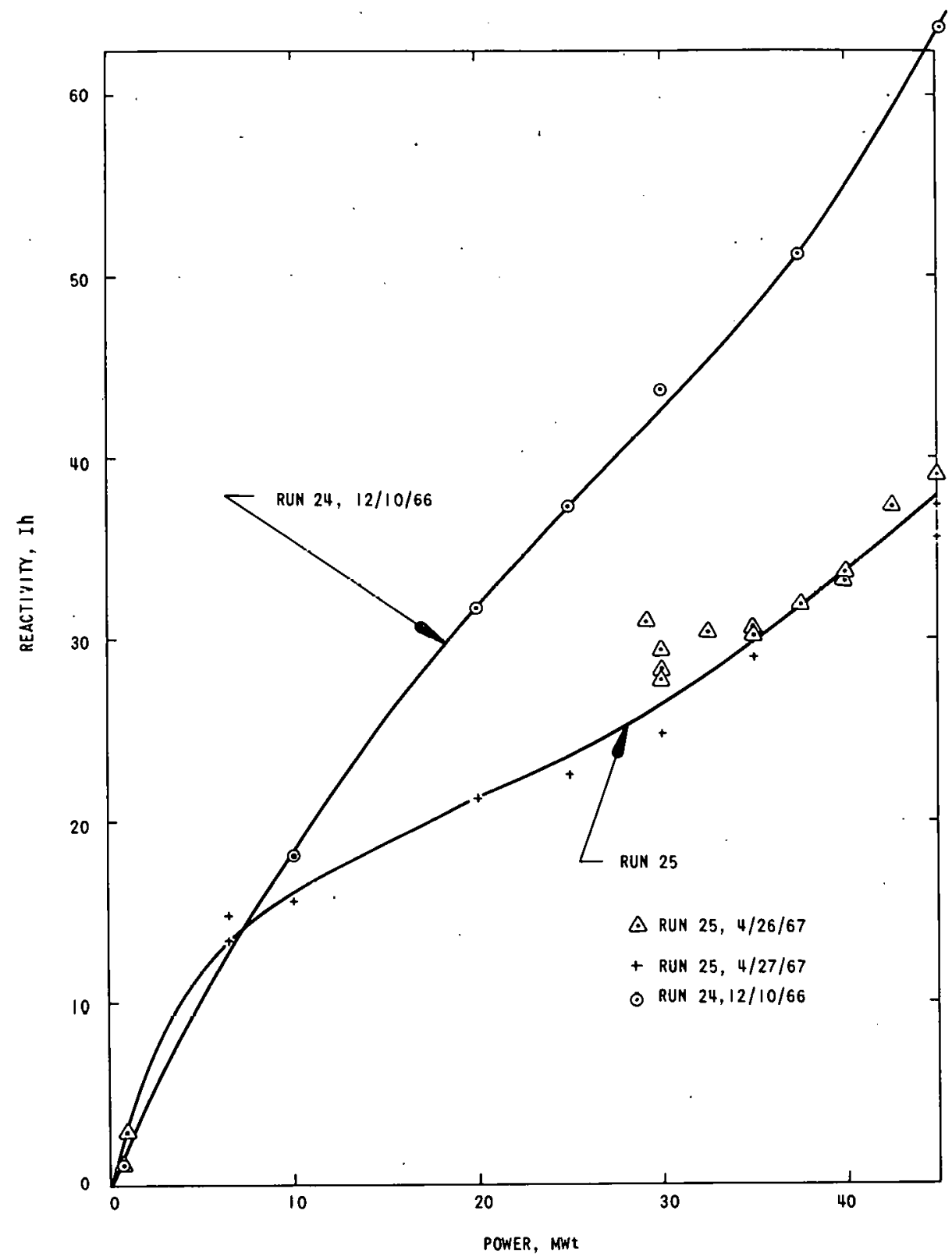

D-103-K-5777 Rev. 1

Fig. 5. Power-coefficient Data for Run 24, December 10, 1966, and Run 25, April 26 and 27, 1967

Despite the overwhelming bulk of evidence indicating that operational stability was not a problem, immediate efforts were devoted to the implementation of techniques that could be used to provide information on the magnitude and the time dependence of individual feedback components. As discussed in Section II, the mechanical failure of the oscillator rod in December 1966 and the long lead time necessary for the fabrication of a replacement rod eliminated conventional transfer-function measurements as a possibility. Efforts to expedite the fabrication of a replacement rod, however were accelerated. The results eventually obtained with the replacement rod are discussed in Section VIII.J. 
Some effort was made to differentiate between prompt and delayed feedback components by exciting the system with the programmed insertion and withdrawal of a carefully calibrated control rod over a fixed distance. Unfortunately, this method, referred to as the trapezoidal reactivity insertion technique, was handicapped by the slow drive speed of the control rods, the poor resolution of the power signal from system noise, and the inability to avoid strong power drifts during the measurements. Therefore, the method never yielded useful information. For completeness, however, the principle of the method is discussed in Section VIII.K.

The method that eventually provided the most important kinetic information during Run 25 was based on the excitation of the system through the steep ramp withdrawal of reactivity. While most of the effort devoted to the implementation of this technique during $R$ un 25 was developmental, the results of actual measurements were useful in providing qualitative and semiquantitative information. For example, from tests conducted in conjunction with the April 26-28 power coefficient measurements, the most prompt-acting power-coefficient component was shown to be strongly negative. From additional measurements conducted periodically throughout Run 25, the relative constancy of the magnitude of the prompt powercoefficient component was demonstrated. The method and typical results obtained during Run 25 are discussed in Section VIII.I.

During the earlier phases of power-coefficient studies (April 21-28) attention was directed to the reproducibility of criticality measurements. On some occasions, differences of the order of 2-3 Ih were noted. To determine the effects of coolant flow rate on the mechanical displacement of subassemblies on criticality measurements, two $50-\mathrm{kWt}$ critical positions were established, one under conditions of full flow and the other under $50 \%$ flow. No detectable change in reactivity was noted.

As discussed above, the only method available for studying the nature of the prompt power-coefficient component was that based on rod drops and, since this method was still under development throughout all of Run 25 , attention was given to alternative methods which would indicate any significant change in the prompt feedback components.

One such method involved measurements of the excess available reactivity under varying conditions of power and flow. In these experiments, the power level and coolant flow were changed in a manner that maintained the power/flow ratio constant. Because the temperature differential across the reactor was maintained constant, the effects of a power change were reflected by changes in the average fuel temperature. Such changes are easily and reliably susceptible to computation. Knowing the temperature changes, the power change, and the reactivity change (from differences in regulating-rod position), an effective fuel-expansion power coefficient component may be derived. This method was successfully implemented during 
Run 25 and was used periodically to demonstrate the absence of significant changes in the power-coefficient component associated with the fuel. Eventually, the data obtained from such tests were used successfully to effect a separation of the measured power coefficient into linear and nonlinear components. A more detailed discussion of the method and the significance of actual results are given in Sections VIII.E and VIII.F.

D. Continuation of Run 25

Following the power-coefficient measurements of April 27 and 28, the power level of the system was reduced to $10 \mathrm{MWt}$. Operations were continued at this level while detailed plans were formulated for a comprehensive program of tests and computations. The system was again brought incrementally to power on May 17. The measured power reactivity decrement (PRD) at $45 \mathrm{MWt}$ was found to be approximately the same as the values established during the April 27 and 28 measurements. On the following day, power was cut back to $40 \mathrm{MWt}$ to carry out trapezoidal reactivity insertion tests. To provide the necessary zero-power calibration for this test, the power level was reduced to $50 \mathrm{kWt}$ on May 18. The following day, powercoefficient data were taken over the range from 0 to $45 \mathrm{MWt}$. The results of these tests are summarized in Fig. 6. A comparison of these data with those established earlier (plotted in Fig. 5) shows that the behavior of the power coefficient remained essentially unchanged.

E. Fission-product Release of May 24, 1967

Upon the completion of the May-19 power-coefficient measurements, plans called for completing Run 25 under 45-MWt operating conditions while the results of various physics tests were being analyzed. Implicit in this approach was the conviction that the system could be safely operated and that the origin of the power coefficient decrease could be identified and remedied. Operations continued without incident until 1210 on May 24, when the fission-gas monitor (FGM) annunciated the release of gaseous fission products to the cover-gas system. In accordance with the existing emergency procedure the release was confirmed from the results of analyses conducted on cover gas samples and the system was shut down. Since details relating to the release are given elsewhere, ${ }^{35,36}$ only a brief resume of principal events following the release will be given here.

From the response of the $\mathrm{FGM}^{37,38}$ and from the results of radiometric analyses conducted on cover gas samples, ${ }^{39}$ it was immediately clear that the release was much too large to be explained in terms of a failure in the driver fuel. In previous calibration tests, with an unclad Mark IA fuel element, it was shown that the maximum signal expected from a single unclad fuel pin in Row 5 was approximately 10. Based on this value and an estimate of 3000 for the signal increase from the FGM, it was concluded that, if driver fuel elements were involved, at least 300 would have been 
affected. If as many as 300 fuel elements were affected, relatively gross damage to the core was indicated. However, the lack of an increase in the signal from the fuel element rupture detector (FERD) eliminated the possibility of fuel exposure that almost certainly would have accompanied gross core damage. Accordingly, attention was focused on experimental subassemblies that contained encapsulated oxide and carbide fuel elements since such materials would release a much larger fraction of the rare-gas fission-product inventories.

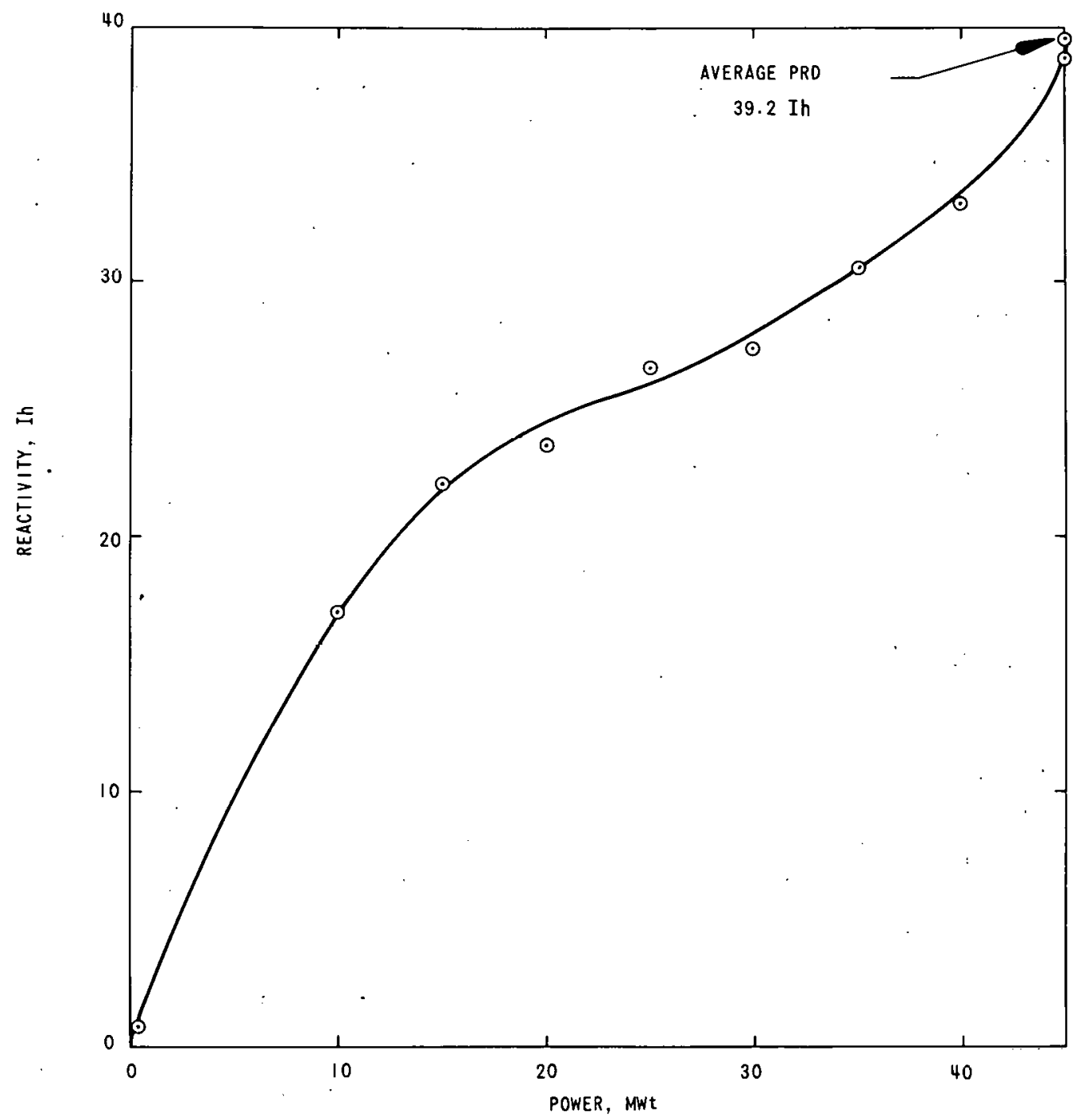

ID-103-K -5778 Rev. I

Fig. 6. Power-coefficient Data for Run 25, May 19, 1967

Aside from a few hours of operation at 2.5 MWt on May 29, the system remained inoperative until June 4 , when the power was increased in 2.5-MWt increments to $30 \mathrm{MWt}$ in an effort to provide reference data for future tests. Operation continued in this manner until June 11, when the FGM system annunciated a second release. The system was immediately shut down. 
The system was restarted on June 19. After reaching $10 \mathrm{MWt}$ and after accumulating approximately $16 \mathrm{MW}-\mathrm{hr}$ of operation since the June $1 \mathrm{l}$ release, a third FGM annunciation was given. The system was again shut down in preparation for the removal of suspect assemblies. Using higher burnup as a criterion of failure, subassemblies XG05, XA08, and XOll were transferred from the core to the storage basket on.June 21. The system was then cautiously brought to $30 \mathrm{MWt}$ in 2.5-MWt increments and was held at this level for an additional accumulation of $150 \mathrm{MWd}$. No indication of a release noted during this period.

Assuming that the suspect was one of the three experimental subassemblies removed from the core on June 21 , the plan of action called for the reinsertion of these subassemblies, one at a time, until the reinsertion of one would lead to an additional release. Accordingly, subassembly XOll was reinserted on June 27.

The power level was again increased in $2.5 \mathrm{MWt}$ increments and, while operating at $7.5 \mathrm{MWt}$, a fourth release occurred. The system was shut down, XOII was removed, and XG05 and XA08 were reinserted in their original locations. The system was again brought to a power level of $30 \mathrm{MWt}$ in 2.5-MWt increments and operated uneventfully in this manner for another $150 \mathrm{MWd}$. Upon completion of the $150 \mathrm{MWd}$ operating segment, the system was shut down to permit the performance of special maintenance functions.

F. Rod-bank Effect

With the suspect subassembly identified, the plan of action called for the completion of Run 25 under 45-MWt operating conditions. The system was started to power on July 5. Between 0 and $15 \mathrm{MW}$, power was increased in 2.5-MWt increments. Between 15-45 $\mathrm{MWt}$, the increments were increased to $5 \mathrm{MWt}$. The value established for the 0-45 MW PRD was $38.8 \mathrm{Ih}$, approximately the same as the earlier values.

Operations under 45-MWt conditions continued without incident until July 20 when the system was shut down to install subassemblies XO2 3 and XO24, which were to be irradiated at $30 \mathrm{MWt}$ for 24 hours. During the subsequent startup it was noted that values of the differential power-coefficient in the range from 10-20 MWt had decreased since the July-6 measurements. The system was shut down and, on the following day, power-coefficient measurements were made at 2.5-MWt increments up to a power level of $20 \mathrm{MWt}$. Following rod-drop tests at $20 \mathrm{MWt}$, the power level was increased to $30 \mathrm{MWt}$. Additional rod-drop tests were conducted and the system was shut down on July 23 to remove XO23 and XO24. Following the removal of these subassemblies, additional power-coefficient and rod-drop studies were carried out over the range from 0 to $45 \mathrm{MWt}$ in an attempt to provide detailed information relating to the decrease noted in the differential power coefficient. 
Summaries of power-coefficient data taken on July 6 (before the decrease) and July 23 (after the decrease) are given in Fig. 7. From an inspection of the information, marked changes in the magnitude and power-dependence of the PRD may be noted. While the leading portion of the curve in the range from 0 to $10 \mathrm{MWt}$ remained strongly negative and essentially unchanged, a significant weakening characterized higher-power data.

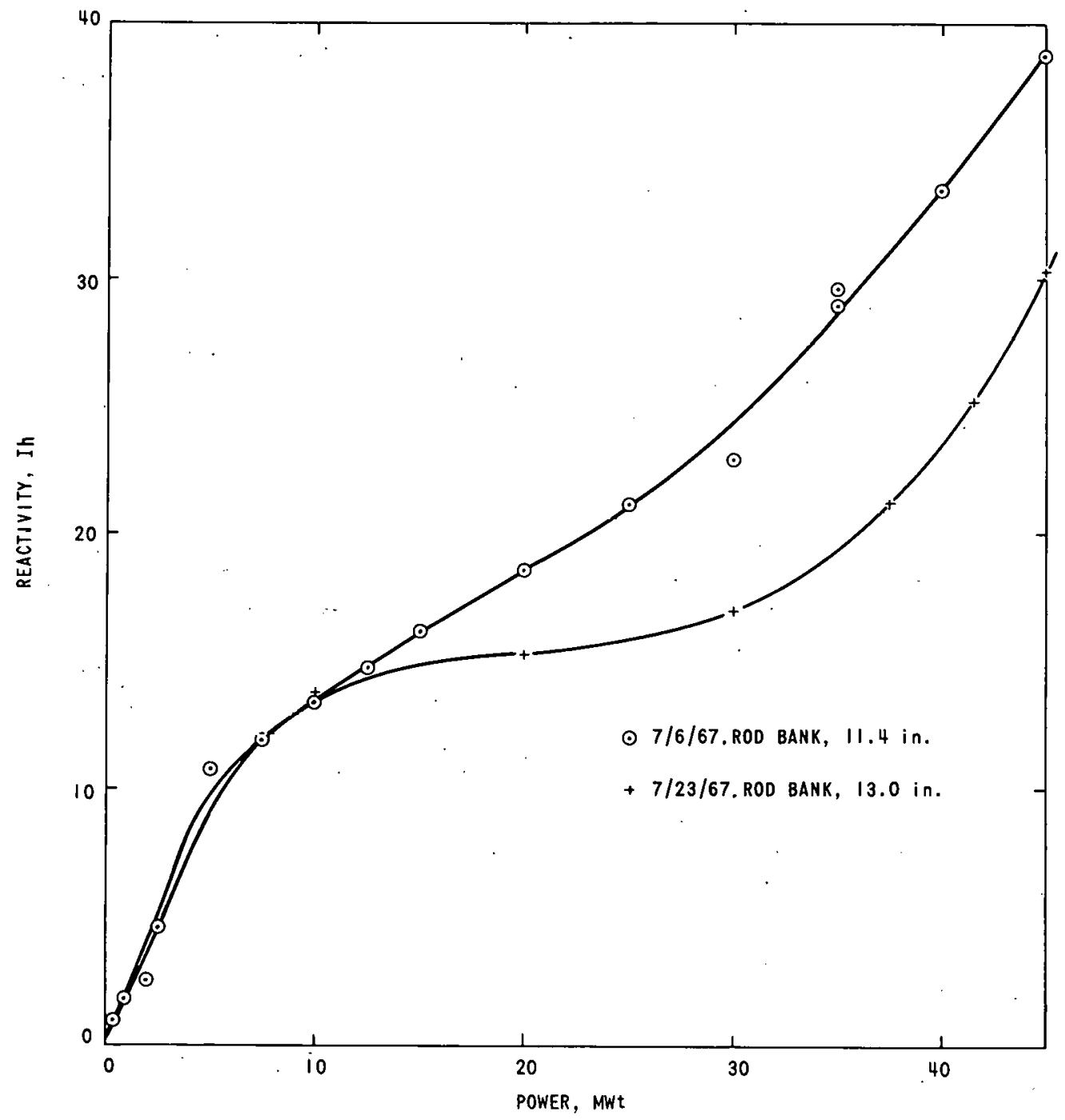

D-103-K-5779 Rev. 1

Fig. 7. Run-25 Power-coefficient Data with Rod Bank of 11.4 and 13.0 in.

Shortly after the decrease in power coefficient was noted, attention was focused on the difference in control-rod positions for the July 6 and July 23 data. As indicated in Fig. 7, the earlier data were taken with control rods banked at a position of 11.4 in., while the later data were taken with the control rods banked at $13.0 \mathrm{in.}$ Eventually the indicated decrease in power coefficient was attributed to the effects of control-rod shaft expansion. Since a detailed description of this effect is given elsewhere, ${ }^{40}$ only a general description of the effect will be given here. 
In EBR-II the control rods are suspended from structural features that are relatively insensitive to changes in coolant outlet temperature. The upper extensions of control rods and parts of the rod handles, however, are immersed in sodium that has traversed the core. Thus, power increases tend to lengthen control-rod shafts. Such effects are sensed by the system as a decrease in elevation of all control rods. While such increases in length cause changes in the position of control rods with respect to the core, such changes are not indicated by the selsyn transmitters. Clearly, the measured power coefficient automatically includes shaft-expansion effects.

A similar effect, of much smaller magnitude (approximately $5-10 \%$ of the total), involves the tendency for driver-fuel elements to "outpace" control-rod fuel elements after a power increase. This phenumenon is a consequence of overcooling curtrol rods by about $29^{\circ} \mathrm{F}$ at $45 \mathrm{MWt}$. Hence, a power increase tends to cause a disproportionale (larger) increase in the elevation of driver fuel. This effect is reflected by the system as a negative feedback component which is also included in the measured power coefficient.

If the control-rod-worth curve were strictly linear as a function of rod position, such effects would go unnoticed, but because the worth curve is strongly nonlinear, the size of such effects depends on the actual position at which the control rods are banked. It is important to emphasize that the extent of rod growth is a linear function of power and that the actual growth between 0 and $45 \mathrm{MW}$ is almost entirely independent of control-rod configuration. The effect is such that when the rods are banked at a relatively low position, at the beginning of a run for example, the shaft growth causes a relatively large reactivity decrease. At the end of a run, with the rods banked at a high position (in the low-worth portion of the control-rod calibration curve), shaft growth causes only a minor reactivity change. Since the associated reactivity effect, whether it is large or small, is a true portion of the power coefficient, the PRD at the beginning of a run (low-banked position-high differential rod worth) will be stronger than it is at the end of the same run (high-banked position--low differential rod worth).

Hence, in comparing power-coefficient values either between different runs or for different time periods in a given run, care must be taken to correct the data for any changes in banked position. Estimates of the corrections as a function of power level and banked position have been made from a knowledge of the differential rod worth; the temperature distribution in control-rod hexes, plenum, and cover plate; and fuel temperatures in driver and control-rod subassemblies. Experimental verification of the bankedcontrol-rod effect and a measurement of its magnitude were provided by a series of experiments conducted during the beginning of Run 26. The results of these experiments are discussed in Section IV.B. 
As outlined above, the power-coefficient data for July 6 and 23 indicated a marked flattening of the power-coefficient curve in the intermediate power range (10-30 MWt) when the banked position of the control rods was increased to 13.0 in. The same data, corrected for differences in the banked-control-rod position, are given in Fig. 8: While the correction does not bring both sets of data into complete agreement it is, nevertheless, clear that the differential power coefficient in the midpower region is particularly sensitive to the position of the control rods.

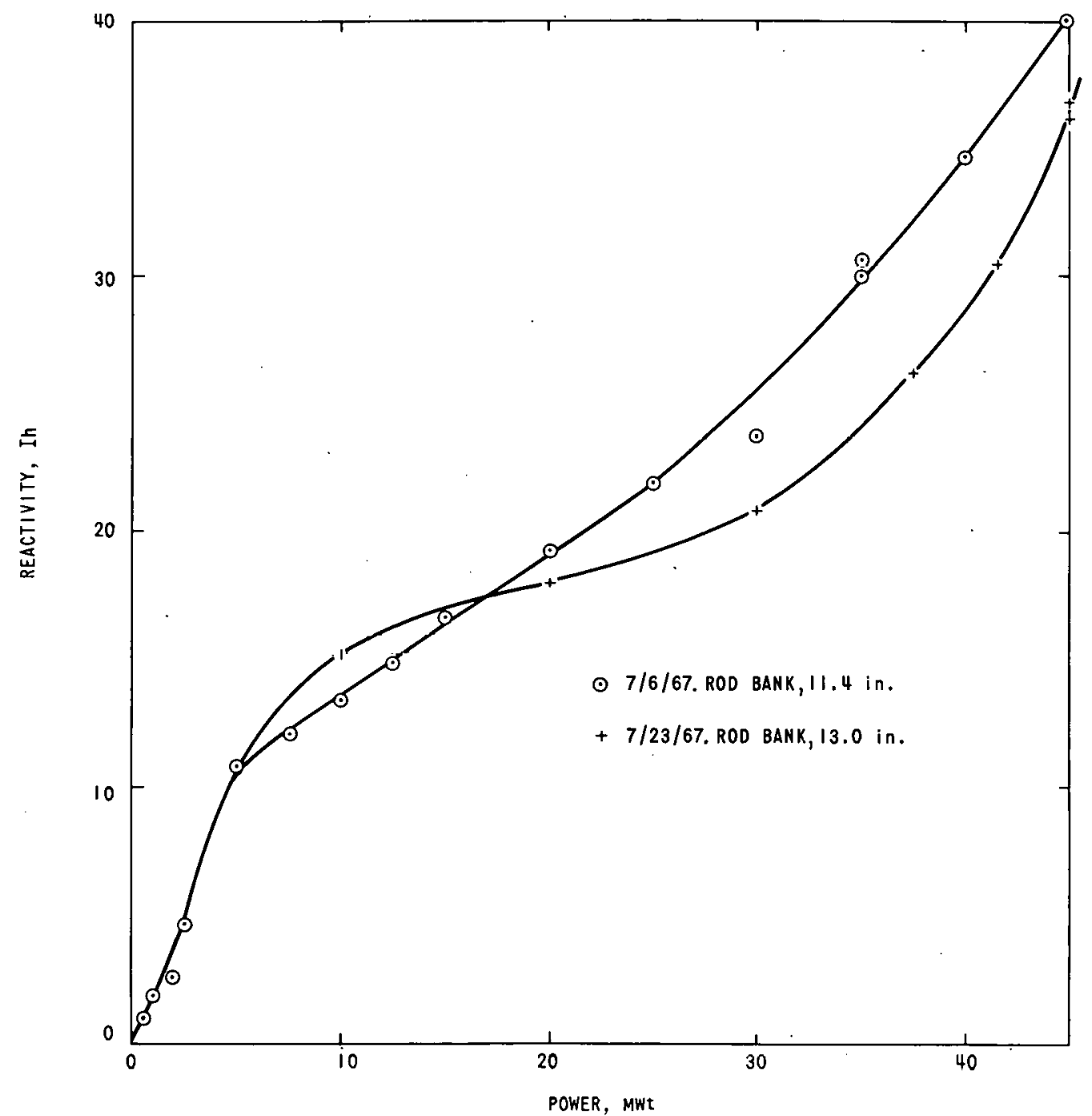

ID-103-K-5780 Rev. 1

Fig. 8. Run-25 Power-coefficient Data, Normalized to a Rod Bank of 11.00 in.

Another example of the importance of the effect may be inferred from Figs. 9 and 10, the first of which compares untreated powercoefficient data for April 27 (at the start of the run) and August 17 (at the end of the run). The same data, corrected for the rod-bank effect, are given in Fig. 10. In Fig. 9, a significant difference may be seen between 
data taken at the beginning and end of Run 25. When corrections have been applied to the data, a single curve (Fig. 10) may be drawn through the various data in such a manner that no single point deviates from the best-fit curve by more than $2 \mathrm{Ih}$. Such agreement suggests that little or no change in the power coefficient occurred during Run 25. On the other hand, the August-17 data were taken at the end of Run 25 after deliberate attempts had been made to randomize clearances throughout the core. The results of such attempts are discussed in the following section.

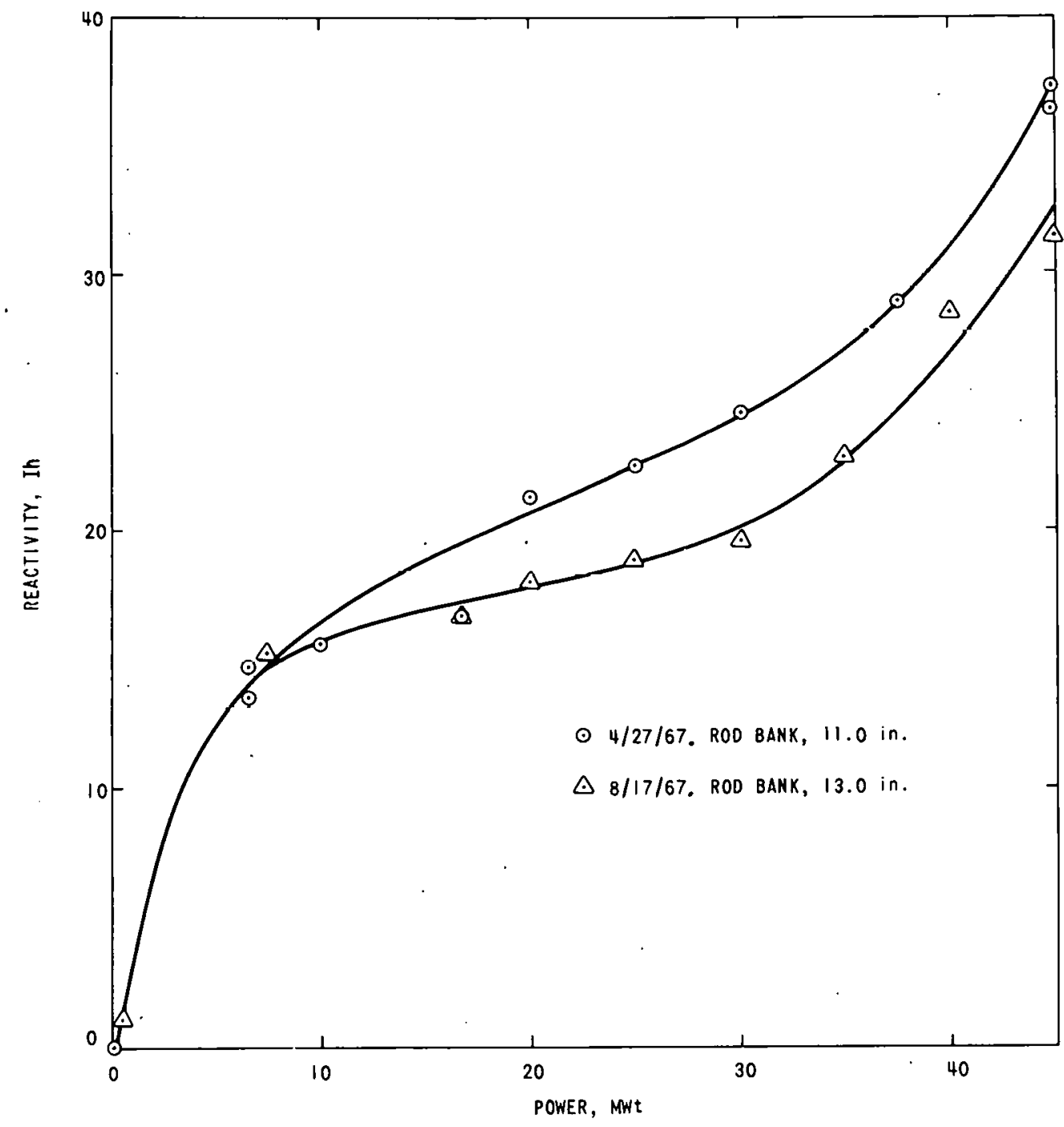

ID -103-K-5781 Rev. I

Fig. 9. Run-25 Power-coefficient Data, Uncorrected for Banked-control-rod Effect 


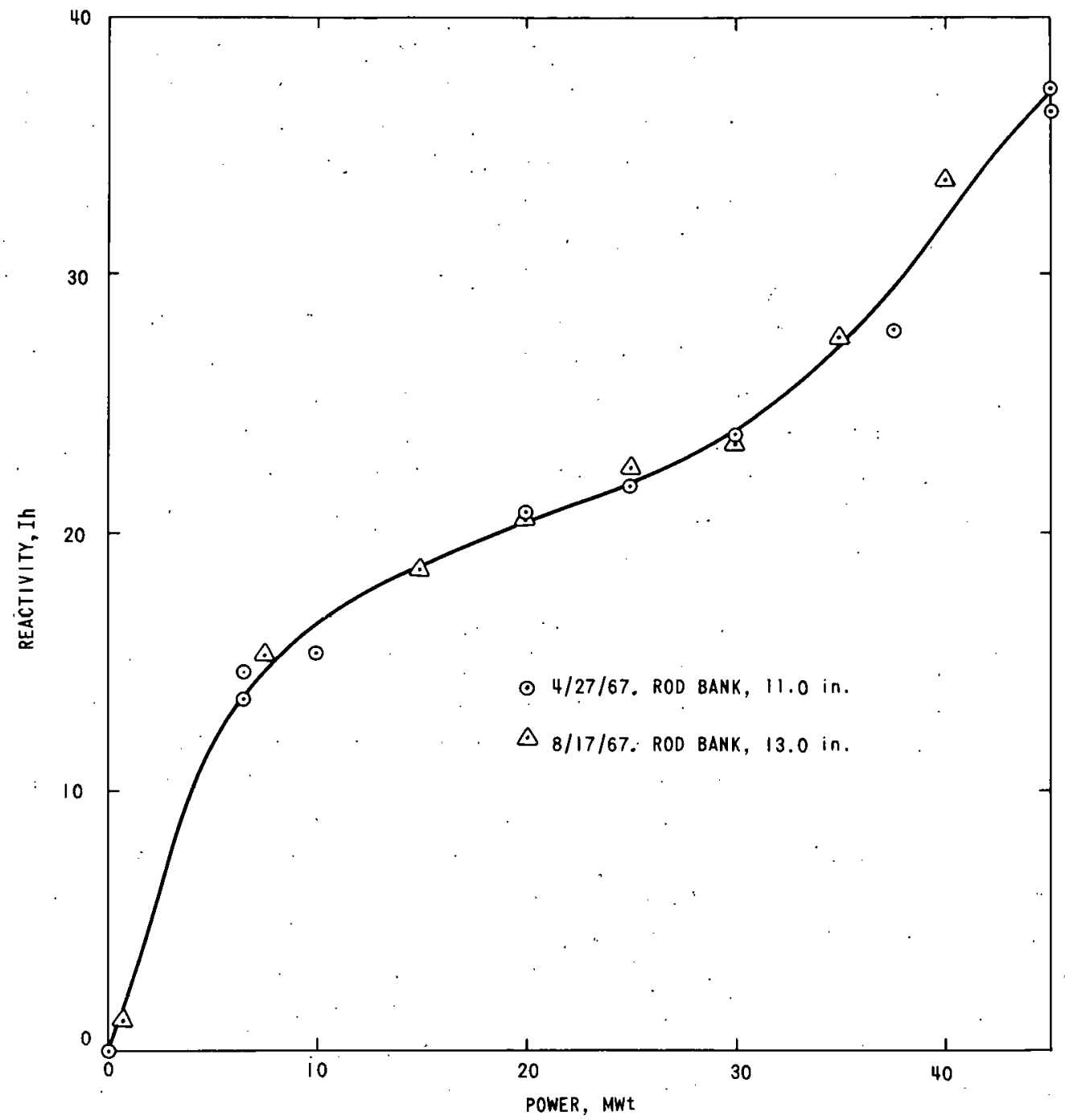

ID-103-K-5782 Rev. 1

Fig. 10. Run-25 Power-coefficient Data, Corrected for Banked-control-rod Effect

G. Randomization of Clearance Systems

The clearance system that exists between neighboring subassemblies is best described in terms of a perfect (highly idealized) situation in which all subassemblies are perfectly vertical and perfectly located in their seats and grid-plate holes. Under these conditions, the nominal clearance between adjacent subassembly tubes is 0.030 in. However, all faces of all subassemblies are equipped with buttons, $3 / 8 \mathrm{in.}$ in diameter and $0.014 \mathrm{in}$. in height, which are formed by dimpling the tube wall. Under the ideal conditions described above, a nominal clearance of 0.002 in. exists between any two buttons.

The subassemblies pivot on seats in the upper grid plate. The nominal clearance between subassembly lower adapters and the lower gridplate holes is $0.008 \mathrm{in.} \mathrm{(diametrical).} \mathrm{Such} \mathrm{a} \mathrm{clearance} \mathrm{permits} \mathrm{any} \mathrm{given}$ 
subassembly a maximum lean of approximately 0.006 in. away from the vertical, at the elevation of the spacer pads. With all core subassemblies standing perfectly vertical, a total clearance of $0.010 \mathrm{in}$. exists between pads (five gaps of $0.002 \mathrm{in}$. each). Thus, if the core subassemblies should lean inward until constrained by either pads or lower adapters, a total clearance of $0.004 \mathrm{in}$. (0.010 less $0.006 \mathrm{in.})$ would still remain between Row $-4,-5$, and -6 spacer pads. On the other hand, if the subassemblies (including blanket subassemblies) should lean outward 0.006 in. at pad elevation, a total of 0.016 in. clearance would exist between pads on the core radius. Thus, the clearance between pads on the core radius may vary from 0.004 to 0.016 in. at zero power, depending on the leaning attitudes of the various subassemblies. Assuming a reactivity equivalent of $3 \mathrm{Ih} / \mathrm{mil}$ (see Section VIII.G), reactivity variations of 8 to 32 Ih may be expected for order-disorder effects.

At one time it was postulated that changes in the power cuefficient might have involved a tendency for decreased clearances between blanket subassemblies. Fundamentally, the model involved the concept that inverse bowing effects in Row -7 and Row -8 stainless steel subassemblies led to a power-sensitive spring action which tended to move core subassemblies inward and blanket subassemblies outward. On shutdown, the "spring" straightened out and allowed freedom of radial movement for both blanket and core subassemblies. Vital to the model was the postulate that clearances between core subassemblies tended to randomize during and after shutdown. At the time it was postulated that the high coolant flow rate through core subassemblies acted as a driving force that tended to disorder the clearances between core units. The much-lower coolant flow through blanket subassemblies was believed insufficient to randomize clearances. If such were true, the effect of a complete power cycle would be reflected by an increase in clearances between all subassemblies lying within Row 8. In other words, clearances would essentially be transferred from the blanket to the core.

During any subsequent startup the increased clearance system in the core would permit a greater degree of inward subassembly bowing which, in turn, would be manifested by a reduction in the overall power coefficient. Such effects would be progressive with time.

To test the validity of these hypotheses, the fuel-handling gripper was used to contact every seventh subassembly in the core and blanket. In this operation the fuel-holddown rig contacted the neighboring six subassemblies and moved each away from the central subassembly. Hopefully, the spreading action would randomize and restore the various clearances to the condition that existed at the start of Run 25. The results of power-coefficient measurements conducted on the randomized loading (August 17) are compared with earlier results (July 23) in Fig. 11. In all cases, the data have been normalized to an 11.0-in. rod-bank condition. From an inspection of 
the data it may be seen that, while the 0-45-MWt PRD values are roughly comparable, the power coefficient in the midpower region strengthened significantly after randomization.

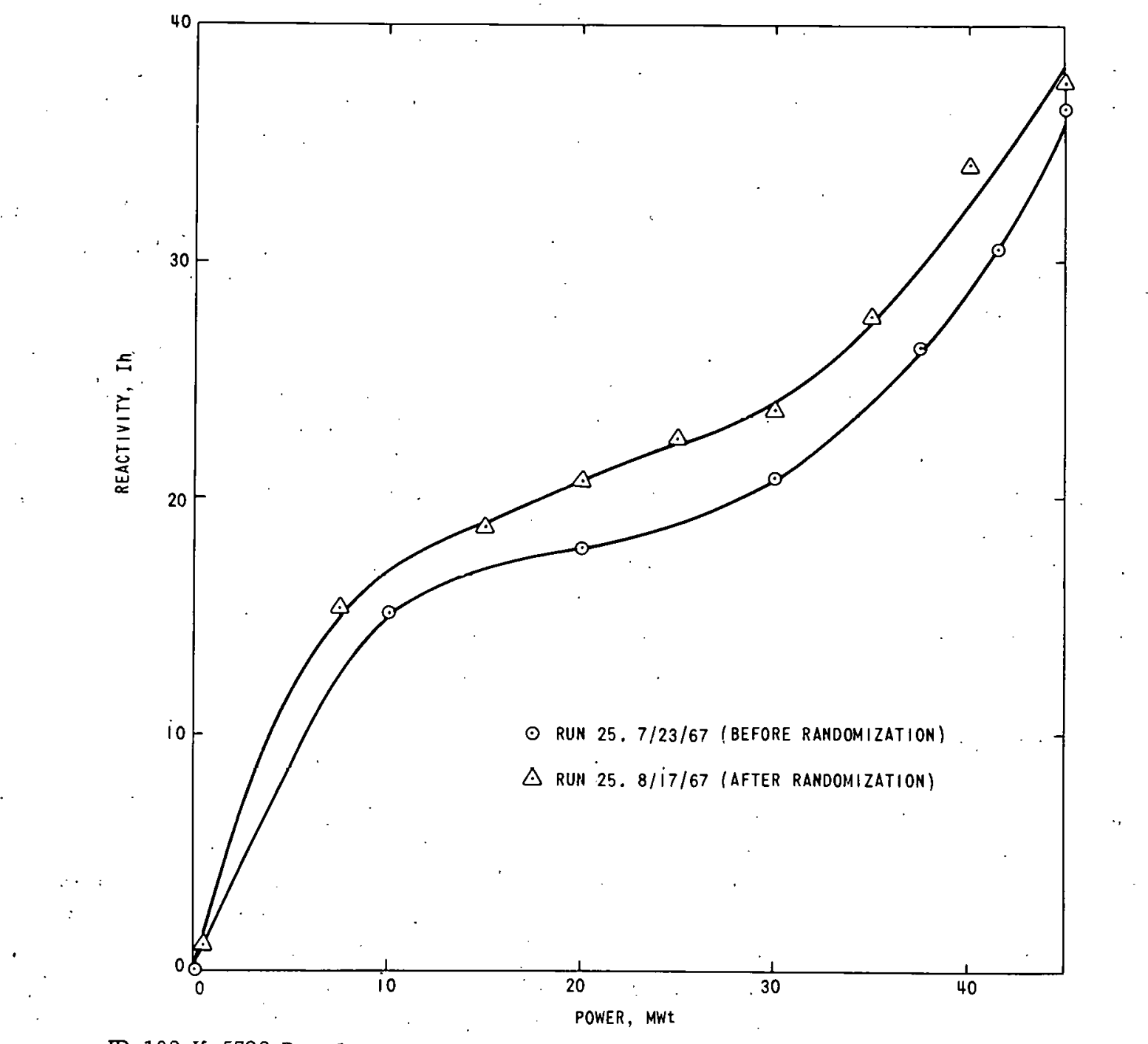

D-103-K-5783 Rev. 1

Fig. 11. The Effect of Clearance Randomization on Run-25 Power Coefficient ; Data Normalized to Rod Bank of 11.00 in.

A more realistic assessment of the success in applying rod-bank corrections and in randomizing subassembly clearances may be inferred from Fig. 10, which compares power-coefficient data taken early in Run 25 , on April 27 (before clearance randomization), and near the end of Run 25 , on August 17 (after clearance randomization). From the data illustrated in Fig. 10 it must be concluded that essentially no change in total PRD or in the shape of the power-coefficient curve occurred during Run 25. Accordingly, it must also be concluded that the indicated decreases in the power coefficient during Run 25 were the results of differences in banked control-rod position and an increasing ordering of clearance systems. On completion of the clearance-randomization experiment, Run 25 was terminated after a total power accumulation of $1552 \mathrm{MWd}$. 


\section{RUN 26}

In the period between the end of Run 25 and the startup of Run 26 on September 23, a number of plant-maintenance activities were carried out. These included an annual leakrate test of secondary-sodium piping penetrations in the reactor building, preventive maintenance on highpressure steam valves, draining and cleaning of the cooling-tower basin, and a reloading of fresh fuel into the core.

Plans called for the installation of the third oscillator rod (Mark-IIB) during Run 26, and it was assumed that the results of transfer-function measurements conducted early in Run 26 would be comparable to those for the Run-25 configuration. To avoid ambiguities, special precautions were taken to maintain the same core configuration and composition that existed in Run 25. All loading changes involved the removal and replacement of subassemblies containing spent fuel, with a few minor exceptions. For example, driver subassembly B-355 was moved to position 6C4 to permit the installation of a special increased-flow subassembly under the thermocouple in 6C4, and blanket subas semblies U-1317 and U-1605, in 9C5 and 13F6, respectively, were removed for surveillance. However, two physical changes were made. First, the primary system was cooled to $350^{\circ} \mathrm{F}$ and subsequently reheated to $700^{\circ} \mathrm{F}$. Second, clearance systems existing at the end of Run 25 were disturbed by subsequent fuel-handling operations.

A. Power-coefficient Measurements during Run-26A Startup

The first experiments planned for the beginning of Run 26 (Run 26A) were the following: power-coefficient measurements, rod-drop tests, control-rod calibrations, reduced-flow measurements, and a quantitative evaluation of the banked-control-rod effect. Low-power experiments were conducted on September 23 and 24. On September 25, power was increased incrementally to $45 \mathrm{MWt}$ for power-coefficient measurements. During the following shutdown, power-coefficient measurements were conducted in the reduced-power mode. Two more sets of power-coefficient measurements were conducted during Run 26A, one for 0-45 MWt on September 26 and another for 0-45-0 MWt on September 29. The results of these measurements for the increasing power mode are summarized in Fig. 12. For comparative purposes, values for the power-coefficient data taken on August 17 (the end of Run 25) have been plotted in the figure. For consistency, all values given in Fig. 12 have been normalized to an 11.0-in. rodbank condition. Similar data for both increasing and decreasing power. modes, for September 25 and 29, are given in Fig. 13.

From an inspection of the results shown in Fig. 12, two observations may be made: (1) the average PRD of 41.9 Ih for the three Run-26A measurements exceeds the final value of 37.4 Ih for Run 25, and (2) for power levels higher than $10 \mathrm{MW}$, the power coefficient for Run 26A is stronger 


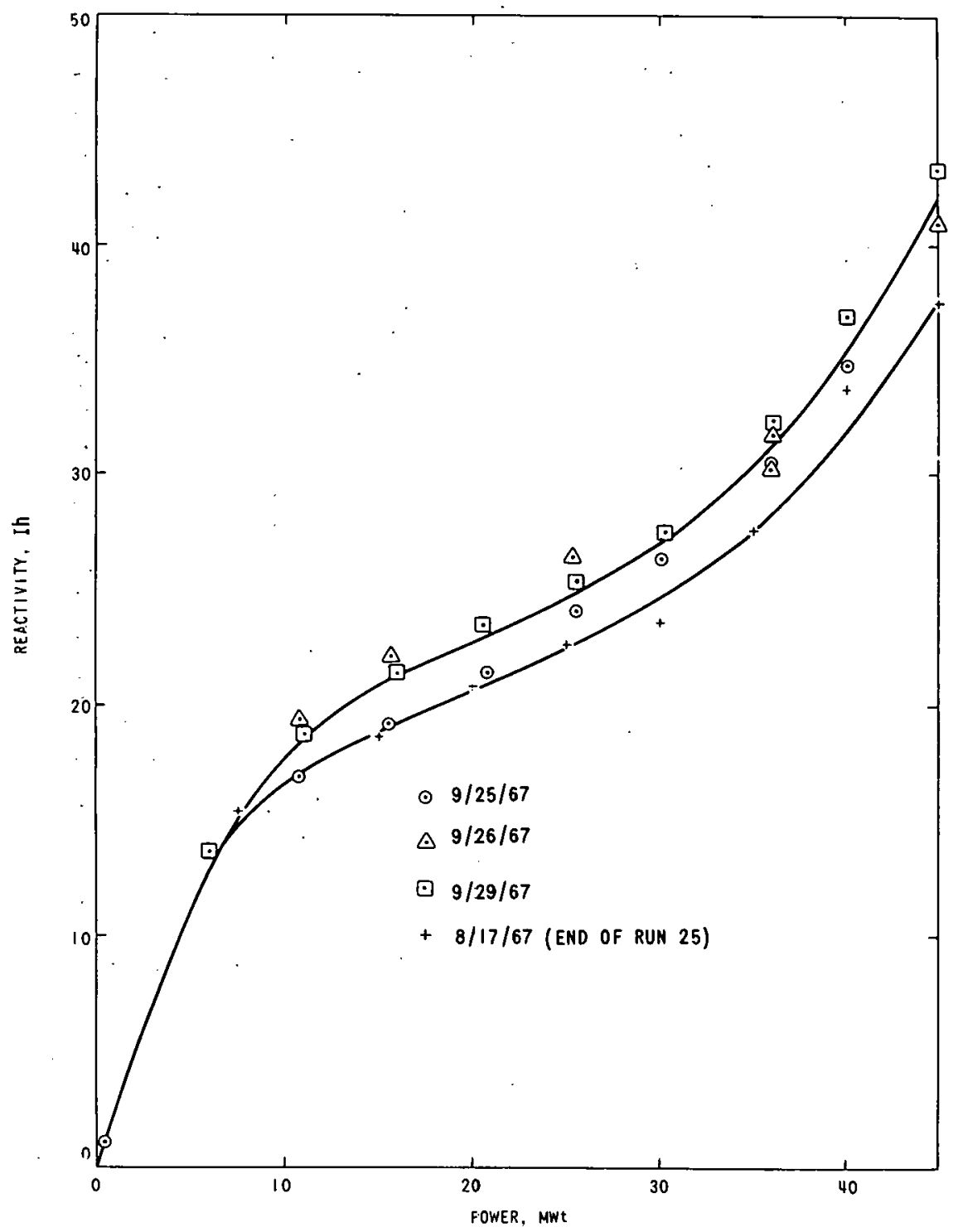

ID-103-K-5784 Rev. 1

Fig. 12. Power-coefficient Data from Run 26A and the End of Run 25, Normalized to a Rod Bank of 11.00 in.

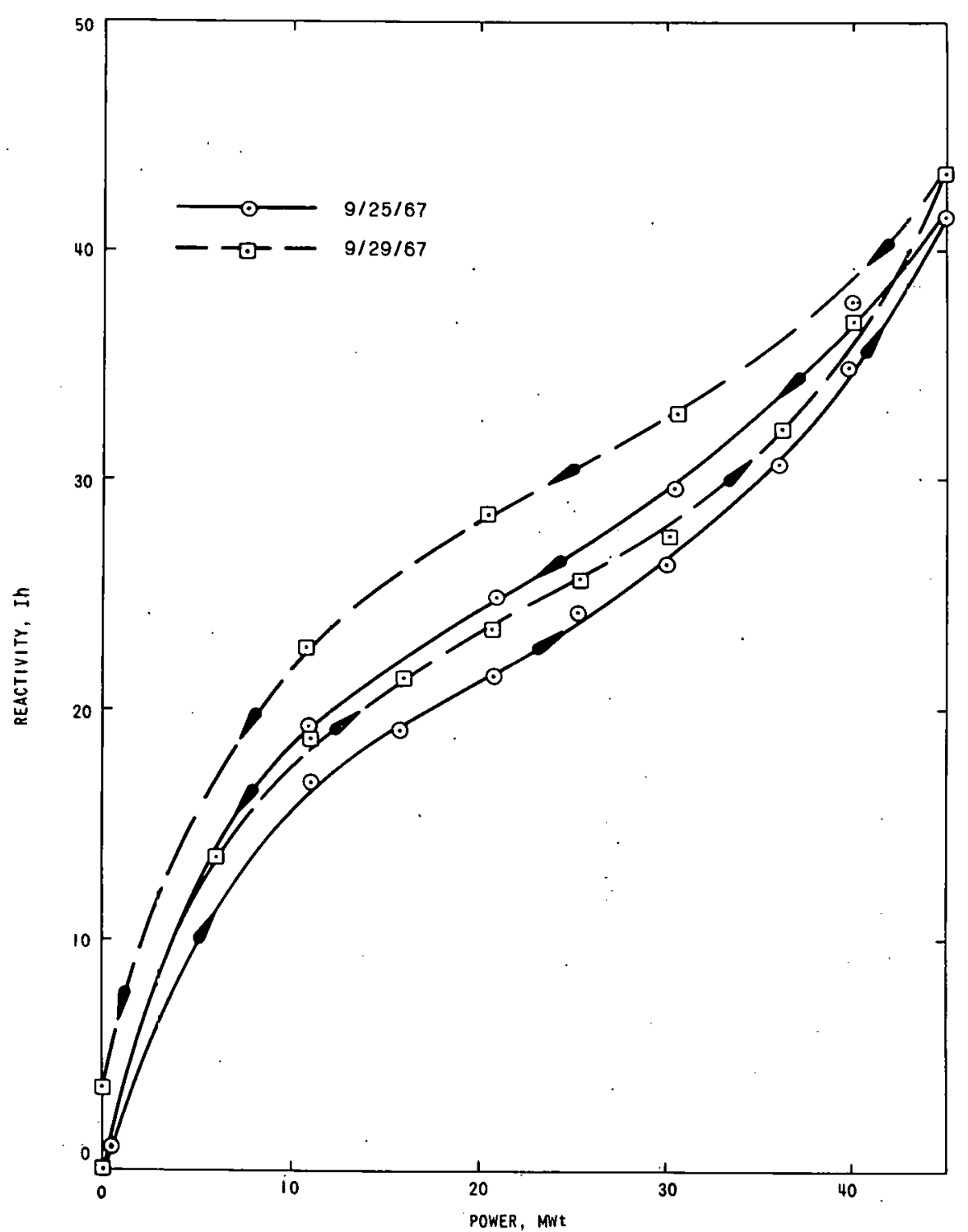

ID-103-K-5785 Rev. 1

Fig. 13. Run-26A Power-coefficient Data for Increasing and Decreasing Power Modes and Normalized to a Rod Bank of $11.00 \mathrm{in}$. 
than that for the end of Run 25. The apparent strengthening of the power coefficient relative to the end of Run 25 suggests the influence of an evenmore rigorous disordering of clearances by extensive fuel-handling operations prior to Run 26.

B. Experimental Investigation of the Banked-control-rod Effect

Experimental verification of the banked control rod effect and a measurement of its magnitude were provided by a series of experiments conducted at the start of Run 26A. Upon reaching $45 \mathrm{MWt}$ with a banked position of 13.0 in., a careful measurement of control-rod positions was made. Rods were then rebanked at $12 \mathrm{in.,}$ then at $11.0 \mathrm{in.,}$ and finally with half at 10 and the other half at 14 in. A summary of PRD data for the various banked positions is given in Table I.

TABLE I. PRD Data for Different Banked Positions of Control Rods

\begin{tabular}{|c|c|c|c|c|c|}
\hline \multirow{2}{*}{$\begin{array}{l}\text { Case } \\
\text { No. }\end{array}$} & \multirow{2}{*}{$\begin{array}{c}\text { Nominal* } \\
\text { Rod-bank } \\
\text { Position } \\
\text { (in.) }\end{array}$} & \multicolumn{3}{|c|}{$\begin{array}{c}\text { Measured PRD } \\
\text { (Ih) }\end{array}$} & \multirow{2}{*}{$\begin{array}{c}\text { Differential } \\
\text { Reactivity } \\
\text { Worth of the } \\
\text { Actual Rod } \\
\text { Configuration** } \\
\text { (Ih/in.) }\end{array}$} \\
\hline & & $9 / 25 / 67$ & $9 / 27 / 67$ & $9 / 29 / 67$ & \\
\hline 1 & 11 & 42.3 & 42.9 & 41.9 & 88.6 \\
\hline 2 & 12 & - & 41.9 & 40.1 & 75.4 \\
\hline 3 & 13 & 37.0 & 39.5 & 38.3 & 68.5 \\
\hline 4 & 10 and 14 &. & 38.4 & 38.1 & 61.6 \\
\hline
\end{tabular}

*Nominal, in that elther 9 or 10 control rods were lanked at the indicatcd pooition. **Values given in this column correspond to what the reactivity change would be if all control rods grew downward 1 in. from their actual positions.

The data in Table I may be used for an experimental evaluation of the banked control-rod effect. As a prelude to such an evaluation, it is important to emphasize the following facts: (1) It was not possible to bank all control rods at the positions indicated in Table I; (2) Unusual care and effort were expended in obtaining the best possible reactivity-position calibrations for each control rod, and; (3) As a consequence of (1) and (2), it was possible to establish rather precise values for the differential reactivity worths of the actual control-rod configurations given in the last column of Table $I$. Thus, while nine of the rods were banked, for example, at $11.0 \mathrm{in.}$, the other three were at different positions. But, since the differential worths were known for all, it was possible to establish values for the reactivity change per inch for the actual configuration. It is these values which are listed in the last column of Table I.

In the following calculations, it was assumed that the power coefficient as measured consists of two components, one resulting from temperature-induced changes in density of fuel, coolant, and-structure, and 
the other intrinsically associated with all processes influenced by the positions of control rods. Hence, the PRD in going from hot critical to $45 \mathrm{MWt}$ is:

$$
\operatorname{PRD}=A_{0}+B \Delta x
$$

where $A_{0}$ includes all PRD components exclusive of control-rod effects, $B$ is the differential reactivity worth of the actual control-rod configuration in $\mathrm{Ih} / \mathrm{in}$, and $\Delta \mathrm{x}$ is the effective distance the control rods drop as a result of going from hot critical to $45 \mathrm{MW}$. Assuming that $A_{0}$ does not change with banked position, as it should not, it is a simple matter to calculate $\Delta x$ from any two different conditions of banked position given in Table I. An average of the values obtained for $\Delta \mathrm{x}$ from the information given in Table $\mathrm{I}$ amounts to $0.16 \mathrm{in}$. This value, deduced exclusively from the results of experimental information, compares reasonably well with the value of 0.14 in. inferred from a calculation of temperature distributions and dimensions of control rods and shafts.

In Equation (1) it had been assumed that $A_{0}$ is invariant with respect to control-rod configuration and position. This assumption is reasonable since all normal power-coefficient components are prime functions of temperature distributions, which are relatively insensitive to actual controlrod configurations.

The average of the experimental and calculated values of $\Delta x$, i.e., $0.16+0.14 / 2=0.15$ in., may be used to adjust the final value of the PRD measured on August 17 at the end of Run 25. First, the differential reactivity worths of the actual rod configurations on April 26, April 27, and August 17 were established from the actual rod positions and the differential worths of each of the 12 control rods. The worths of the configurations amounted to 107.8 and $60.3 \mathrm{Ih} / \mathrm{in}$. for beginning (April 26 and 27) and final (August 17) data, respectively. These values corresponded to nominal banked positions of 11.0 and 13.0 in., respectively. The correction to be applied to the final data is thus $0.15(107.8-60.3)=7.1 \mathrm{Ih}$.

Two power-coefficient runs were conducted on April 26 and 27. Values obtained for the reactivity defect were 39.2 and $37.3 \mathrm{Ih}$, respectively, giving an average value of 38.3 Ih for the nominal'11.0-in. banked position. The final value of 31.5 Ih for the reactivity defect under 13.0-in. nominal banked conditions was measured on August 17 at the end of Run 25. Addition of 7.1 Ih gives $38.6 \mathrm{Ih}$, a value almost exactly that measured at the start of the run.

The data given in Table I may be displayed in different form by applying corrections to the higher-banked-position data, assuming a value of 0.15 in. for control-rod growth. The data of Table I normalized to the nominal $11.0-$ in. banked position are given in Table II. 
TABLE II. PRD Normalized to Nominal Banked Pósition of $11.0 \mathrm{in}$.

\begin{tabular}{cccc}
\hline & \multicolumn{2}{c}{$\begin{array}{c}\text { Normalized PRD for } \\
\text { Nominal 11.0-in. } \\
\text { Banked Position } \\
\text { (Ih) }\end{array}$} \\
$\begin{array}{c}\text { Rominal } \\
\text { Position } \\
\text { (in.) }\end{array}$ & \multicolumn{3}{c}{$9 / 29$} \\
\hline 11 & $9 / 25$ & $9 / 27$ & $9 / 29$ \\
12 & $42.3^{*}$ & $42.9 *$ & $41.9^{*}$ \\
13 & - & 43.9 & 42.1 \\
10 and 14 & 40.0 & 42.5 & 40.3 \\
\hline
\end{tabular}

*Actual values for the nominal 11.0-in. banked position.
From the data in Table II it may be inferred that the assumed average value of 0.15 in. for the control-rod growth effects a reasonable consistency between reactivity defects measured under a variety of banked conditions.

The data given in Table II may be presented in another form, which has more meaningful implications for assessing the behavior of the power coefficient over a period of time. For example, if all powercoefficient components intrinsically associated with control rods are sub-

tracted from the measured power coefficient, the residue is the sum of all other power-coefficient components. Such residues should remain relatively invariant with time. The results of such a correction or subtraction are given in Table III. In a very real sense, the values given are those for a hypothetical EBR-II core which has no control rods. Again, all values for the residual PRD (actually measured under widely varying bank positions) are in reasonable agreement, thereby indicating that the assumed value of $0.15 \mathrm{in}$. for controlrod growth is reasonably consistent with experimentally established data and the results of calculations.

In a final experiment the

TABLE III. PRD for Hypothetical EBR-II Core without. Control Rods

\begin{tabular}{cccc}
\hline $\begin{array}{c}\text { Nominal } \\
\text { Rod-bank } \\
\begin{array}{c}\text { Position } \\
\text { (in.) }\end{array}\end{array}$ & \multicolumn{3}{c}{$\begin{array}{c}\text { Normal Power- } \\
\text { coefficient Residue } \\
\text { (Ih) }\end{array}$} \\
\cline { 2 - 4 } & $9 / 25$ & $9 / 27$ & $9 / 29$ \\
\hline 11 & 29.1 & 29.7 & 28.7 \\
12 & - & 30.7 & 28.9 \\
13 & $26: 8$ & 29.3 & 28.1 \\
10 and 14 & - & 28.2 & 28.9 \\
\hline
\end{tabular}
entire rod bank was raised 0.150 in. Differences in reactivity were established by a carefully calibrated "regulating" rod. The actual changes in reactivity are compared with calculated values in Table IV.

TABLE IV. Comparison of Measured and Calculated Reactivity Changes for Shifts in the Banked Position

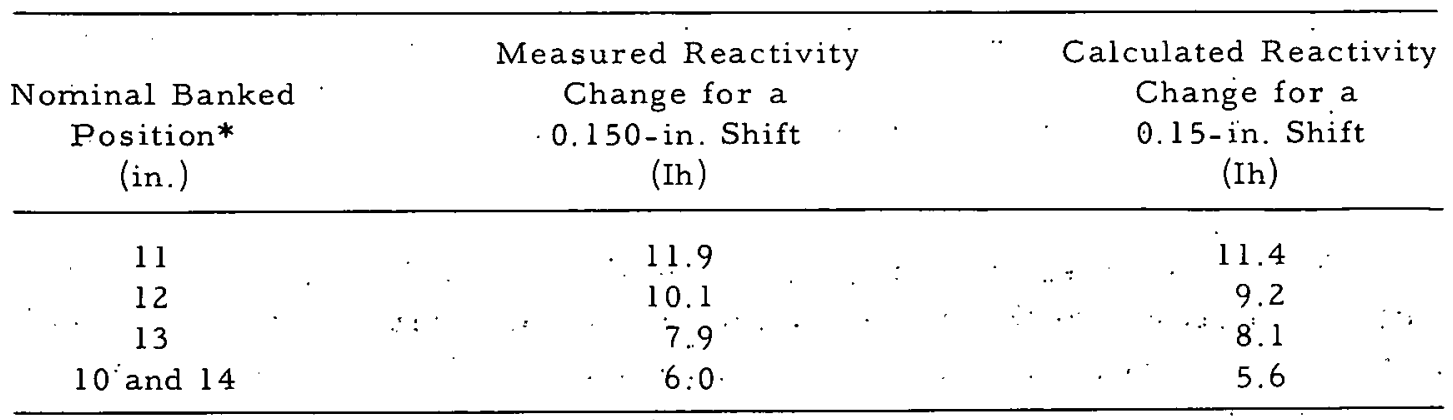

*In the se measurements, the actual rod configurations differed from those characterizing the data in Tables I through III. 
In all cases, a reasonable agreement between measured and calculated values may be seen, thereby indicating that the assumed value of 0.15 in. for control-rod growth is very likely reasonable.

In summarizing the results of analyses conducted in the study of the banked-rod effect, the following conclusions may be cited: (1) Calculations based on thermal and mechanical considerations indicate a rod growth of $0.14 \mathrm{in.}$. between hot critical and $45 \mathrm{MWt},(2)$ the average of experimental results indicates a growth of 0.16 in., and (3) the use of the average of these two growth values, i.e., 0.15 in., and the differential worths of actual control-rod configurations leads to an upward revision of the final PRD value of Run 25 (August 17) to $38.6 \mathrm{Ih}$, almost precisely the average value of 38.3 Ih measured at the start of Run 25 .

\section{Continuation of Run 26 (Run 26B)}

Following the completion of the power-coefficient measurements and the studies of the rod-bank effect described above, the system was shut down on September 29 after a total power accumulation of $96 \mathrm{MWd}$. On the following day, a plant cooldown to $600^{\circ} \mathrm{F}$ was started in preparation for the installation of the Mark-IIB oscillator rod and drive mechanism. First the drive assembly for control-rod No. 7 was removed because problems had been encountered with the sticking of the gripper jaws. After its removal, the drive for control-rod No. 8 was moved to the No.-7 position. The rotary oscillator drive was then installed in the No.-8 position. The installation of the oscillator rod was completed on October 5, and final preoperational checkout was finished on October 11. At that time the stainless steel dummy subassembly XO00 was replaced by experimental subassembly XO25: and two other experimental subassemblies (XO26 and XO27) were added. Criticality was achieved on October 13, and the power level was increased incrementally to $45 \mathrm{MWt}$ on October 14. A summary of power-coefficient data taken for a complete 0-45-0-MWt power cycle is given in graphical form in Fig. 14. A comparison of the data given in Fig. 14 with that taken at the beginning of Run 26 (September 25 and 29), given in Fig. 13, reveals that the power coefficient remained essentially unchanged.

During the approach to power, torque measurements were conducted on the oscillator rod at each 5-MWt power increase. Up to a power level of $25 \mathrm{MWt}$, no indication of rubbing was noted. At $30 \mathrm{MWt}$, however, the torque needed to rotate the rod increased significantly, and the conclusion was reached that the oscillator rod was rubbing. Torque measurements were not conducted for power levels higher than $30 \mathrm{MWt}$. On the following day, October 15 , the power level was reduced to $500 \mathrm{kWt}$ in preparation for rod-drop tests up to $45 \mathrm{MW}$ and for transfer-function measurements up to the highest power level practicable. During the following four days, roddrop tests and reduced-flow experiments were carried out under a wide 
variety of power and flow conditions. Despite the evidence from torque measurements that indicated a rubbing problem, attempts were made during this period to obtain as much useful transfer-function information as possible. At $500 \mathrm{kWt}$, excellent information was obtained over the frequency range from 0.002 to $8.8 \mathrm{~Hz}$; at $22.5 \mathrm{MWt}$, over the range from 0.006 to $6.2 \mathrm{~Hz}$; at $30 \mathrm{MWt}$, over the range from 0.1 to $4.0 \mathrm{~Hz}$; and at $41.5 \mathrm{MWt}$, over the range from 0.2 to $4.0 \mathrm{~Hz}$. To avoid confusion in the chronology of power-coefficient studies, a discussion of the transfer-function results has been deferred until Section VIII.J.

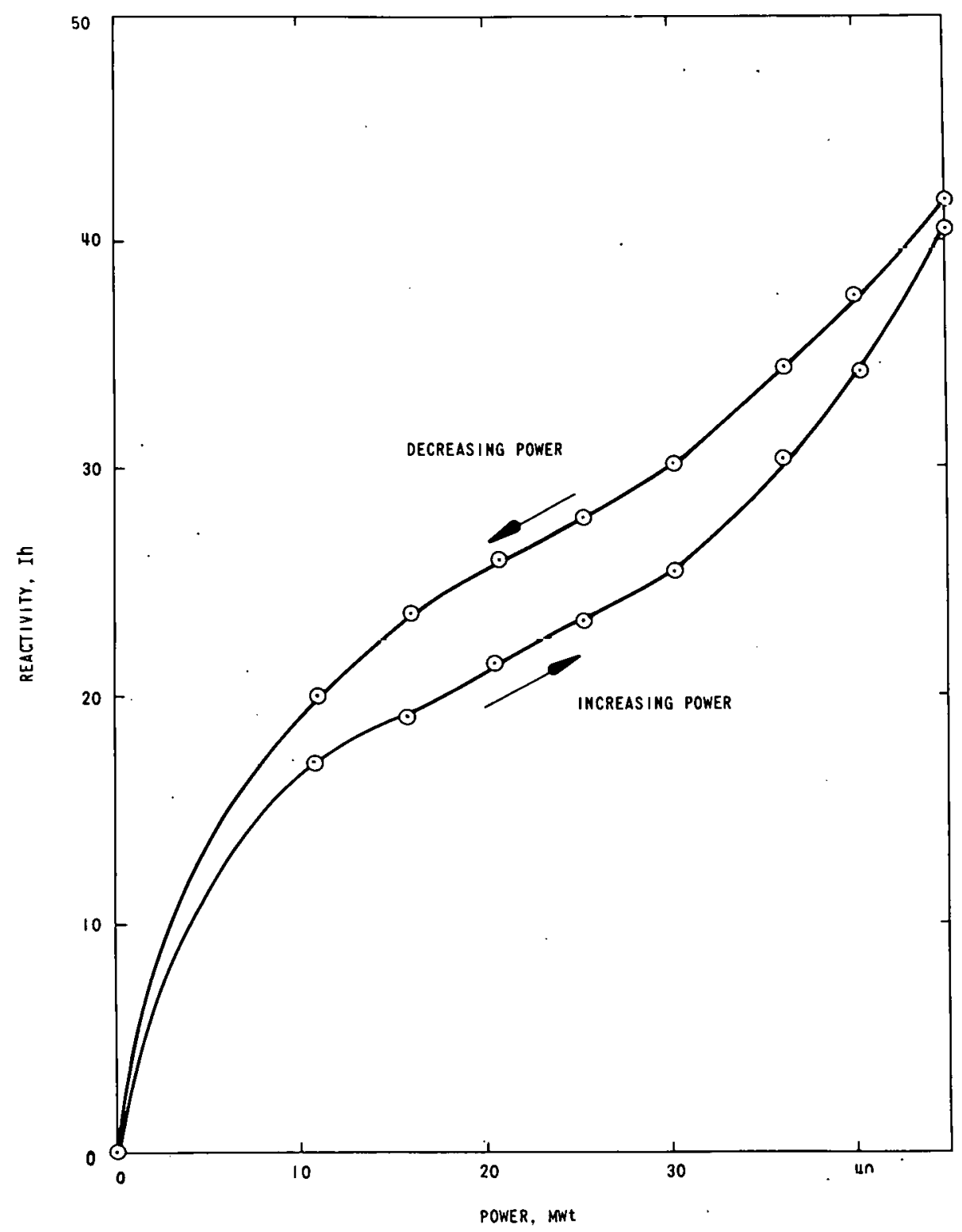

ID-103-K -5786 Rev. 1

Fig. 14. Run-26B Power-coefficient Data Taken on October 14, 1967. Normalized to a Rod Bank of 11.00 in. 
During subsequent operation of the reactor, the various physics tests referred to above were completed. In the course of these tests, additional power-coefficient measurements were made on the following dates: October 15, 17, 20, and 27, and November 18. Figure 15 summarized the results of these measurements. In general, the 0-45-MWt PRD remained essentially unchanged throughout the period. On the other hand, a definite trend toward lower differential power-coefficient values in the midpower region may be seen. Whereas a similar trend during Run 25 could be explained in terms of a difference in banked-control-rod positions, such is not the case for the data illustrated, which have been corrected for the rodbank effect. The persistent trend toward lower differential-power-coefficient values must be concluded to be real. While a discussion of the apparent

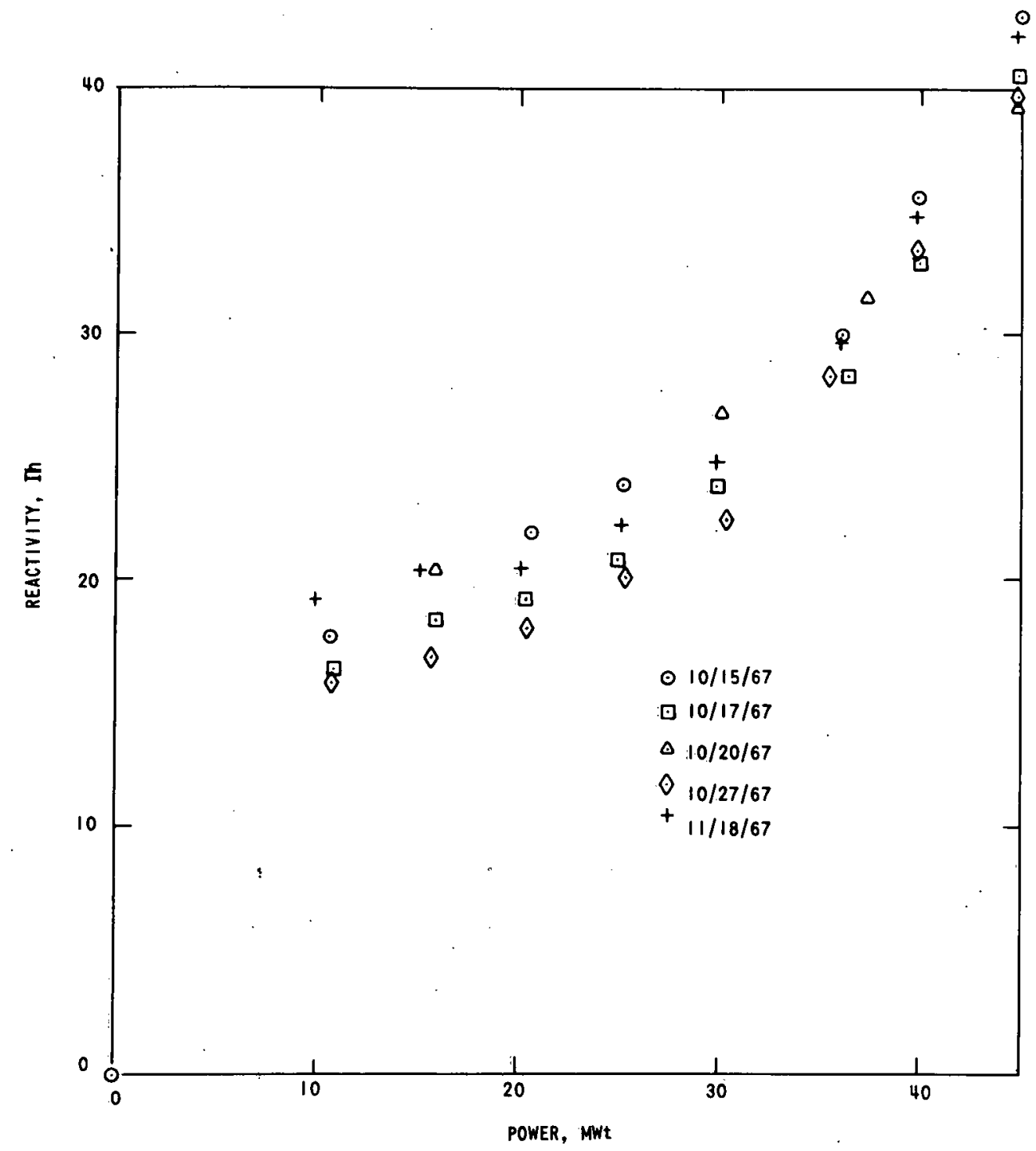

ID-103-K-5787 Rev. 1

Fig. 15. Run-26B Power-coefficient Data, Normalized to a Rod Bank of 11.00 in. 
decrease will be deferred to Section IX.C, it is important to emphasize, at this point, that all of the power-coefficient data taken during Run 26B (between October 13 and November 20) involved the same core configuration and composition. Run $26 \mathrm{~B}$ was terminated on November 20 after a total power accumulation of $1115 \mathrm{MWd}$.

Marked changes in the reactivity balance of the system were noted on November 7, while the reactor was operating at a power level of $45 \mathrm{MWt}$. At 1100 on November 7 , the excess reactivity available in control-rod No. 5 was $48.8 \mathrm{Ih}$. At this time the power level was reduced to $22.5 \mathrm{MWt}$ and held at this level for $7 \frac{1}{2} \mathrm{hr}$ to complete a series of reduced-flow tests. When the power level was raised again to $45 \mathrm{MWt}$, the excess reactivity (corrected for burnup) was remeasured as $55.6 \mathrm{Ih}$. During a period of sustained operation at $45 \mathrm{MWt}$, reactivity (exclusive of burnup) was gradually lost until the excess reactivity returned to its approximate initial value. The actual chronology is given in Table $\mathrm{V}$.

TABLE V. Reactivity Drift on November 7 and 8,1967

\begin{tabular}{lcc}
\hline Time & $\begin{array}{c}\text { Excess Reactivity } \\
\text { Available in } \\
\text { (MWt) }\end{array}$ & $\begin{array}{c}\text { Control-rod No. 5* } \\
\text { (Ih) }\end{array}$ \\
\hline 0800, November 7 & 45.0 & 48.2 \\
1100 & 45.0 & 48.8 \\
1130 & 22.5 & - \\
1825 & 22.5 & - \\
1902 & 45.0 & 55.6 \\
2400 & 45.0 & 51.6 \\
0800, November 8 & 45.0 & 49.9 \\
\hline
\end{tabular}

*Reactivity values corrected to 1100 on November 7 .

Similar behavior had been noticed in an earlier series of reducedflow tests conducted during the period of October 2.3 and 24 . The results of these measurements are summarized in Table VI.

TABLE VI. Reactivity Drift on October 23 and 24, 1967

\begin{tabular}{lcc}
\hline \multicolumn{1}{c}{ Time } & $\begin{array}{c}\text { Excess Reactivity } \\
\text { Available in } \\
\text { (MWt) }\end{array}$ & $\begin{array}{c}\text { Control-rod No. 5* } \\
\text { (Ih) }\end{array}$ \\
\hline 2400, October 22 & 45.0 & 48.0 \\
0800, October 23 & 45.0 & 49.1 \\
1000 & 22.5 & - \\
2325 & 45.0 & 54.8 \\
2400 & 45.0 & 53.3 \\
0800, October 24 & 45.0 & 51.0 \\
1600 & 45.0 & 51.2 \\
\hline
\end{tabular}

*Corrected to 0800 on October 23. 
In both instances, for October 23 and 24 and November 7 and 8, a return to $45 \mathrm{MWt}$ after operating at 22.5 resulted in a significant gain in reactivity. With continued operation at $45 \mathrm{MWt}$, the reactivity gain gradually disappeared.

The effects of a scram on the reactivity balance during this period are summarized in Table VII.

TABLE VII. Effects of a Scram on Reactivity Balance, November 6, 1967

\begin{tabular}{lcc}
\hline Time & $\begin{array}{c}\text { Excess Reactivity } \\
\text { Available in } \\
\text { Power Level } \\
\text { (MWt) }\end{array}$ & $\begin{array}{c}\text { Control-rod No. 5* } \\
\text { (Ih) }\end{array}$ \\
\hline 0000, November 6 & 45.0 & 53.0 \\
0800 & 45.0 & 52.4 \\
0836 & Scram & - \\
1155 & 45.0 & 53.6 \\
1600 & 41.5 & $56.4 * *$ \\
\hline
\end{tabular}

*Corrected to 0000 , November 6 .

**52.4 Ih at 45.0 MWt (estimated).

The results summarized in Tables $V$ through VII suggest that prolonged operation in the midpower region causes a more reactive configuration through a net decrease in core radius. For a sudden decrease in power, as for a scram, the core outline upon return to power remains essentially unchanged. The significance of these effects is described under Section IX.C.

D. Continuation of Run 26 (Run 26C)

Following the Run 26B shutdown, several loading changes were made. Insertions consisted of two fresh driver surveillance subassemblies (C-2111 and C-2113) and four experimental subassemblies (XO27, XO28, $\mathrm{XO} 31$, and XO32). Removals consisted of two standard driver and four halffueled subassemblies. Experiments XO15 and XO16, previously located in grid positions $4 \mathrm{~A} 2$ and $4 \mathrm{D} 3$, were relocated to positions $4 \mathrm{D} 2$ and $4 \mathrm{~F} 3$, respectively. Criticality was achieved on November 22, and control rods were calibrated on November 23. The power was increased in 5-MWt increments. During the ascent from 20 to $25 \mathrm{MWt}$, the signal from the FGM began to increase at a rate too large to be explained in terms of the power increase. The power level was reduced to $17.5 \mathrm{MWt}$. Meanwhile, the signal continued to increase until the alarm point was reached. At this point, when it became obvious that a fission-product release had occurred, the reactor was shut down.

On the following day, the system was again brought to a power level of $25 \mathrm{MWt}$. A second release occurred, but this time the system was operated for approximately eight hours to obtain more meaningful information 
from cover-gas analyses. From measurements of the ${ }^{133} \mathrm{Xe} /{ }^{135} \mathrm{Xe}$ ratio in the cover gas, it was concluded that the release involved fuel material that was inserted immediately prior to the Run-26C startup. ${ }^{41}$ Accordingly, the two fresh driver surveillance subassemblies (C-2111 and C-2113) were removed. The reactor was restarted on November 25, and operating power was reached the following day. No other fission-product gas release was noted during the remainder of the run. (In fact, the next fission-product gas release occurred approximately three months later, on March 5, 1968.)

During Run 26C, marked changes were again noted in the power coefficient, and on these occasions, too, the definite trend towards lower power-coefficient values could not be explained in terms of the bankedcontrol-rod effect. An illustration of this trend is given in Fig. 16, which summarizes the results of power-coefficient data taken on November 25 and 30 .

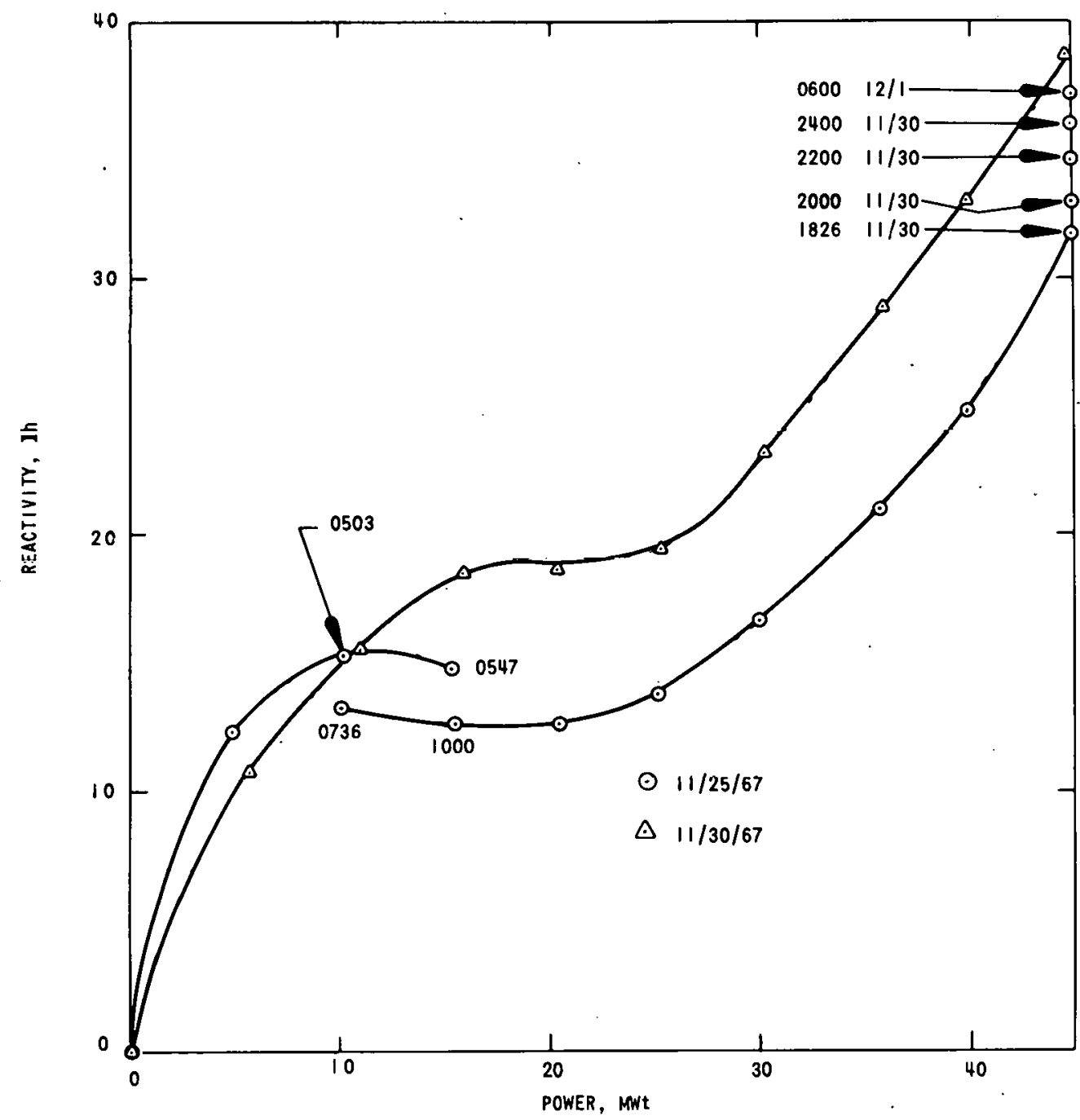

ID-103-K -5788 Rev. 1

Fig. 16. Run-26C Power-coefficient Data Taken on November 25 and 30 , Normalized to a Rod Bank of 11.00 in. 
The data taken on November 30 are particularly interesting since, in the range from 10 to $15 \mathrm{MWt}$, a positive differential power coefficient is indicated. It is believed, however, that small increases in reactivity during the course of the measurements were responsible for the indicated positive nature of the differential power coefficient in this range. Since the data given for November 30 in Fig. 16 illustrate the worst case of an apparent deterioration of the power coefficient, a detailed chronological summary of events during the measurements is considered beneficial.

On the preceding day, November 29, the power level was reduced to 22.5 MWt to complete reduced-flow experiments. On the return to $45 \mathrm{MWt}$ the regulating rod did not return to the comparable 45-MWt operating position. The sense of the difference was such that, upon return to $45 \mathrm{MWt}$, the system had gained 1.4 Ih of reactivity. After $3 \mathrm{hr}$ at $45 \mathrm{MWt}$, the regulating rod was returned to its original position at 1815 on November 29 . Therefore, after correction for temperature and burnup effects, 1.4 Ih of reactivity was lost.

Two scrams occurred shortly thereafter, one from $45 \mathrm{MWt}$ at 1840 on November 29, and the other from $50 \mathrm{kWt}$ at 0150 on November 30. During the ascent to power following the $50-\mathrm{kWt}$ scram it was noted, in increasing the power from 10.2 to $15.3 \mathrm{MWt}$, that the indicated reactivity decrement decreased from 15.3 to $14.8 \mathrm{Ih}$. Pertinent reactivity balance data during this and ensuing periods are given in Table VIII.

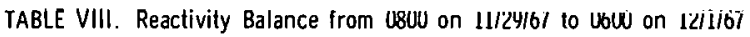

\begin{tabular}{|c|c|c|c|c|c|c|c|}
\hline Time & Power (MWt) & $\begin{array}{l}\text { Reactivity Excess } \\
\text { (Ih) }\end{array}$ & $\begin{array}{l}\text { Power Reactivity } \\
\text { Decrement (Ih) }\end{array}$ & Time & Power (MWt) & $\begin{array}{l}\text { Reactivity Excess } \\
\text { (Ih) }\end{array}$ & $\begin{array}{l}\text { Power Reactivity } \\
\text { Decrement (Ih) }\end{array}$ \\
\hline $0800(11 / 29 / 67)$ & 45.0 & 43.8 & 38.0 & & \multicolumn{2}{|c|}{ Reduced Power - Reduced Flow } & - \\
\hline \multicolumn{4}{|c|}{ Reduced Power - Reduced Flow } & $0736(11 / 30167)$ & 10.0 & 68.5 & 13.3 \\
\hline & & & & 1000 & 15.3 & 69.1 & 12.7 \\
\hline 1515 & 45.0 & 45.2 & 36.6 & 1325 & 20.4 & 69.2 & 12.6 \\
\hline 1615 & 45.0 & 44.0 & 37.8 & 1500 & 25.1 & 68.0 & 13.8 \\
\hline 1715 & 45.0 & 44.5 & 37.3 & 1620 & 30.1 & 65.1 & 16.7 \\
\hline 1815 & 45.0 & 43.8 & 38.0 & 1703 & 35.8 & 60.8 & 21.0 \\
\hline 1840 & Scram & & & 1740 & 40.0 & 57.1 & 24.7 \\
\hline 2255 & 0.05 & 80.8 & 1.0 & 1826 & 45.0 & 50.1 & 31.7 \\
\hline 2350 & .0 .05 & 81.4 & 0.4 & 1900 & 45.0 & 50.1 & 31.7 \\
\hline $0040(11 / 30 / 67)$ & 0.05 & 82.0 & -0.2 & 2000 & 45.0 & 48.8 & 33.0 \\
\hline 0150 & Scram & & & 2200 & 45.0 & 47.2 & 34.6 \\
\hline \multirow[t]{2}{*}{0222} & 0.05 & $81.8^{\circ}$ & 0 & 2400 & 45.0 & 45.8 & 36.0 \\
\hline & & & (Reference) & $0200(12 / 1 / 67)$ & 45.0 & 46.5 & 35.3 \\
\hline 0335 & 4.9 & 69.5 & 12.3 & 0400 & 45.0 & 45.1 & 36.7 \\
\hline 0503 & 10.2 & 66.5 & 15.3 & 0600 & 45.0 & 44.6 & 37.2 \\
\hline 0547 & 15.3 & 67.0 & 14.8 & & & & \\
\hline
\end{tabular}

Since the indication of a positive differential power coefficient was clear, the shift supervisor ordered a power cutback to $10 \mathrm{MWt}$ and requested further instructions from project management. It soon became apparent that reactivity was being fed to the system while the power coefficient was being measured. For example, 2.0 Ih of reactivity were fed to the system between 0503 and 0736 (see Table VIII). 
Concluding that a slow reactivity drift was responsible for the indicated positive effect noted at 0547 , the power level was increased to 15.3 $\mathrm{MWt}$ at 1000 . In this case, a 0.6 -Ih increase in reactivity was noted in comparison with the $073610-\mathrm{MWt}$ reference value. At this point it was still not clear whether the reactivity balance of the system was still drifting in a positive direction or the differential power coefficient was actually positive. To test for further drifts, the power was increased to $15.3 \mathrm{MWt}$ and held at this level for approximately three hours. During this period drifting appeared to diminish. At the end of this period (at 1325), 'the power was raised to $20.4 \mathrm{MWt}$, and a reactivity gain of 0.1 Ih was indicated. At 1500 , the power was increased to $25 \mathrm{MWt}$. This time, a loss of 1.2 Ih in reactivity was noted. Reasoning that reactivity drifting was responsible for the earlier positive indications and that drifting effects had run their course, the power level was again increased in $5-\mathrm{MWt}$ increments to $45 \mathrm{MWt}$. It is considered particularly significant that, between 1826 on November 30 and 0600 on December 1 (both at $45 \mathrm{MWt}$ ), approximately 5.5 Ih were lost from the system. This behavior indicated that after hysteresis effects had run their course, the final PRD of 37.2 Ih compared well with the value of 38.0 Ih established at 1815 on November 29, just prior to the first scram. The effects of hysteresis in the power range from 10 to $15 \mathrm{MWt}$ and at $45 \mathrm{MWt}$ power are illustrated in Fig. 16 by indicating time values for the various data points.

Similar reactivity drifting effects were noted near the end of Run 26C. In this case, too, drifting was such that reactivity was inserted while power-coefficient data were being taken. A summary of pertinent information is given in Table IX and is illustrated graphically in Fig. 17. The extent of drifting during the measurements was so pronounced that upon reaching $25 \mathrm{MWt}$, the power coefficient averaged over the entire power range $(-0.47 \mathrm{Ih} / \mathrm{MWt})$ fell below the operating limits of $-0.50 \mathrm{Ih} / \mathrm{MWt}$. Accordingly, power was reduced to $50 \mathrm{kWt}$ and held at this level for 12 hours to study the effects of drifting. During this time, approximately 5.5 Ih of reactivity were lost. Upon completion of the critical measurements the reactor was shut down at 1000 on December 12, thereby terminating Run 26C

TABLE IX. Reactivity Balance from 1400 on $12 / 9 / 67$ to 1000 on $12 / 12 / 67$

\begin{tabular}{|c|c|c|c|c|c|c|c|}
\hline Time & Power (MWt) & $\begin{array}{l}\text { Reactivity Excess } \\
\text { (In) }\end{array}$ & $\begin{array}{l}\text { Power Reactivity } \\
\text { Decrement (Ih) }\end{array}$ & Time & Power (MWt) & $\begin{array}{l}\text { Reactivity Excess } \\
\text { (Ih) }\end{array}$ & $\begin{array}{l}\text { Power Reactivity } \\
\text { Decrement (Ih) }\end{array}$ \\
\hline $1400(12 / 9 / 67)$ & 45.0 & 63.1 & 35.9 & \multicolumn{4}{|c|}{ Reduced-flow Experiments and Shutdown; Three Scrams } \\
\hline 2200 & 45.0 & 63.0 & 36.0 & & & & \\
\hline $0200(12 / 10 / 67)$ & 45.0 & 64.3 & 34.9 & $2125(12 / 11 / 67)$ & 20.0 & 86.8 & 12.2 \\
\hline 0630 & 45.0 & 63.4 & 35.6 & 2220 & 22.5 & 87.0 & 12.0 \\
\hline 0858 & 45.0 & 63.4 & 35.6 & 2300 & 25.0 & 87.1 & 11.9 \\
\hline & & & & 2400 & 0.05 & 103.5 & -4.5 \\
\hline \multirow{2}{*}{\multicolumn{4}{|c|}{ Reduced-flow Experiments and Shutdown; Three Scrams }} & $0200(12 / 12 / 67)$ & 0.05 & 104.1 & -5.1 \\
\hline & & & & 0300 & 0.05 & 104.4 & -5.4 \\
\hline $0325(12 / 11 / 67)$ & 0.5 & 96.5 & 2.5 & 0400 & 0.05 & 104.4 & -5.4 \\
\hline 0730 & 0.5 & 97.4 & 1.6 & 0500 & 0.05 & 104.6 & -5.6 \\
\hline 1436 & 0.05 & 99.3 & -0.3 & 0600 & 0.05 & 104.6 & -5.6 \\
\hline 1520 & 0.05 & 99.3 & $=0.3$ & 0700 & 0.05 & 104.8 & -5.8 \\
\hline 1630 & 0.05 & 98.7 & 0.3 & 0800 & 0.05 & 104.6 & -5.6 \\
\hline 1902 & 10.0 & 83.5 & 15.5 & 0900 & 0.05 & 104.8 & -5.8 \\
\hline 2017 & 15.0 & 84.9 & 14.1 & 1000 & 0.05 & 104.5 & -5.5 \\
\hline
\end{tabular}




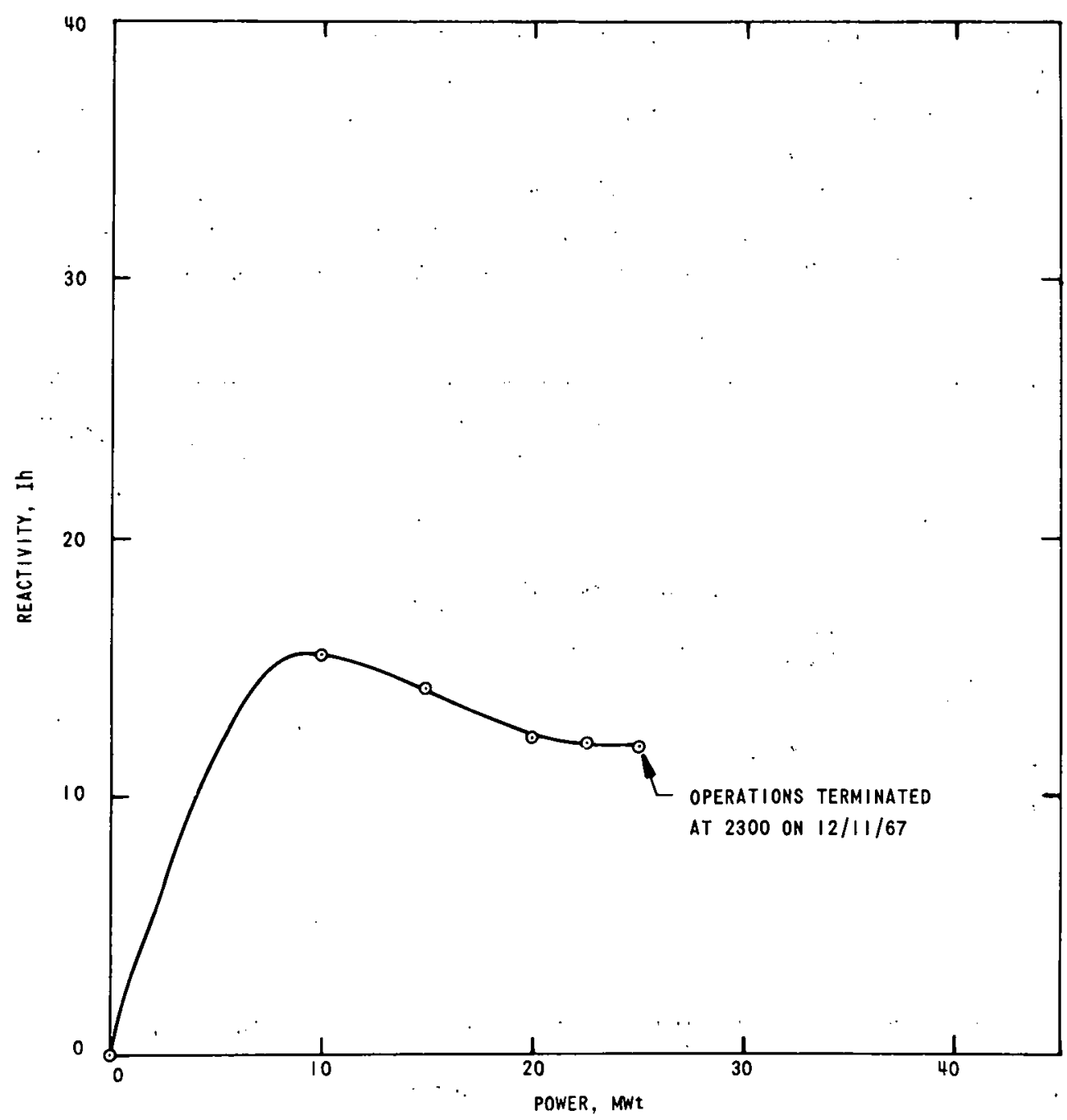

ID-103-K-5789 Rev. 1

Fig. 17. Run-26C Power-coefficient Data Taken on December 11, 1967 , Normalized to a Rod Bank of 11.00 in.

after $620 \mathrm{MWd}$ of operation. The origin and the significance of reactivity drifting are discussed in Section IX.C.

Although unrelated to the overall power-coefficient problem, another event of significance occurred during Run $26 \mathrm{C}$. On December 6 , the ${ }^{135} \mathrm{Xe}$ activity in the cover gas had reached an equilibrium value of approximately $1.0 \times 10^{-2} \mu \mathrm{C} / \mathrm{ml}$. The ${ }^{133} \mathrm{Xe}$ activity, however, was still increasing. At approximately 1800 on December 6 , both activities began an additional increase, with the ${ }^{135} \mathrm{Xe}$ activity tending to level off at a higher equilibrium level during the period from December 9 to 11 . At no time prior to, during, or after the indicated time of increase was any evidence noted of an increase in the signals from the FGM and FERD systems. Therefore, it was concluded that the release was very likely the result of a sodium-bond leak from either a driver element or experimental capsule. For such a failure, ${ }^{133} \mathrm{I}$ and ${ }^{135} \mathrm{I}$ would be chemically fixed in the bond and, upon their 
release to the primary sodium system, would ultimately lead to an increase in the concentration of the ${ }^{133} \mathrm{Xe}$ and ${ }^{135} \mathrm{Xe}$ daughters in the cover gas. The time-dependent behavior, illustrated graphically in Fig. 18, is completely consistent with this mechanism. No attempt was made to search for and locate the suspect during Run $26 \mathrm{C}$ since little burnup was left in the run and since there was a reasonable chance that if the suspect was a driver element it would be discharged in the normal course of refueling for Run 27.

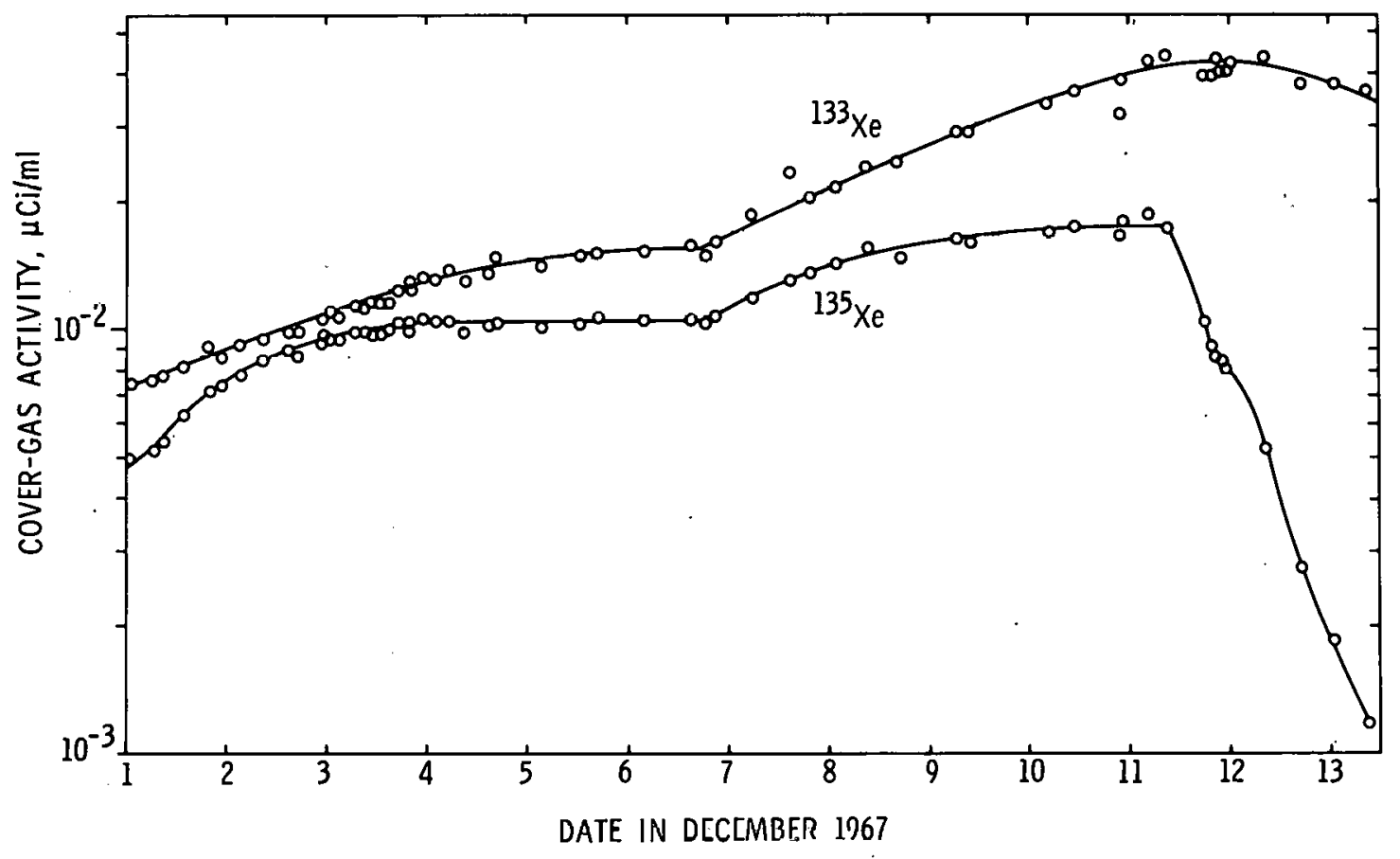

ID-103-J-5530 Rev. 2

Fig. 18. ${ }^{133} \mathrm{Xe}$ and ${ }^{135} \mathrm{Xe}$ Activities in Cover Gas, December 1-13, 1967 


\section{RUN 27}

At the end of Run 26, plans called for the refueling of the core followed by 45-MWt operation for $1250 \mathrm{MWd}$. During the early phases of startup for Run 27, plans also called for locating the origin of the indicated December-6 fission-product release. Later portions of the run were to be used for additional physics measurements. As it turned out, Run 27 was plagued with a wide variety of difficulties which considerably delayed the completion of additional physics tests.

Aside from the calibration of control rods on December 19, Run 26 was essentially completed on December 12. On December 21, refueling operations began.

\section{A. Damage to the No.-12 Control-rod Guide Thimble}

On December 23, after replacing ten spent driver subassemblies and relocating XOI 5 and XOl6, interference was noted at the 20 -in. elevation while inserting a new control rod in the No.-9 position (grid location 5Bl). The control rod was rotated $180^{\circ}$ and reinserted without difficulty. The next control-rod replacement proceeded normally. During the removal of controlrod L446 from the No.-12 position (5C3), interference was again encountered, this time at the 52- and 69-in. elevations. Despite the interference, the control rod was successfully removed and placed in the storage basket. Trouble with the core holddown mechanism at this time delayed unrestricted fuel-handling operatinns until the neccssary repdirs were completed on January 5. Meanwhile, control-rod L446, removed from the No.-12 position, was inspected in the Fuel Cycle Facility and was found to have extensive abrasion marks over an area $3 / 8$ in. by $14-1 / 2$ in. along the upper portion of one flat. The six subassemblies surrounding the $5 \mathrm{C} 3$ position were lifted and tested for binding. Of the six, subassemby C-2039, in position 5C 4 showed evidence of sticking. Upon removal and inspection, two deep scratches were found on the flat adjacent to position 5C3. Since damage to the No.-12 control-rod guide thimble was clearly indicated, the damaged thimble was removed and replaced. On inspection in the Fuel Cycle Facility, it was found that the top edge of one flat had been pushed out toward grid position $5 \mathrm{C} 4$, as shown in Fig. 19. The edge had been pushed down a maximum of $3 / 8$ in. over a width of 1 in. Details of the damage are illustrated in Fig. 20.

In reconstructing the sequence of events, it was concluded that the damage was caused by the hangup of subassemblies inserted in position 5 C4. Normal subassemblies have a slight overhang of the hexagonal tube beyond the bottom adapter. Contact between the projection and the neighboring flat of the 5C3 thimble during insertion in position 5C4 could lead to the type of damage noted. 


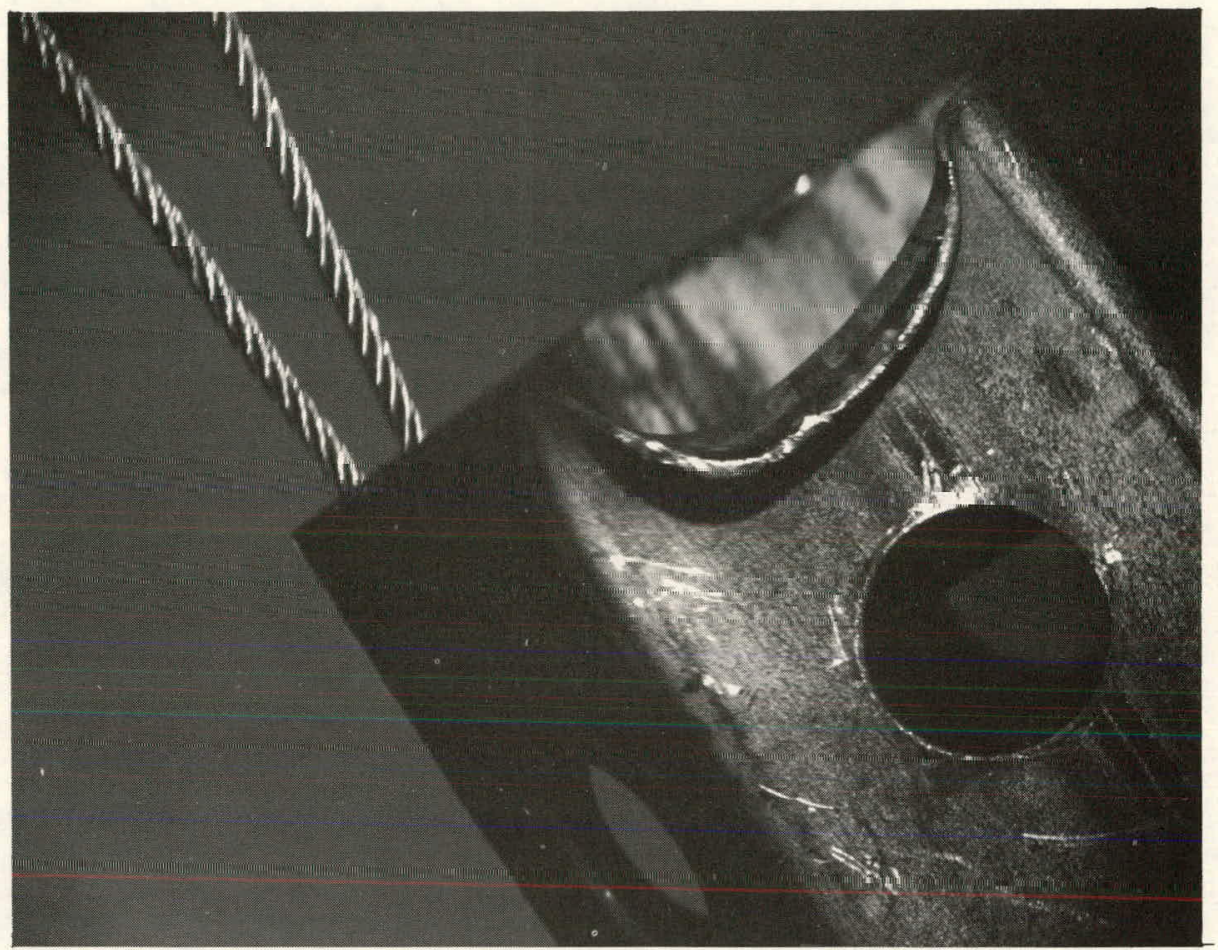

ID $-103-\mathrm{J}-5642$

Fig. 19. Damage at Top of No.-12 Control-rod Thimble

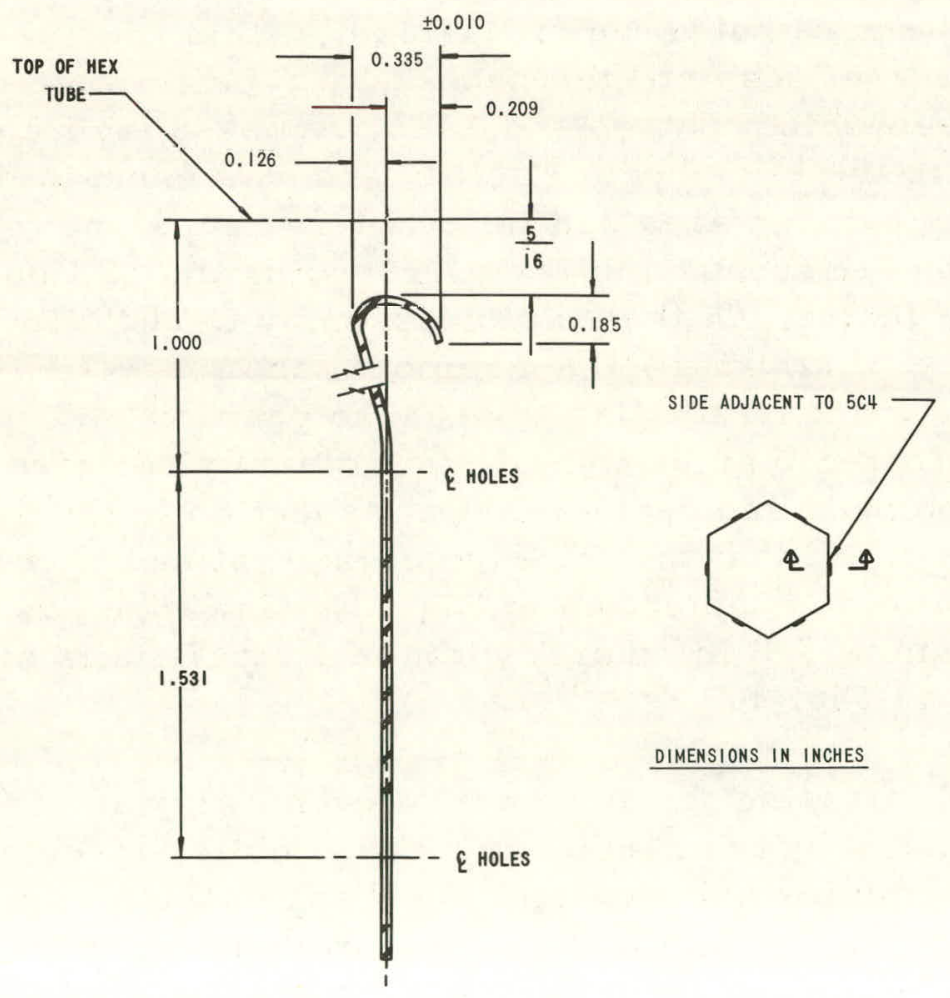

ID-103-J-5673 Rev. 1

Fig. 20. Dimensions of Deformation of No. -12 Control-rod Thimble 
A review of fuel-handling history indicated previous difficulties with insertions in position $5 \mathrm{C} 4$ that were consistent with the postulated mechanism. It was thought that the first recorded fuel-handling difficulty, on January 17, 1967, could have caused the outward deformation of the thimble flat. The second recorded difficulty, on September 20, 1967, could then have caused the flat to be pushed inward and the resulting outer edge downward to form the lip observed in Fig. 19. The removal of control-rod L446 on December 23, 1967 would very likely have pushed the inward bulge outward and the lip outward and upward.

During replacement of the damaged thimble, on January 18, 1968 , special scalloped subassemblies surrounding position $5 \mathrm{C} 3$ (used to permit replacement operations) were removed. While returning the plug through the auxiliary gripper hole, a small amount of water entrapped in a blind hole in the plug caused a minor explosion by contacting the hot sodium. Cleanup operations were completed on January 20.

B. Reactivity Anomaly of January 29, 1968

During the approach to criticality on January 29 , it became apparent after six control rods had been inserted that the excess available reactivity, as estimated by subcritical counting, would exceed the expected value by 150-200 Ih. In accordance with standard operating procedures, the system was shut down pending a resolution of the indicated discrepancy. Since this particular discrepancy. might have been related to the power-coefficient changes notcd during Ru1 26 and later during Kuns 27-29, a review, in some detail, of the information made available through a series of criticality measurements is instructive.

During the period between the end of Run 26C on December 11, 1967, and the startup of Run 27, a number of loading changes were made. These were primarily the replacement of 21 driver subassemblies, five control rods, and one safety rod with fresh fuel. Other transfer operations during this period, along with estimates of the respective reactivity worths, are summarized in Table $X$.

TABLE X. Transfer of Experiments between Runs $26 \mathrm{C}$ and $27 \mathrm{~A}$ (period of $12 / 11 / 67$ to $1 / 29 / 68$ )

\begin{tabular}{|c|c|c|c|c|c|}
\hline . & Out & & & In & \\
\hline Subassembly & Position & $\begin{array}{l}\text { Reactivity } \\
\text { Worth }^{\text {a }} \text { (Ih) }\end{array}$ & Subassembly & Position & $\begin{array}{l}\text { Reactivity } \\
\text { Worth (Ih) }\end{array}$ \\
\hline XA08 & $4 F^{2}$ & 185 & $\mathrm{C}-2007^{\mathrm{b}}$ & $4 \mathrm{~F} 2$ & 240 \\
\hline $\mathrm{XG05}$ & $4 \mathrm{C} 2$ & 207 & $\mathrm{XO} 29$ & $4 \mathrm{E} 3$ & 253 \\
\hline Driver & $5 \mathrm{E} 2$ & 335 & $\mathrm{XO} 33$ & $5 \mathrm{E2}$ & 284 \\
\hline \multirow[t]{2}{*}{ Driver } & $4 \mathrm{Bl}$ & $\frac{335}{1062}$ & $C-2138^{\circ}$ & $4 \mathrm{Bl}$ & $\frac{355}{1132}$ \\
\hline & & Difference: & $1132-1062=70 \mathrm{Ih}$ & & \\
\hline
\end{tabular}

\footnotetext{
${ }^{a}$ Values established from MACH-1, one-dimensional perturbation code. Reference to a hypothetical void.

$\mathrm{b}_{\text {Half-fueled driver. }}$

cStandard driver, but with a central 19 -element cluster of $70 \%$-enriched fucl.
} 
Prior to startup, an estimate of $k_{\text {ex }}$ was made. This involved evaluations of the following: (1) the $k_{\text {ex }}$ remaining at the end of Run $26 \mathrm{C}$, (2) the increase in reactivity resulting from the replacement of spent fuel with fresh, (3) the decrease in reactivity resulting from ${ }^{239} \mathrm{Pu}$ dilution (recycled fuel is lower in ${ }^{239} \mathrm{Pu}$ content than discharged fuel), and (4) the reactivity change expected from the relocation operations summarized in Table X. A summary of the calculated reactivity changes is given in Table XI.

TABLE XI. Calculated $\mathrm{k}_{\mathrm{ex}}$ for Run $27 \mathrm{~A}$

\begin{tabular}{|c|c|c|}
\hline \multicolumn{2}{|l|}{ Item } & Ih \\
\hline \multicolumn{2}{|c|}{$\begin{array}{l}\text { Reactivity remaining after Run- } 26 C \text { shutdown } \\
\text { Replacement of spent with fresh fuel } \\
\text { Plutonium dilution } b \\
\text { Relocation operations (see Table } X \text { ) }\end{array}$} & $\begin{array}{r}95 \\
153 \\
-14 \\
70\end{array}$ \\
\hline \multicolumn{2}{|l|}{ 'l'otal } & $\overline{304}$ \\
\hline \multicolumn{2}{|c|}{ Measured from subcritical counting } & 450 \\
\hline \multicolumn{2}{|l|}{ Discrepancy } & 146 \\
\hline \multicolumn{3}{|c|}{$\begin{array}{l}\text { a Measured at the end of Run } 26 \mathrm{C} \text {. } \\
\mathrm{b}_{\text {Estimated from fuel content of discharged and fresh fuel. }}\end{array}$} \\
\hline Item & $\begin{array}{l}\text { Original } \\
\text { Estimate (Ih) }\end{array}$ & $\begin{array}{c}\text { Deduced from } \\
\text { Criticality } \\
\text { Measurements (Ih) }\end{array}$ \\
\hline Reactivity at end of Run $26 \mathrm{C}$ & 95 & 95 \\
\hline \multicolumn{3}{|l|}{ Replacement of spent fuel minus } \\
\hline $\begin{array}{l}\text { Experimental-subassembly changes } \\
\text { Worth of C-2138 (driver with } 19\end{array}$ & Worth of C-2138 (driver with 19 & 67 \\
\hline $70 \%$-enriched elements) & 20 & 29 \\
\hline Relocation of XO15 and XOl6 & - & 13 \\
\hline Total & 304 & 394 \\
\hline
\end{tabular}

Reactivity at end of Run 26C

Replacement of spent fuel minus plutonium dilution

Experimental-subassembly changes

Worth of C-2138 (driver with 19 $70 \%$-enriched elements)

Relocation of XO15 and XOl6 Total

dicted and measured values for $\mathrm{k}_{\text {ex }}$, criticality measurements were carried change to a simple series of relocations or substitutions, the associated reactivity for each loading change made prior to Run 27 was evaluated. In all, seven criticality measurements were made. The results are summarized in Table XII. 
Thus, of the 450 Ih of excess reactivity associated with the January-29 Run-27 startup, 394 Ih were eventually accounted for. The remaining 56 Ih were tentatively attributed to core-rearrangement effects that followed the removal and replacement of the damaged control-rod guide thimble.

\section{Run-27A Startup}

On completion of the criticality measurements described above, the core was essentially in the same condition as existed during the original January-29 Run-27 startup. Criticality was achieved on February 5, and power was increased in 5-MWt increments to $45 \mathrm{MWt}$ on February 6 . A summary of power-coefficient data taken for ascending and descending power modes is given in Fig. 21. From a comparison of the data with those taken during the initial Run-26 startup (shown in Figs. 12 and 13), it may be seen that, although the 0-45-MWt PRD's are essentially the same, a definite tendency toward weakening of the power coefficient is indicated

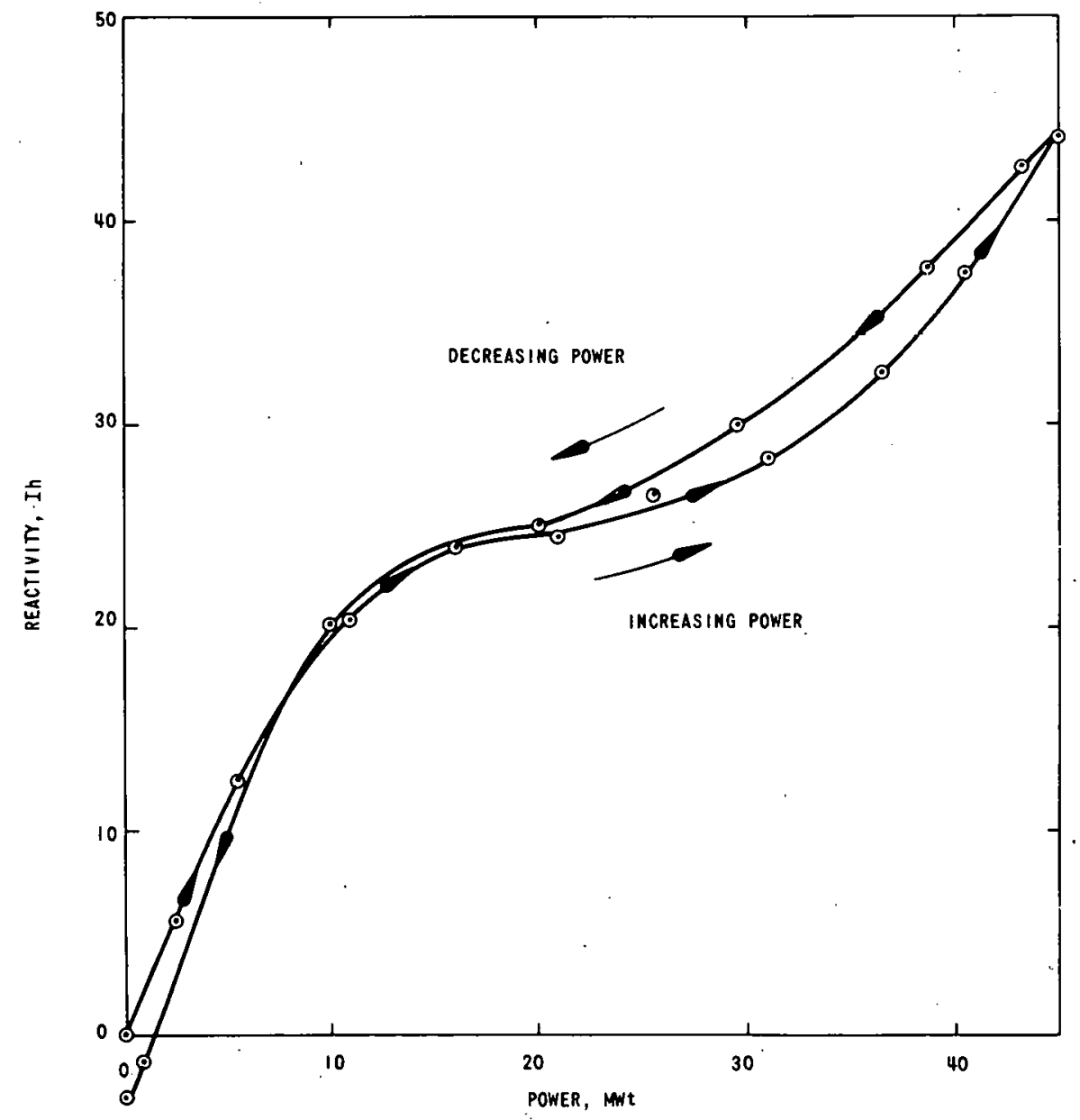

ID-103-K-5790 Rev. 1

Fig. 21. Run-27A Power-coefficient Data Taken on February 5, 1968, Normalized to a Rod Bank of 11.00 in. 
in the midpower region in Fig. 21. Also in evidence is a change in the reactivity balance of the system while the data were being taken, with the sense of the change such that 3.5 Ih of reactivity were inserted. The indicated flattening of the power-coefficient curve in the midpower region, coupled with the fact that reactivity was inserted during the measurements, suggests that reactivity drifting, such as that observed during the later portions of Run 26, was still present.

Measurements of the PRD in the range from 0 to $45 \mathrm{MWt}$ were repeated on February 8, 23, and 28. Figure 22 summarizes the data from these measurements. From a comparison of these data with those taken on February 5, a trend toward higher power-coefficient values is evident. The significance of this trend is discussed under Section IX.C.

Between February 5 and February 9, rod-drop, reduced-flow, and noise measurements were conducted. On their completion, the power level was increased back to $45 \mathrm{MWt}$. On February 9, a scram from $45 \mathrm{MWt}$

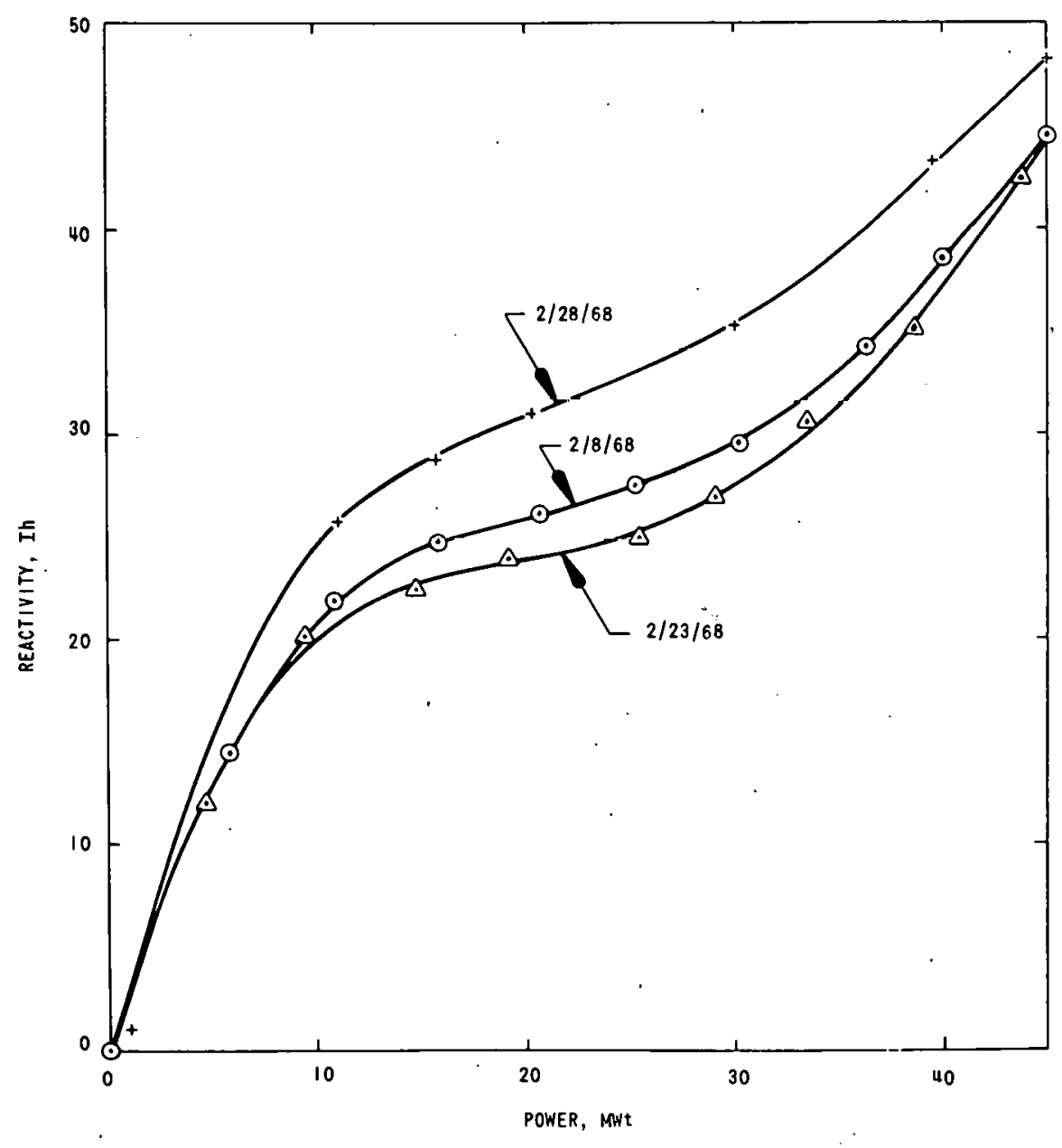

ID-103-K-5791 Rev. 1

Fig. 22. Run-27A Power-coefficient Data Taken on February 8, 23, and 28, 1967, Normalized to a Rod Bank of 11.00 in. 
occurred. Then, while the system was still shut down, a sodium fire occurred in the west wing of the sodium boiler plant when a freeze plug in a breached line gave way and released approximately 50 gallons of molten sodium. Cleanup operations began the following day, and in approximately two weeks the system was ready for operation.

Between February 24 and February 28, additional physics tests were conducted, consisting essentially of power-coefficient measurements. The results of these measurements are included in Fig. 22.

D. Fission-product Release of March 5, 1968

Run 27A was terminated on February 28 after a total power accumulation of $283 \mathrm{MWd}$. During the run there was no evidence of a leaker. Accordingly, it was tentatively concluded that the subassembly responsible for the December-6 fission-product release had been removed during fuelhandling operations prior to Run 27. Whether the suspect was a driver subassembly discharged at the end of Run 26, XA08, or XG05 (both of the last in the storage basket during Run 27A) was not known. To narrow the search, XG05 was reinstalled in grid-position 4C.2. Other. fuel-handling operations at this time included the installation of three prototype reorificed driver subassemblies in Rows 4, 5, and 6. Fuel-handling operations were completed on February 29.

On March l, the system was brought incrementally to a power level uf $45 \mathrm{MWL}$ with a measured PRD of $43.1 \mathrm{~h}$. E's sentially no change was noted in the nature of the power coefficient in the midpower region. Operations under 45-MWt conditions continued until March 5, when a reduced-flow test was begun. Critical measurements were made at $41.5 \mathrm{MW}$.t and $100 \%$ flow. On completion of the 41.5-MWt measurements, the power was reduced to $22.5 \mathrm{MWt}$, and in the course of reducing the flow rate to $54 \%$, a scram occurred. The system was restarted and the power leveled at $45 \mathrm{MWt}$ to complete the interrupted reduced-flow studies. When a routine cover-gas sample taken at 1545 indicated increases in the activity levels for ${ }^{133} \mathrm{Xe}$ and ${ }^{135} \mathrm{Xe}$, the completion of the reduced-flow tests was postponed. To provide additional gas-activity data, operations were continued under 45-MWt conditions until 2001. At that time, the system was shut down, thereby terminating Run $27 \mathrm{~B}$ after $177 \mathrm{MWd}$ of operation (total so far in Run 27, $460 \mathrm{MWd}$ ).

E. Search for the Origin of the March 5, 1968 Fission-product Release

Fuel-handling operations for Run $27 \mathrm{C}$ included the removal of XG05, $\mathrm{XO} 30$, and four driver subassemblies, and the installation of XA08, A-788, and four driver subassemblies. The system was brought to $45 \mathrm{MWt}$ on March 8, and in the following three days, a comprehensive series of physics tests was conducted. On March 11 , evidence of a small fission-product 
release was again indicated from the results of analyses conducted on cover gas samples. Accordingly, the system was shut down at 1900 , thereby completing Run $27 \mathrm{C}$ after $62.5 \mathrm{MWd}$ of operation (total so far in Run 27, $523 \mathrm{MWd})$.

During the following three weeks the reactor remained in the shutdown condition while repairs and modifications were made in primary-pump control circuitry. Also completed during this period were fuel-handling operations, which included the removal of XA08, A-812, and two driver subassemblies and the installation of X900 and three driver subassemblies. Later in this period, ten subassemblies containing fuel elements made with seamless-tube cladding were removed and replaced because it was thought that microcracks in the cladding might have been responsible for the March-5 and March-11 fission-product releases.

Criticality was achieved on March 30, and power was increased incrementally to $45 \mathrm{MWt}$ on March 31 . Figure 23 summarizes the powercoefficient data taken during the ascent. Operations continued at $45 \mathrm{MWt}$

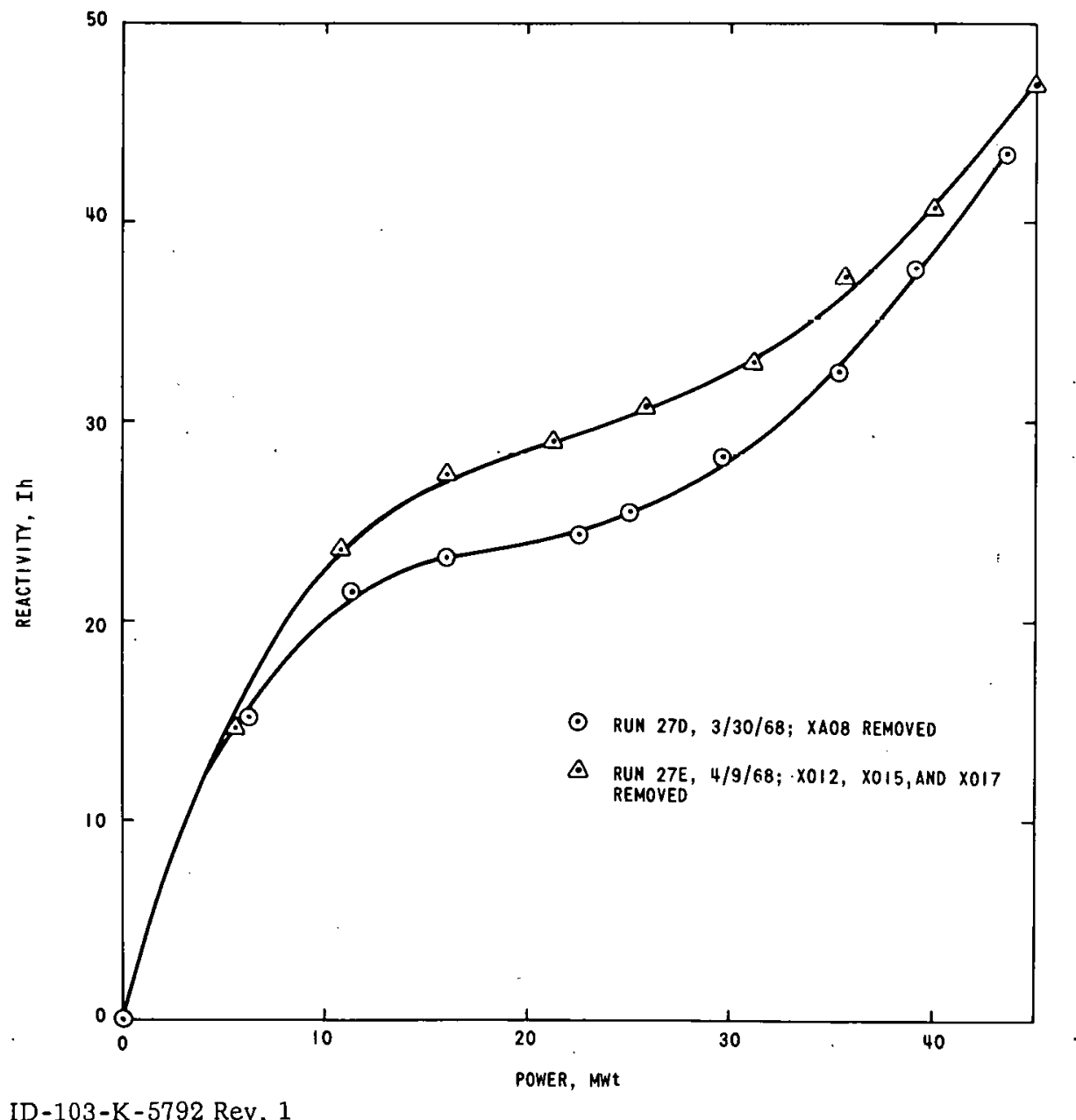

ID-103-K-5792 Rev. 1

Fig. 23. Power-coefficient Data for Runs 27D and 27E, Normalized to a Rod Bank of 11.00 in. 
until 0356 on April 6, when the system was shut down after it became apparent that another fission-product release had occurred. In this case the following signal/noise ratios were noted: for ${ }^{133} \mathrm{XE}, 25$; for ${ }^{135} \mathrm{Xe}, 44$; and for the FGM, 53. No increase in any of the FERD channels was noted. The shutdown completed Run $27 \mathrm{D}$ after $286 \mathrm{MWd}$ of operation (total so far in Run 27, $809 \mathrm{MWd}$ ).

Concluding from the magnitude of the release that an experimental subassembly must be involved, the following experiments were removed: $\mathrm{XOl} 2, \mathrm{XO} 15$, and $\mathrm{XO} 17$. Also removed at this time was C-2138, a subassembly containing $1970 \%$-enriched fuel elements, and B-372, a Row- 6 driver.

Run 27E began on April 7. Figure 23 summarizes the powercoefficient data taken during the run startup. Operations continued without incident until a scram at 1916 on April 11 . An attempt at this time to initiate a fission-product gas release by decreasing the coolant flow was successful. Accordingly, it was concluded that the leaker was still in the core at the beginning of Run 27E. Run $27 \mathrm{E}$ was terminated at this time after $90 \mathrm{MWd}$ of operation (total so far in Run 27,899 MWd).

The next step consisted of the removal of all experimental subassemblies containing ceramic fuels with burnups greater than $0.6 \mathrm{a} / 0$. These included XO19, XO20, XO27, and XO32. Run 27F was started on April 13, and operating power was reached on April 14. Operations continued without incident until 0142 on April 16, when a scram occurred. Again, attempts were made to reinitiate gas release by reducing the coolant flow. From the analyses of cover-gas samples taken before and after flow reduction, it was concluded that another small release had occurred. Accordingly, Run $27 \mathrm{~F}$ was terminated after $68 \mathrm{MWd}$ of operation (total in Run 27, $967 \mathrm{MWd).}$

Fuel-handling operations completed at the end of Run $27 \mathrm{~F}$ involved the removal of all remaining experimental subassemblies containing ceramic fuel: XG02, XG03, XG04, XO10, XO31, and XO33. Only two fueled experiments (XO28 and XO29) remained in the core, the former containing. U-Pu-Zr ternary alloy fuel and the latter encapsulated Mark-II $\mathrm{U}-5 \mathrm{Fz}$ fuel elements.

The system was brought to criticality at 1946 on April 17 and to power on April 18. Operations continued until 1224 on April 19, when the reactor was shut down after it became apparent that another small fissionproduct release had occurred. Run $27 \mathrm{G}$ was terminated after $49 \mathrm{MWd}$ of operation (total so far in Run 27, $1016 \mathrm{MWd}$ ). Attempts to initiate an additional release by decreasing coolant flow were unsuccessful. In restarting the primary pumps, however, a relatively large increase occurred, causing an approximate 30-fold increase in the FGM signal. 
In subsequent fuel-handling operations, it was noted that, when XO28 was lifted approximately $10 \mathrm{ft}$, cover-gas activities increased $10-20 \%$. Therefore, XO28 was transferred to the storage basket.

Run 27H was started on April 26: Operations continued without incident, and the system was shut down on May 2 after competing $206 \mathrm{MWd}$ of operation without any indication of an additional fission-product release (total so far in Run 27, $1222 \mathrm{MWd}$ ).

Run 27I was characterized by the reinsertion of XO28. The system was brought to power on May 4 and operated until 0539 on May 6, when a. large release was annunciated by the FGM. The system was shut down, thereby concluding Run 27 after a total power accumulation of $1317 \mathrm{MWd}$. From the results of Runs 27G (with XO28 in), $27 \mathrm{H}$ (XO28 out), and 27I (XO28 in), it was concluded that XO28 was the subassembly responsible for the many fission-product releases noted during Run 27.

During the many startups between Runs 27D and 27I, several sets of power-coefficient data were obtained. Despite the large variation in the complement of experiments during this period, the PRD remained essentially unchanged. As an illustration, power-coefficient data taken at the beginnings of Runs $27 \mathrm{~F}$ throught $27 \mathrm{I}$ are given in Fig. 24.

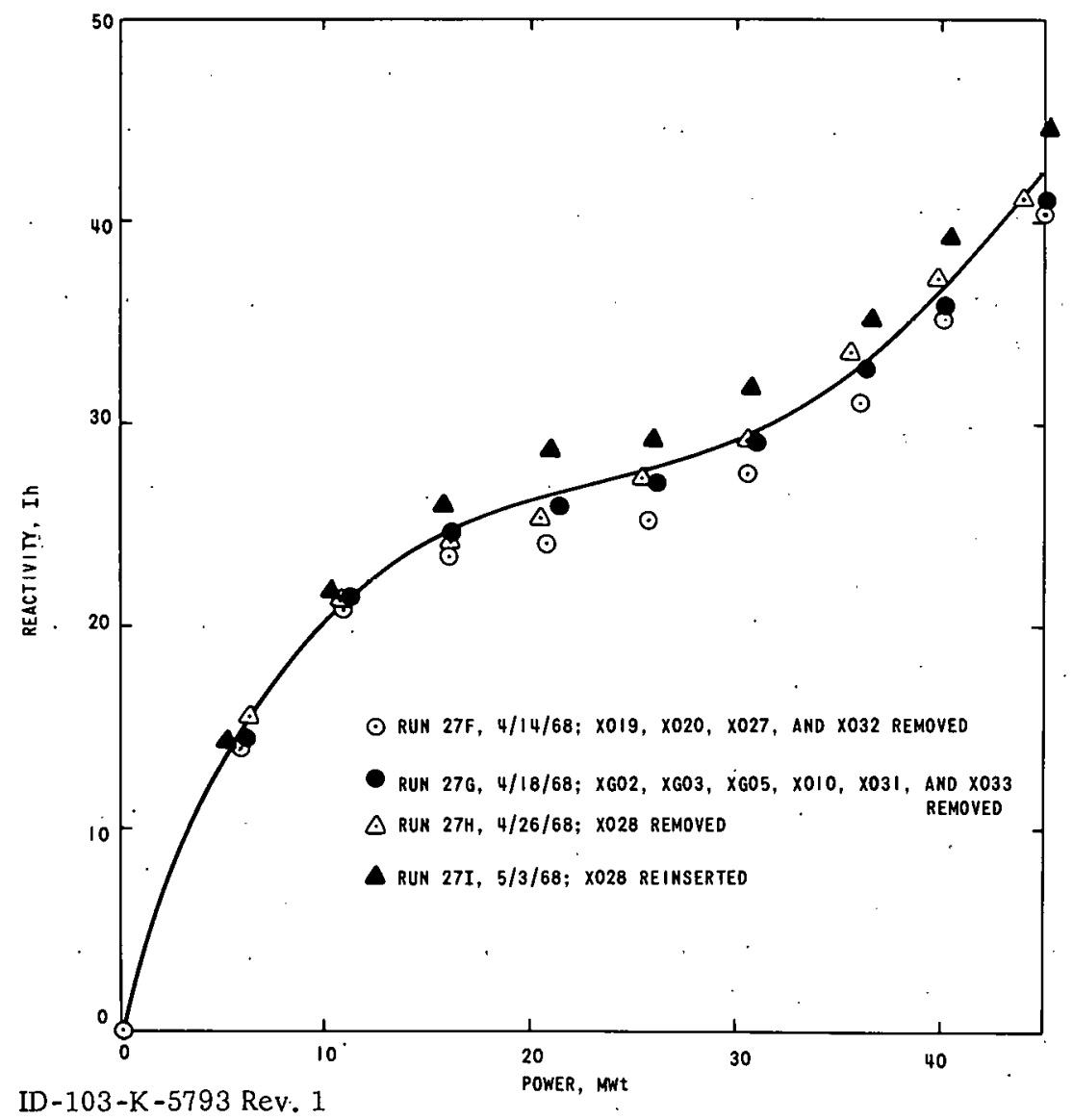

Fig. 24. Power-coefficient Data for Runs 27F through 27I, Normalized to a Rod Bank of 11.00 in. 
VI. RUN 28

\section{A. $\operatorname{Run} 28 \mathrm{~A}$}

The removal of all irradiation subassemblies containing ceramic fuels at the end of Run 27 provided an excellent opportunity to evaluate theeffects of core composition on the power coefficient. Accordingly, a comprehensive series of physics tests was conducted during Run $28 \mathrm{~A}$ on the reference core configuration illustrated in Fig. 25. Included in the Run-28A test series were power-coefficient measurements, rod-drop studies under various conditions of power and flow, reduced-flow tests, and studies of long-term power oscillations.

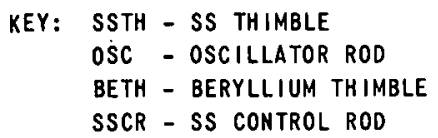

C - CONTROL ROD

S - SAFETY ROD

D - DRIVER FUEL

$P$ - $\frac{1}{2}$ DRIVER FUEL, $\frac{1}{2}$ SS

$B$ - DEPLETED URANIUM

$R$ - SS REFLECTOR

$X$ - EXPERIMENTAL SUBASSEMBLY

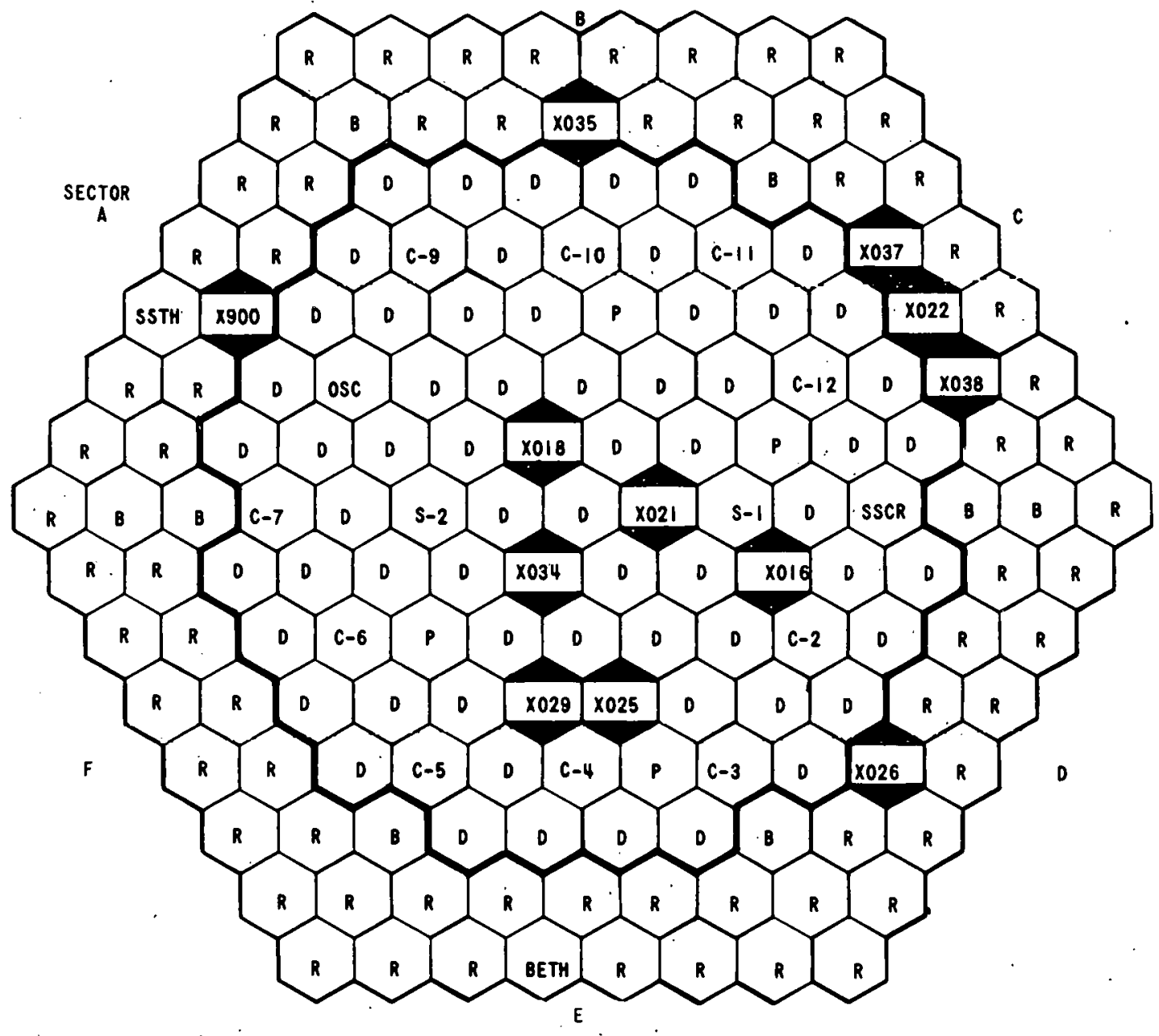

ID-103-K-5794 Rev. 1

Fig. 25. EBR-II Loading Pattern for Run $28 \mathrm{~A}$ 
Summaries of power-coefficient data taken during the Run-28A startup and four days later in Run $28 \mathrm{~A}$ are given in Fig. 26. From a comparison of the data given in Fig. 26 with those taken during the Run-27 startup (shown in Figs. 21 and 22), it seems clear that (1) the overall 0-45-MWt $P R D$ increased, and (2) the power coefficient in the midpower region strengthened. When comparing the data, it must be realized that (I) a "crack" possibly left between subassemblies after removing the bent control-rod thimble before the Run-27 startup might have been still present during Run 28A, and (2) all ceramic-fueled subassemblies were removed before Run 28A. The significance of the indicated strengthening of the power coefficient is discussed in Section IX.C. Run 28A was concluded on May 13 after accumulating $154 \mathrm{MWd}$ of operation.

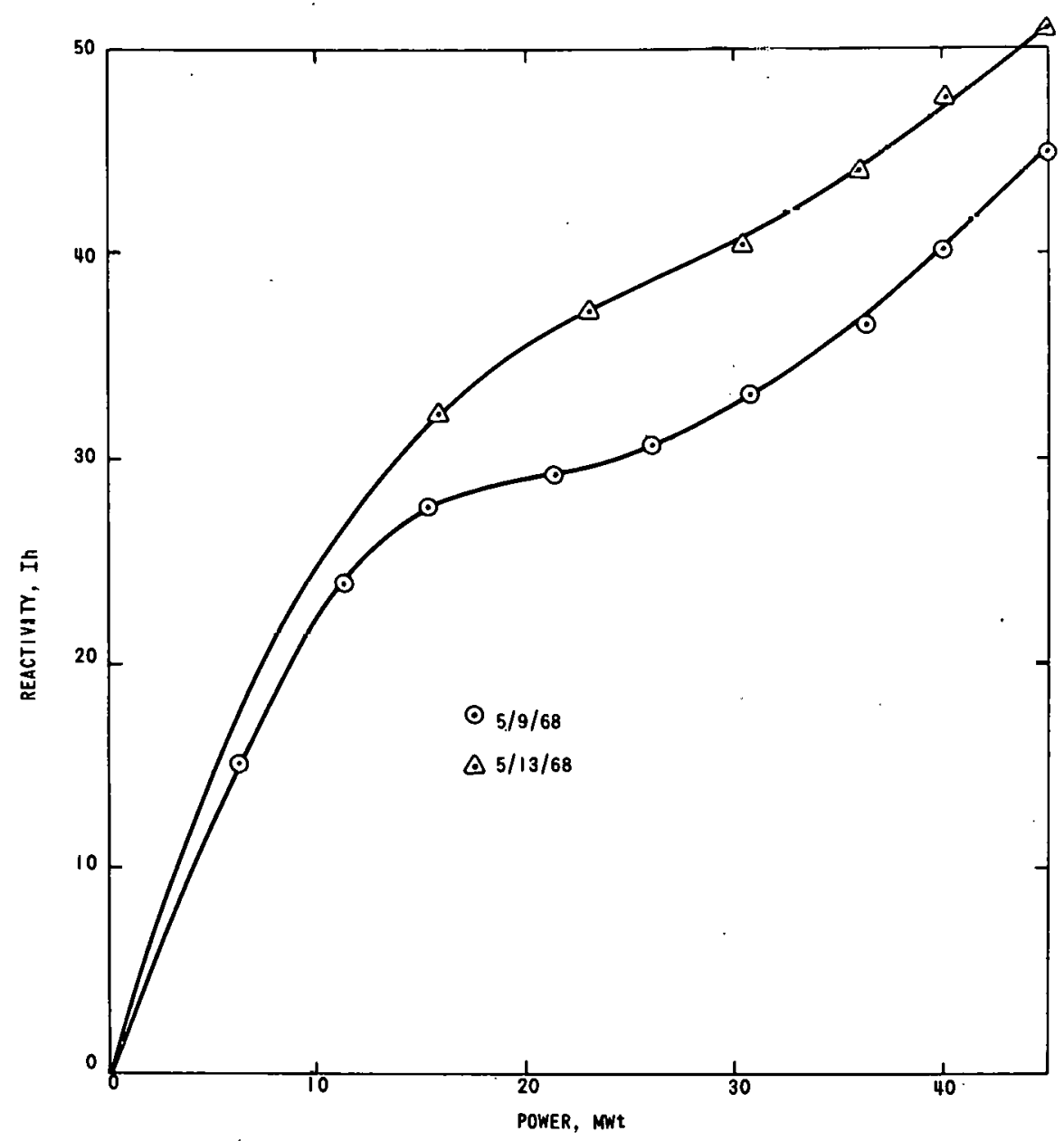

ID-103-K -5795 Rev. 1

Fig. 26. Run-28A Power-coefficient Data, Normalized to a Rod Bank of 11.00 in.

B. Run 28B

Prior to the startup of Run $28 \mathrm{~B}$, the loading changes shown in Table XIII were made. 
TABLE XIII. Loading. Changes prior to Run-28B Startup

\begin{tabular}{|c|c|c|c|}
\hline Grid Position & In & & Out \\
\hline $4 \mathrm{Bl}$ & $70 \%$ enriched & & Driver \\
\hline $7 \mathrm{Bl}$ & $\mathrm{XGO}_{4}$ & Deple & eted blanket \\
\hline $6 \mathrm{~B} 5$ & $\mathrm{XO} 20$ & & Driver \\
\hline $6 \mathrm{Cl}$ & $\mathrm{XO} 31$ & Deple & eted blanket \\
\hline $7 \mathrm{Dl}$ & $\mathrm{XG03}$ & Deple & eted blanket \\
\hline $6 \mathrm{D} 2$ & xol9 & & Driver. \\
\hline $6 \mathrm{Fl}$ & $\mathrm{XO} 32$ & Deple & éted blanket \\
\hline $4 \mathrm{Fl}$ & $70 \%$ enriched & & Driver \\
\hline $7 \mathrm{~F} 3$ & XOl 0 & Stainless & steel reflector \\
\hline $7 \mathrm{Al}$ & $\mathrm{XG02}$ & Stainless & steel reflector \\
\hline $3 \mathrm{Bl}$ & Driver surveillance & Driver & surveillance \\
\hline
\end{tabular}

The changes reflect attempts to (1) reinstall irradiation experiments in outer rows first, and (2) keep the core outline unchanged. Criticality was achieved on May 15 and the reactor was brought to an operating power level of $45 \mathrm{MWt}$ on May 17. Summaries of power-coefficient data for the Run-28B startup and for later measurements in Run 28 B are given in.Fig. 27. Although

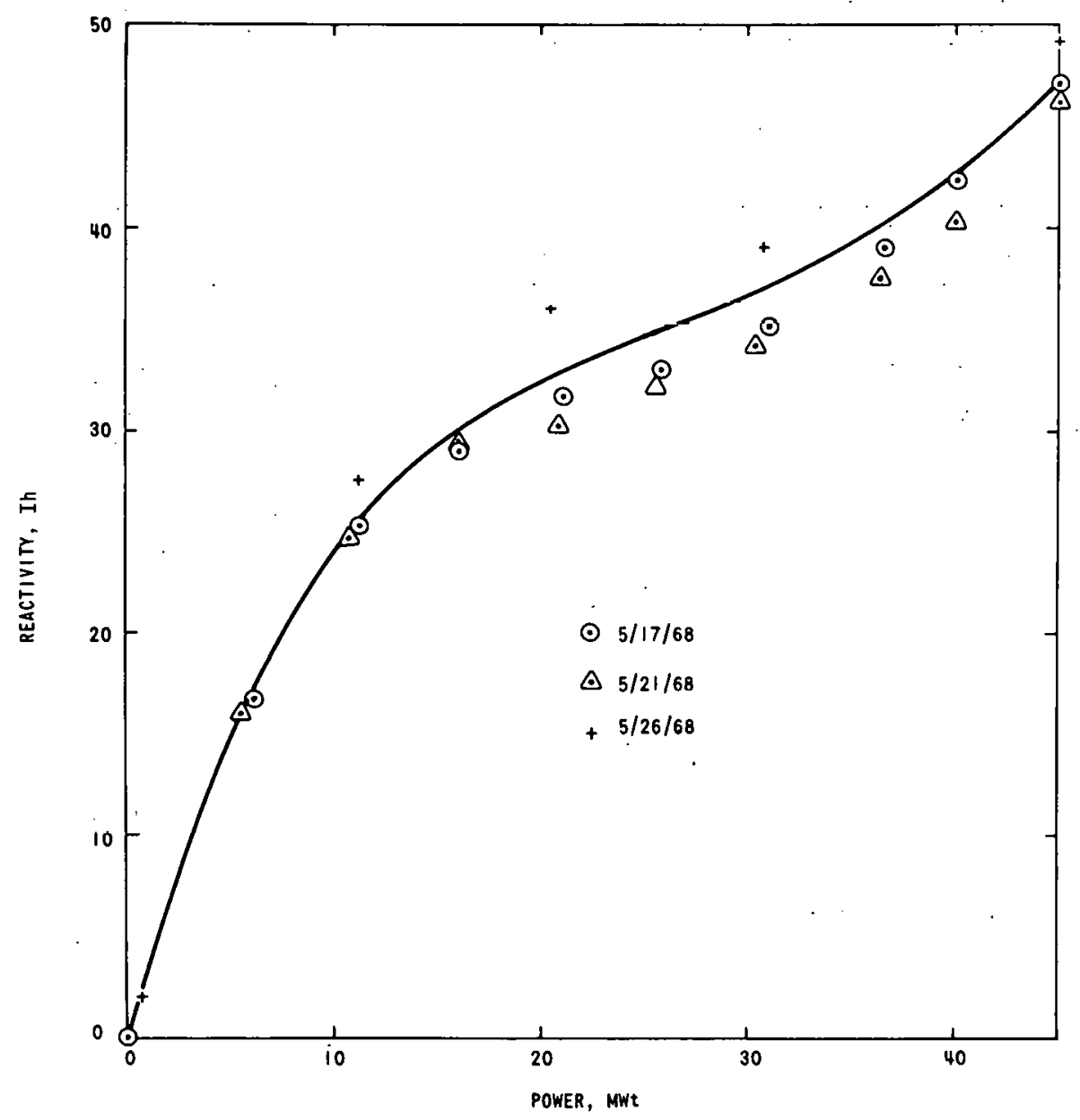

ID-103-K-5796 Rev. 1

Fig. 27. Run-28B Power-coefficient Data, Normalized

to a Rod Bank of 11.00 in. 
considerable dispersion exists for the various data, it is nevertheless clear that the power coefficient not only remained relatively strong throughout Run $28 \mathrm{~B}$ but actually tended to strengthen. Run $28 \mathrm{~B}$ was terminated on May 26 after a total power accumulation of $303 \mathrm{MWd}$ (total so far in Run 28, $457 \mathrm{MWd}$ )。

C. $\operatorname{Run} 28 \mathrm{C}$

Fuel-handling operations at the end of Run $28 \mathrm{~B}$ involved the reinsertion of the remaining irradiation subassemblies. A summary of the transfer operations and a pictorial illustration of the Run-28C reference loading are given in Table XIV and Fig. 28, respectively.

Criticality was achieved. on May 29, and the system was brought to operational power on May 30. Summaries of power-coefficient data for the startup and for another measurement two weeks later are given in Fig. 29. As with previous Run-28 data, a trend toward strengthening of the power coefficient may be seen. Run $28 \mathrm{C}$ was terminated on May 15 after a total power accumulation of $670 \mathrm{MWd}$ (total in Run 28,1127 MWd).

TABLE XIV. Loading Changes prior to Run-28C Startup

\begin{tabular}{ccc}
\hline Location & In & Out \\
\hline $4 \mathrm{~A} 2$ & $\mathrm{XO15}$ & Half-fueled driver \\
$4 \mathrm{R} 2$ & $\mathrm{XO12}$ & Half-fueled driver \\
$4 \mathrm{~B} 3$ & $\mathrm{XO27}$ & Half-fueled driver \\
$4 \mathrm{C} 3$ & $\mathrm{XO17}$ & Half-fueled driver \\
$5 \mathrm{E} 2$ & $\mathrm{XO} 33$ & Half-fueled driver \\
$4 \mathrm{~F} 2$ & $\mathrm{XA08}$ & Half-fueled driver \\
\hline
\end{tabular}




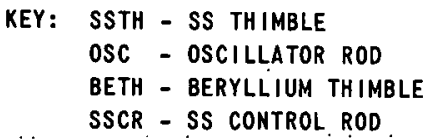

C - CONTROL ROD

S - SAFETY ROD

D - DRIVER FUEL

B - DEPLETED URANIUM

$R$ - SS REFLECTOR

$X$ - EXPERIMENTAL SUBASSEMBLY

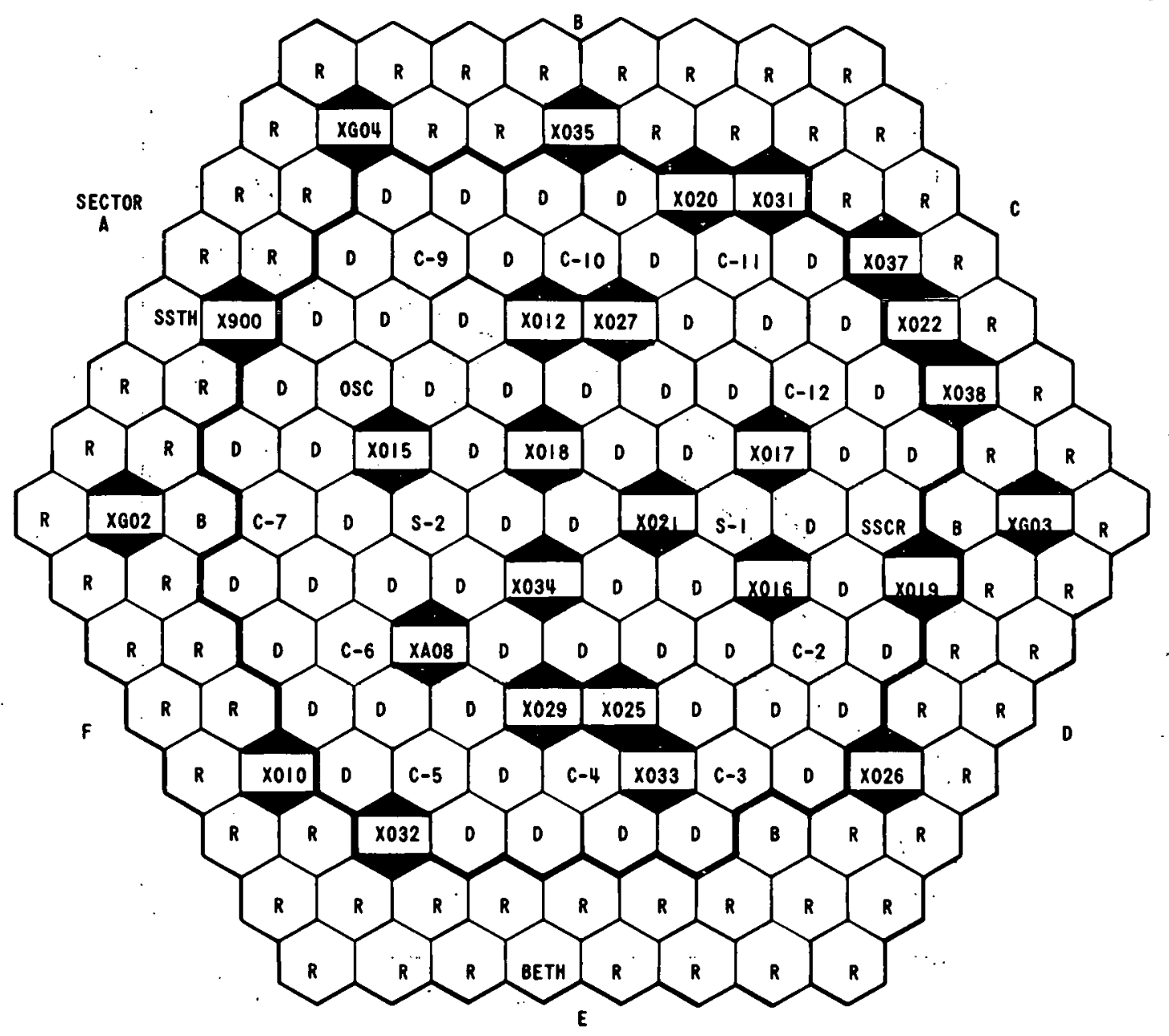

ID -103-K-5797 Rev. 1

Fig. 28. EBR-II Loading Pattern for Run 28C 


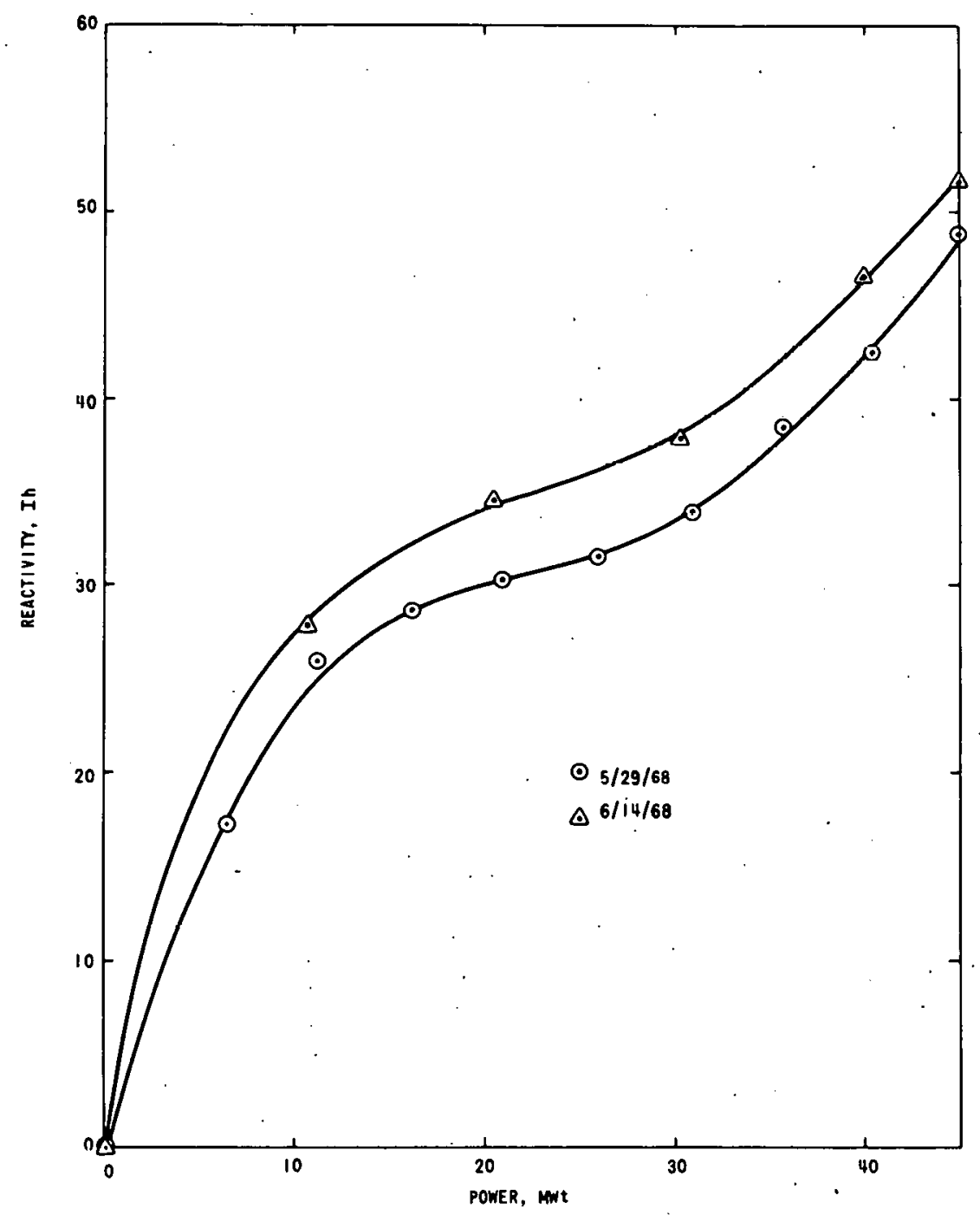

ID-103-K-5798 Rev. 1

Fig. 29. Run-28C Power-coefficient Data, Normalized to a Rod Bank of 11.00 in. 
VII. RUN 29

Although plans had been made to replace the stainless steel reflector as early as December 1967, the inability to fabricate Row-7 depleteduranium blanket subassemblies for use in Run 27 and the failure of subassembly XO28 in Run 28 resulted in a postponement of the replacement to Run 29. To provide as much information as possible on the worth of the stainless steel reflector subassemblies relative to depleted uranium and on the effects of individual rows of stainless steel subassemblies on the power coefficient, it was decided to divide Run 29 into four portions. These were: Run 29A, a reference configuration in which all irradiation subassemblies in Row 7, except those in corner locations, were replaced with stainless steel subassemblies; Run 29B, in which all stainless steel units in Row 7 were replaced with depleted-uranium blanket subassemblies; Run 29C, in which all stainless steel units in Row 8 were 'replaced with depleted uranium; and Run 29D, in which all irradiation experiments in Row 7 that had been removed before the Run-29A startup were reinserted.

For each of Runs 29A through 29C, extensive physics tests were conducted, including power-coefficient measurements in both ascending and descending modes, rod-drop tests, trapezoidal reactivity-insertion studies, reduced-flow (constant- $\Delta \mathrm{T}$ ) experiments, and low-frequency oscillation studies under various conditions of power and flow.

A. $\operatorname{Run} 29 \mathrm{~A}$

Criticality was achieved on June 26, and the system was brought to operating power in 5-MWt increments on June 29. A summary of powercoefficient data taken during the initial startup, in both ascending and descending modes, is given in Fig. 30. After the completion of physics experiments the reactor was shut down on July 5, thereby completing Run $29 \mathrm{~A}$ after a total power accumulation of $188 \mathrm{MWd}$.

B. $\underline{\operatorname{Run} 29 B}$

Fuel handling for Run 29B consisted essentially of replacing the stainless steel reflector in Row 7 with newly fabricated depleted-uranium subassemblies. Startup began on July 9, and a power level of $45 \mathrm{MWt}$ was reached on July 10. A summary of power-coefficient data for the complete 0-45-0-MWt cycle is given in Fig. 31. From a comparison of the data with those illustrated for Run 29A in Fig. 30, it is clear that the replacement of stainless steel in Row 7 was reflected by an increase in the total PRD from 51.4 to $57.0 \mathrm{Ih}$ and a slight decrease in the degree of hysteresis. Physics tests conducted during Run $29 \mathrm{~B}$ consisted primarily of reduced-flow measurements. Following the completion of these tests, the system was shut down on July 11 after accumulating only $24 \mathrm{MWd}$ (total so far in Run 29, $212 \mathrm{MWd}$ ). 


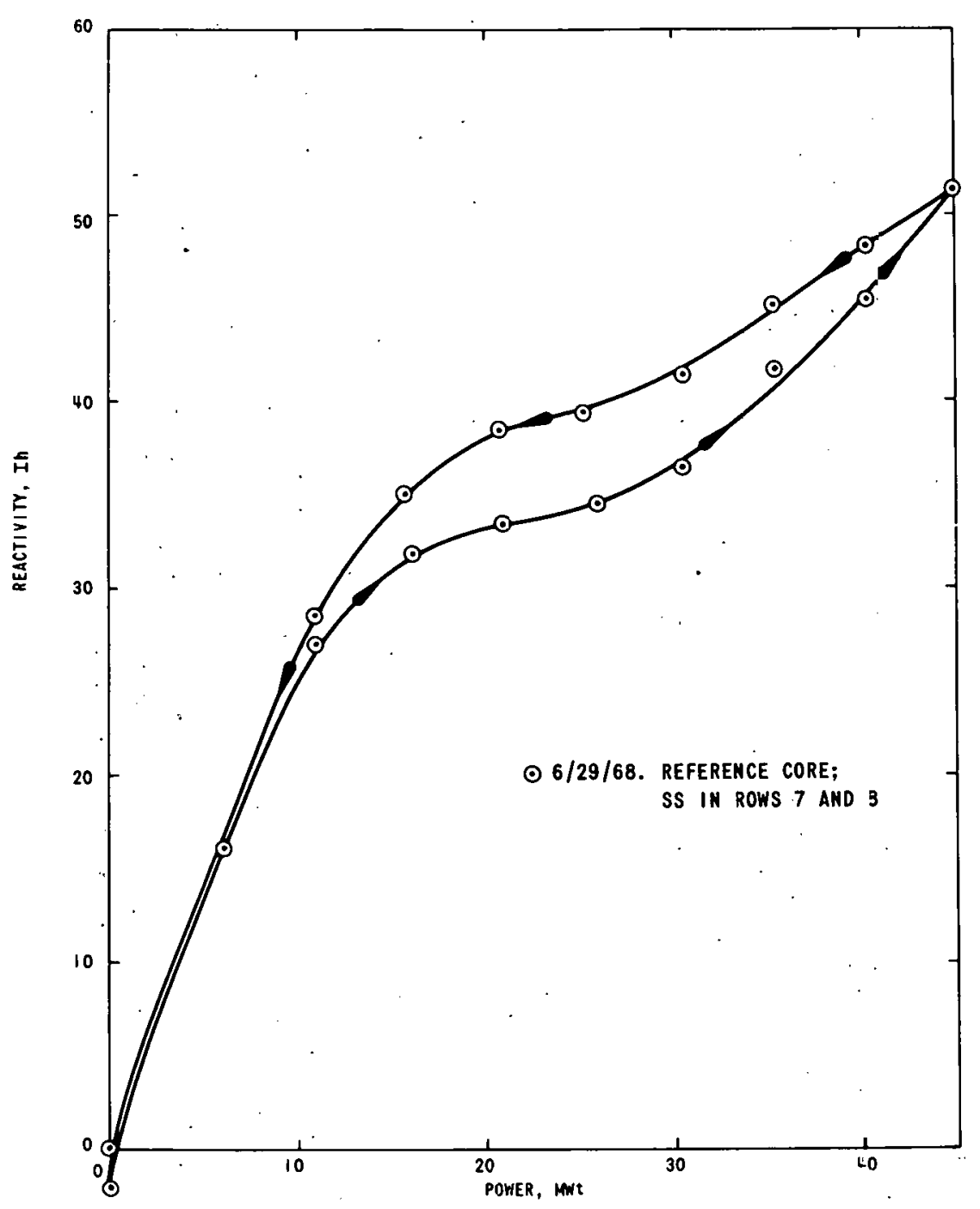

ID-103-K-5799 Rev. 1

Fig. 30. Run-29A Power-coefficient Data, Normalized to a Rod Bank of 11.00 in.

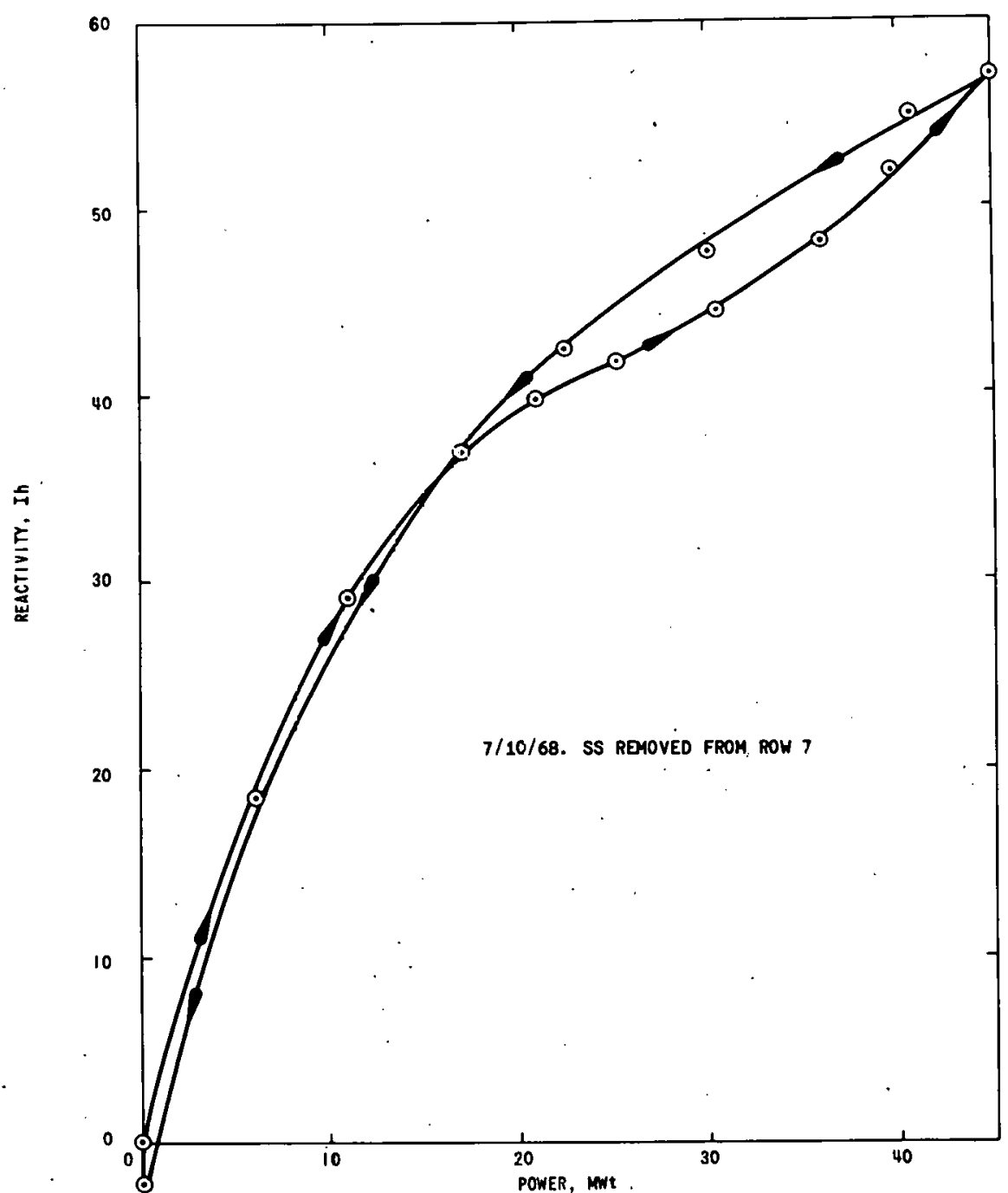

ID-103-K-5800 Rev. 1

Fig. 31. Run-29B Power-coefficient Data, Normalized to a Rod Bank of 11.00 in. 


\section{Run $29 \mathrm{C}$}

Fuel-handling operations for Run 29C began on July 11 . These consisted essentially of exchanging stainless steel units in Row 8 with depleteduranium subassemblies in Row 14. Fuel-handling operations were completed on July 14. The reactor was restarted on July 15 and was brought to $45 \mathrm{MWt}$ on July 17. A summary of power-coefficient data for the complete 0-41.4-0MWt cycle is given in Fig. 32. In this case, the removal of the stainless steel from Row 8 resulted in a large increase in the PRD and an additional slight decrease in the degree of hysteresis. The results of repeat measurements, carried out for the power cycle 0-45-0-MWt, are given in Fig. 33.

The effect of removing the stainless steel reflector on the power coefficient is illustrated more concisely in Fig. 34, which compares powercoefficient data for the reference core (Run 29A) with that resulting from

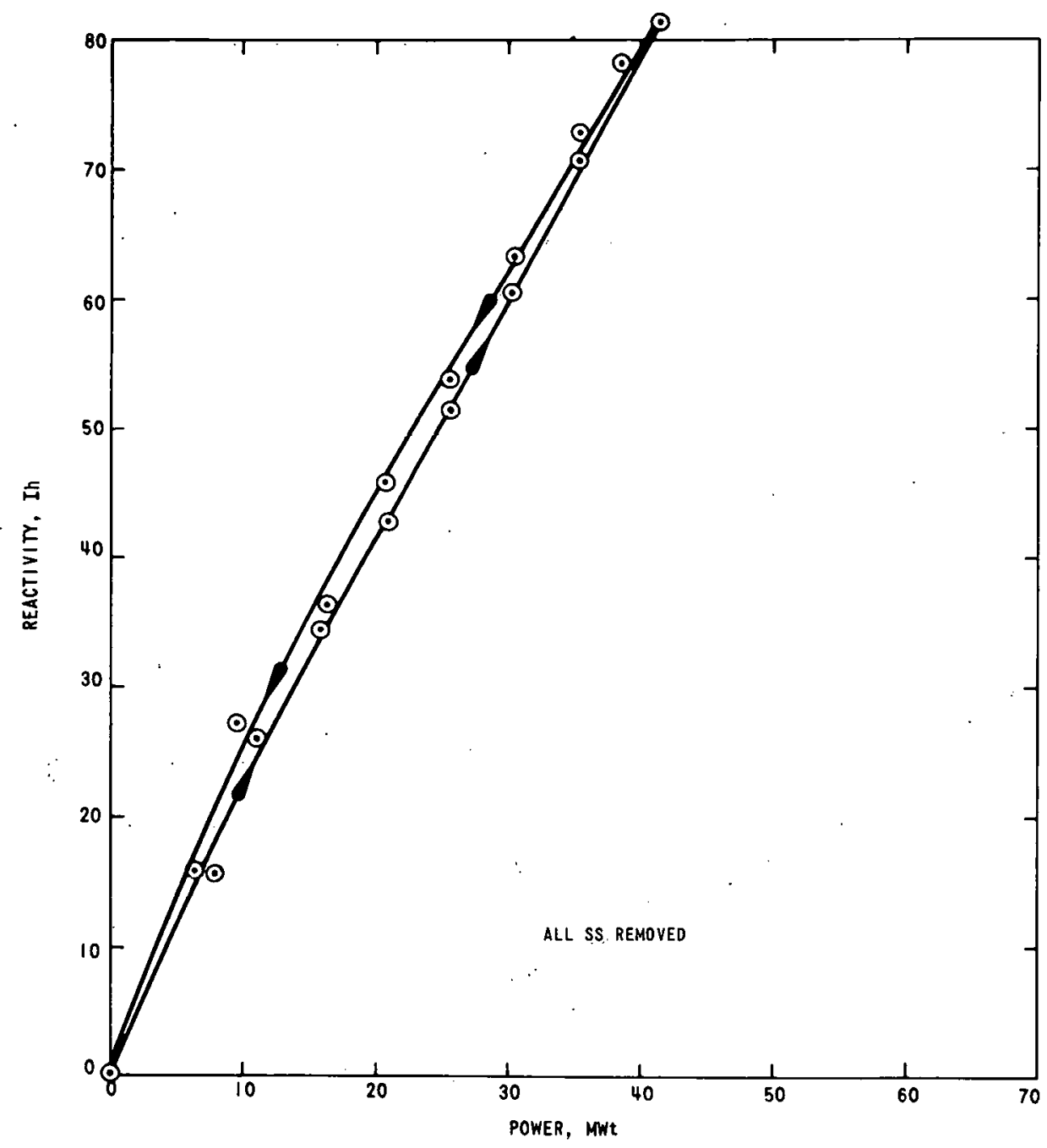

ID-103-K -5801 Rev. 1

Fig. 32. Run-29C Power-coefficient Data Taken on July 16, 1968, Normalized to a Rod Bank of 11.00 in. 


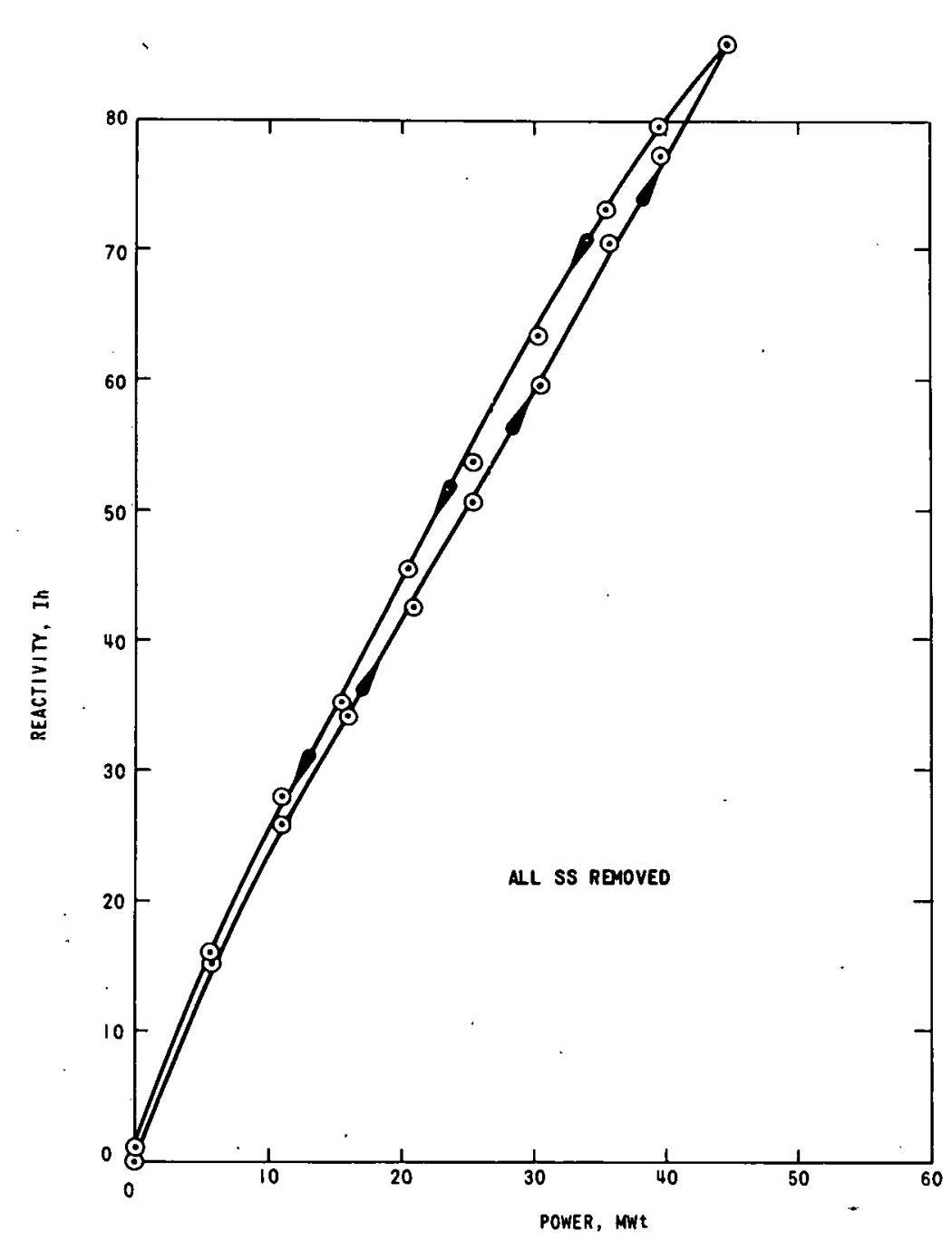

ID-103-K-5802 Rev. 1

Fig. 33. Run-29C Power-coefficient Data Taken July 17, 1968, Normalized to a Rod Bank of 11.00 in.

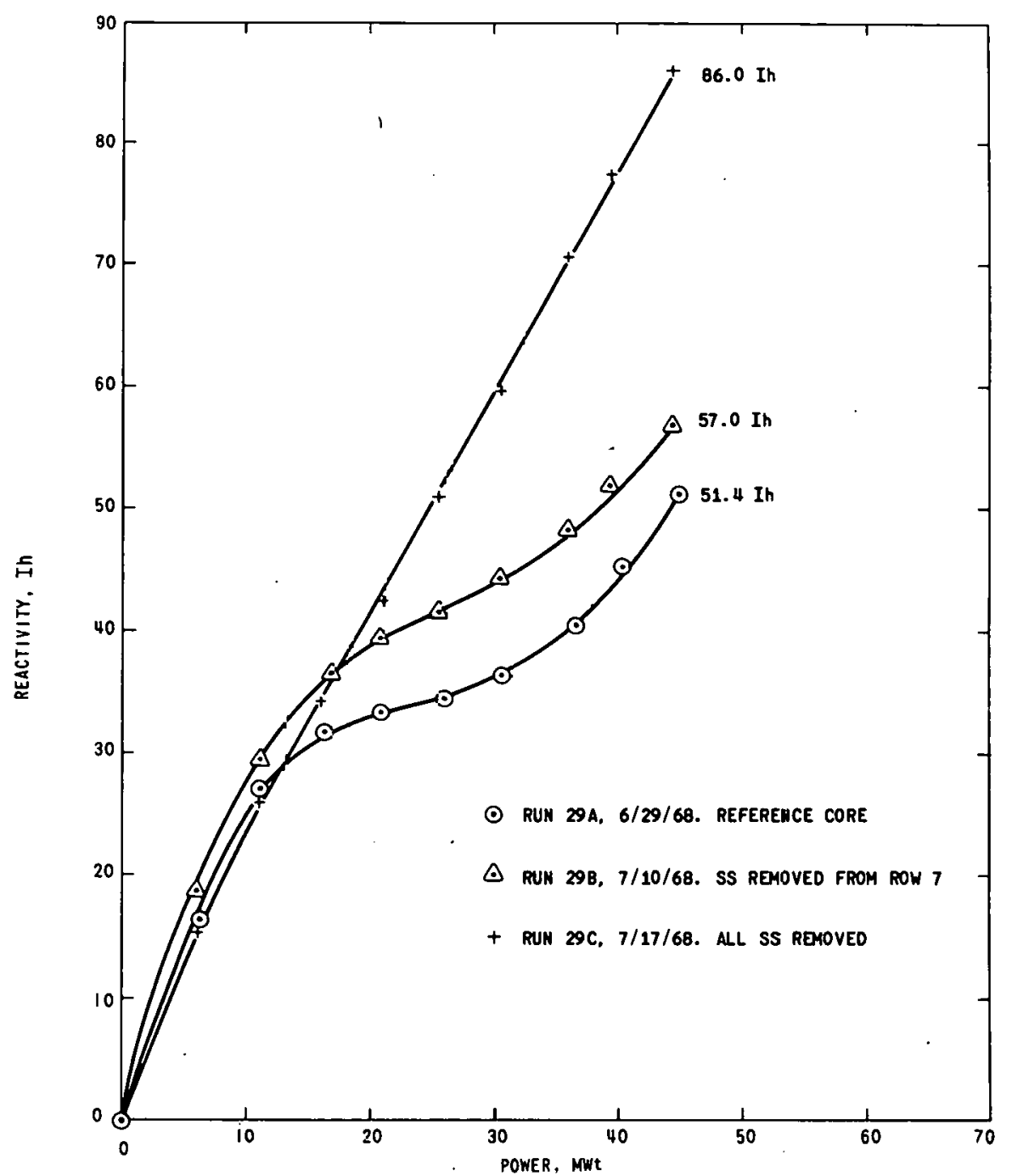

ID-103-K-5803 Rev. 1

Fig. 34. Comparison of Power-coefficient Data for Runs 29A, 29B, and 29C 
the removal of stainless steel from Row 7 (Run 29B) and from Row 8 (Run 29C). The removal not only strengthened the total PRD but eliminated, for all practical purposes, the inflection noted in the midpower region. D. Relative Reactivities of Depleted Uranium and Stainless Steel in the

The replacement of stainless steel in Rows 7 and 8 provided an excellent opportunity to measure the relative worths of depleted uranium and stainless steel in these positions. The replacement of stainless steel in Row 7 resulted in a decrease of $355 \mathrm{Ih}$. The replacement in Row 8 resulted in an additional decrease of $225 \mathrm{Ih}$, thereby giving a total of $580 \mathrm{Ih}$ for the reflector changeover.

E. Summary of Startup Power-coefficient Data

An interesting comparison between various power-coefficient data is given in Fig. 35. In this illustration, all data were taken during initial startup

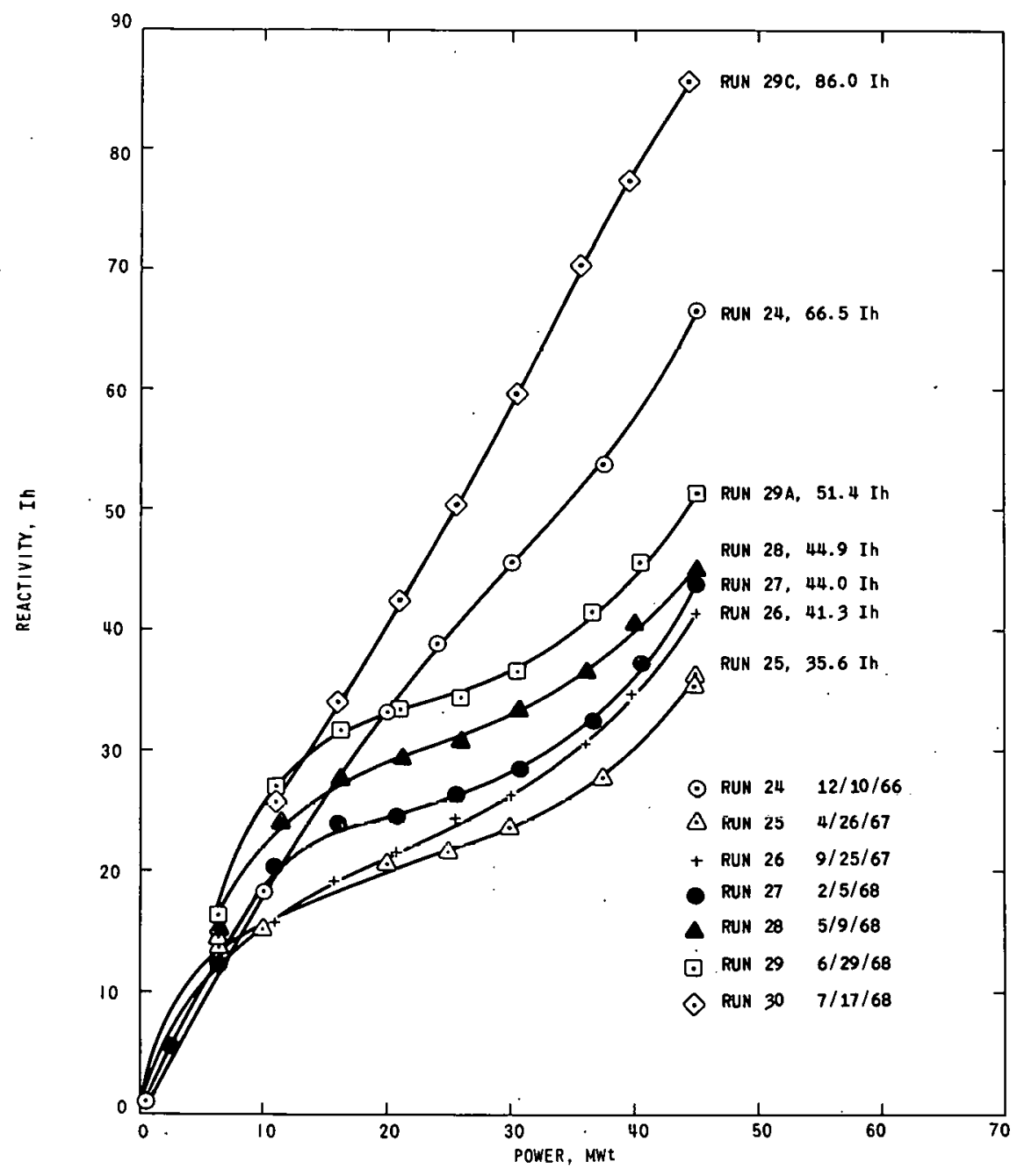

D-103-K-5804 Rev. I

Fig. 35. Comparison of Startup Power-cóefficient Data for Runs 24 through 29C, Normalized to a Rod Bank of 11.00 in. 
and all have been normalized to a control rod bank of $11.0 \mathrm{in}$. The data indicate that, after Run 25, a tendency developed toward increasing PRD values. In fact, during the startup of Run $29 \mathrm{~A}$ (with the stainless steel reflector), the total PRD was only 15.1 Ih lower than the last previous value established with the original depleted-uranium reflector.

An additional illustration of the trend towards higher PRD values is given in Fig. 36, which summarizes 0-45-MWt PRD values established throughout a given run. For those cases in which the power level was not exactly at $45 \mathrm{MWt}$, corrections were applied by extrapolating existing PRD curves to $45 \mathrm{MWt}$. Horizontal bars have been drawn through the various data sets to define arithmetic mean values. Again a definite trend towards higher power-coefficient values may be seen. The significance of this trend will be discussed under Section IX.C.

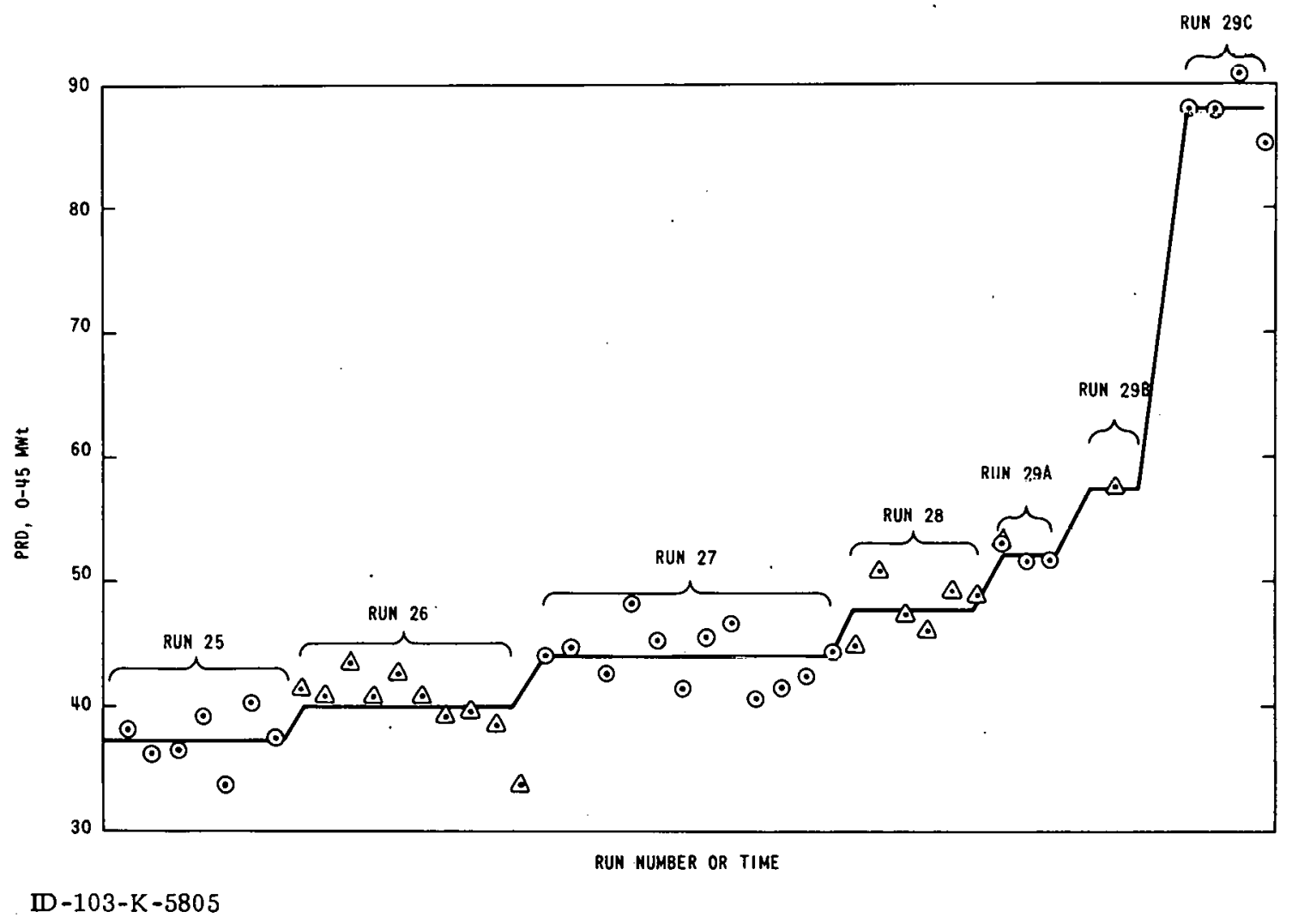

Fig. 36. Variation in PRD with Time during Runs 25 through 29C; All Values Normalized to a Rod Bank of 11.00 in. 


\section{SUPPORT STUDIES}

In an effort to preserve continuity throughout the period from April 1967 to July 1968, Sections III through VII have dealt almost exclusively with a chronological summary of static power-coefficient measurements since the results of these measurements are considered readily indicative of changes in the nature of the feedback. Although not immediately obvious in Sections III through VII, much concurrent effort was devoted to other studies intended to provide as much information as possible on the origin of the power-coefficient decrease. In this section, an attempt will be made to review the various efforts and how such efforts could contribute to the formulation of a model that could explain the decrease in the power coefficient. Realizing that a complete summary of all auxiliary efforts would likely lead to confusion, only those that gave results which are reliable, typical, and relevant to the formulation of a feedback model will be cited. As discussed previously in Section I, complete summaries and the treatment of experimental information are given elsewhere.

\section{A. Temperature Calculations}

Within a few days after the discovery of the weakened powercoefficient condition, attention was focused on what appeared to be a reversal of the normal temperature gradients across stainless steel subassemblies in Row 8 . Since a detailed treatment of pertinent temperature evaluations has been given by Cushman,, 4,5 only the significance of this work will be given here. Fundamcntal to an understanding of the considerations which follow is the concept that replacement of the depleted uranium by stainless steel in Rows 7 and 8 caused an increase in the neutron and gamma fluxes in Row 9. Since the flow rates in Rows 8 and 9 were essentially the same, the greater power generation in Row 9 (relative to that in Row 8) led to the transfer of heat from Row 9 into Row 8. As a consequence, the outer edges of subassemblies in Row 8 ran hotter than inner edges that bordered on stainless steel-filled subassemblies in Row 7. Such a temperature gradient is considered reversed; the normal gradient is one in which inner surfaces of the hexes have higher temperatures than outer surfaces. In Row 7, temperature gradients across the hexes were normal because the inner surfaces bordered on fueled subassemblies and the outer surfaces bordered on the nonheat-producing stainless steel subassemblies in Row 8 .

In evaluating the temperature gradients across Row- 7 and Row- 8 stainless steel subassemblies, Cushman assumed the following:

1. Heat is transferred by conduction from Row 6 (filled with standard driver subassemblies) to Row 7. The effect on temperatures in Row 6 is negligible since the amount of heat transferred to Row 7 (approximately $3 \mathrm{~kW}$ ) is small compared with the total heat generated (approximately $500 \mathrm{~kW}$ ). 
2. No heat is transferred between the 7 th and 8 th rows.

3. Row-8 subassemblies receive heat by conduction from Row 9 . The amount of heat transfer red significantly affects temperatures in Rows 8 and 9.

4. Values of internal power generation and primary-coolant flow rates are given in Table XV.

TABLE XV. Thermal-hydraulic Information on Rows 6-9 in Run 25

\begin{tabular}{lrc}
\hline Row & $\begin{array}{c}\text { Power } \\
(\mathrm{kW})\end{array}$ & $\begin{array}{c}\text { Plow Rate of } \\
\text { Primary Coolant } \\
\text { (gpm) }\end{array}$ \\
\hline 6 & 509 & 72.0 \\
7 & 22 & 6.2 \\
8 & 9 & 5.9 \\
9 & 39 & 5.9 \\
\hline
\end{tabular}

5. The axial power generations in the 7 th, 8 th, and 9 th rows have the same relative distribution.

6. The radial power-generation rates assumed for the 7 th, 8 th, and 9 th rows are based on calculations of the gamma flux and on experimentally measured fission rates. Specific power-generation rates for. Rows 7 through 9 are given for gamma and fission heating in Figs. 37 and 38, respectively. In these figures, the pin position designates the order in which a pin is reached when moving outward along the radial centerline of a subas sembly.

7. The effective heat conductance between the midpoint of one hex can to the flowing sodium of the adjacent hex can is $1890 \mathrm{Btu} / \mathrm{hr}-\mathrm{ft}^{2}-{ }^{\circ} \mathrm{F}$.

8. Conduction occurs across a blanket subassembly. Also, sodium mixing between adjacent channels does not occur. Hex-wall temperatures under 45-MW operating conditions were evaluated at the following elevations: $27 \frac{1}{2}$ and $7 \frac{1}{2}$ in. below midplane; at midplane; and $7 \frac{1}{2}, 15$, and $27 \frac{1}{2}$ in. above midplane. Pertinent temperatures for the hex walls are summarized in Table XVI.

TABLE XVI. Hex Temperatures $\left({ }^{\circ} \mathrm{F}\right)$ as a Function of Radius and Elevation

\begin{tabular}{lccccccc}
\hline \multicolumn{1}{c}{ Elevation } & $\begin{array}{c}\text { Outer } \\
\text { Edge of } \\
\text { Row } 6\end{array}$ & $\begin{array}{c}\text { Inner } \\
\text { Edge of } \\
\text { Row } 7\end{array}$ & $\begin{array}{c}\text { Outer } \\
\text { Edge of } \\
\text { Row } 7\end{array}$ & $\begin{array}{c}\text { Inner } \\
\text { Edge of } \\
\text { Row } 8\end{array}$ & $\begin{array}{c}\text { Outer } \\
\text { Edge of } \\
\text { Row } 8\end{array}$ & $\begin{array}{c}\text { Inner } \\
\text { Edge of } \\
\text { Row }\end{array}$ & $\begin{array}{c}\text { Outer } \\
\text { Edge of } \\
\text { Row } 9\end{array}$ \\
\hline $27 \frac{1}{2}$ in. below midplane & 700 & 700 & 700 & 700 & 700 & 700 & 700 \\
$7 \frac{1}{2}$ in. below midplane & 700 & 710 & 707 & 704 & 703 & 722 & 713 \\
Midplane & 758 & 747 & 726 & 717 & 738 & 759 & 749 \\
$7 \frac{1}{2}$ in. above midplane & 834 & 807 & 753. & 729 & 774 & 807 & 802 \\
15 in. above midplane & 882 & 851 & 770 & 737. & 803 & 819 & 832 \\
$27 \frac{1}{2}$ in. above midplane & 882 & 868 & 781 & 743 & 810 & 825 & 845 \\
\hline
\end{tabular}




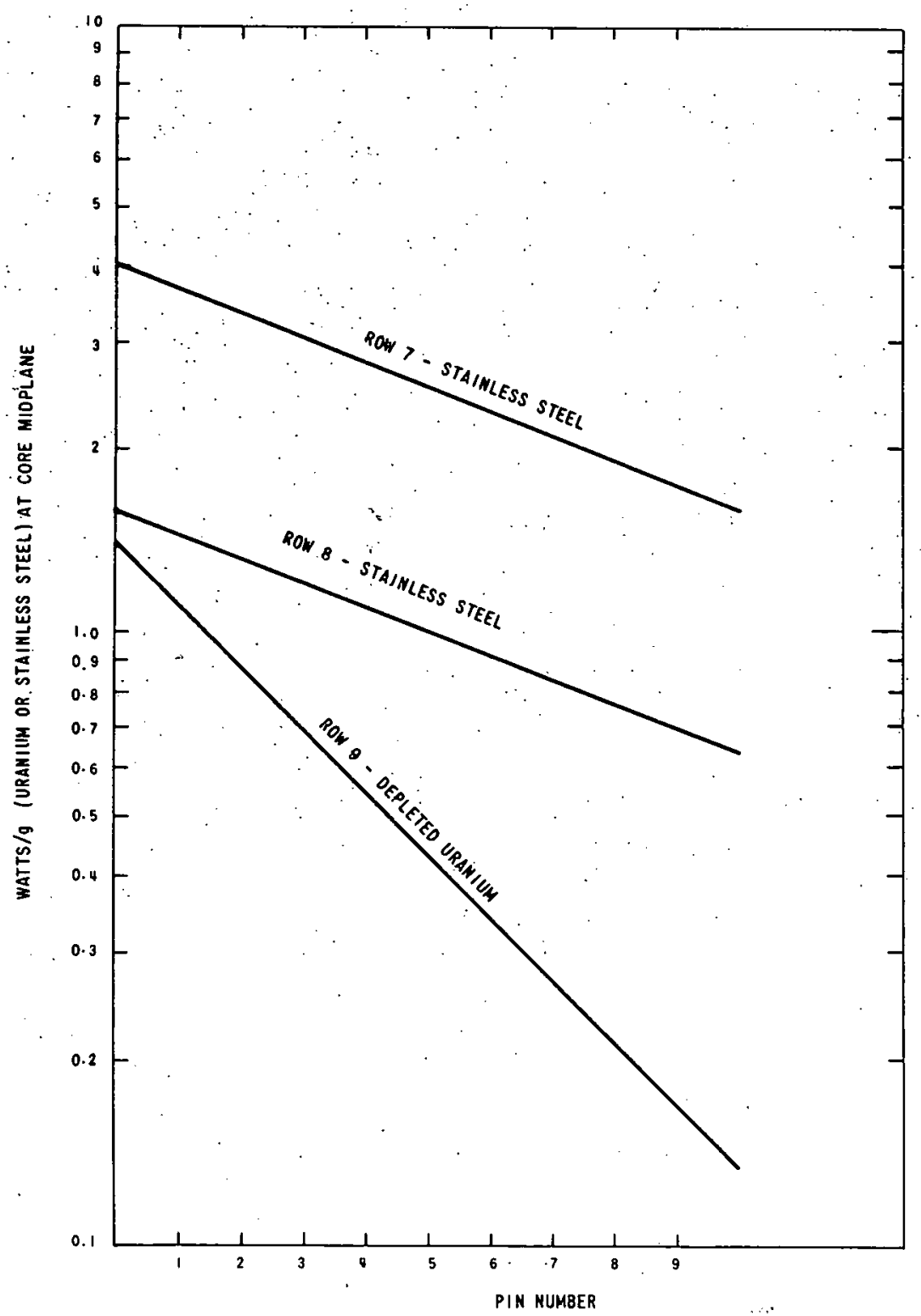

ID-103-K-5806 Rev. 1

Fig. 37. Gamma-heat Production in Rows 7 through 9

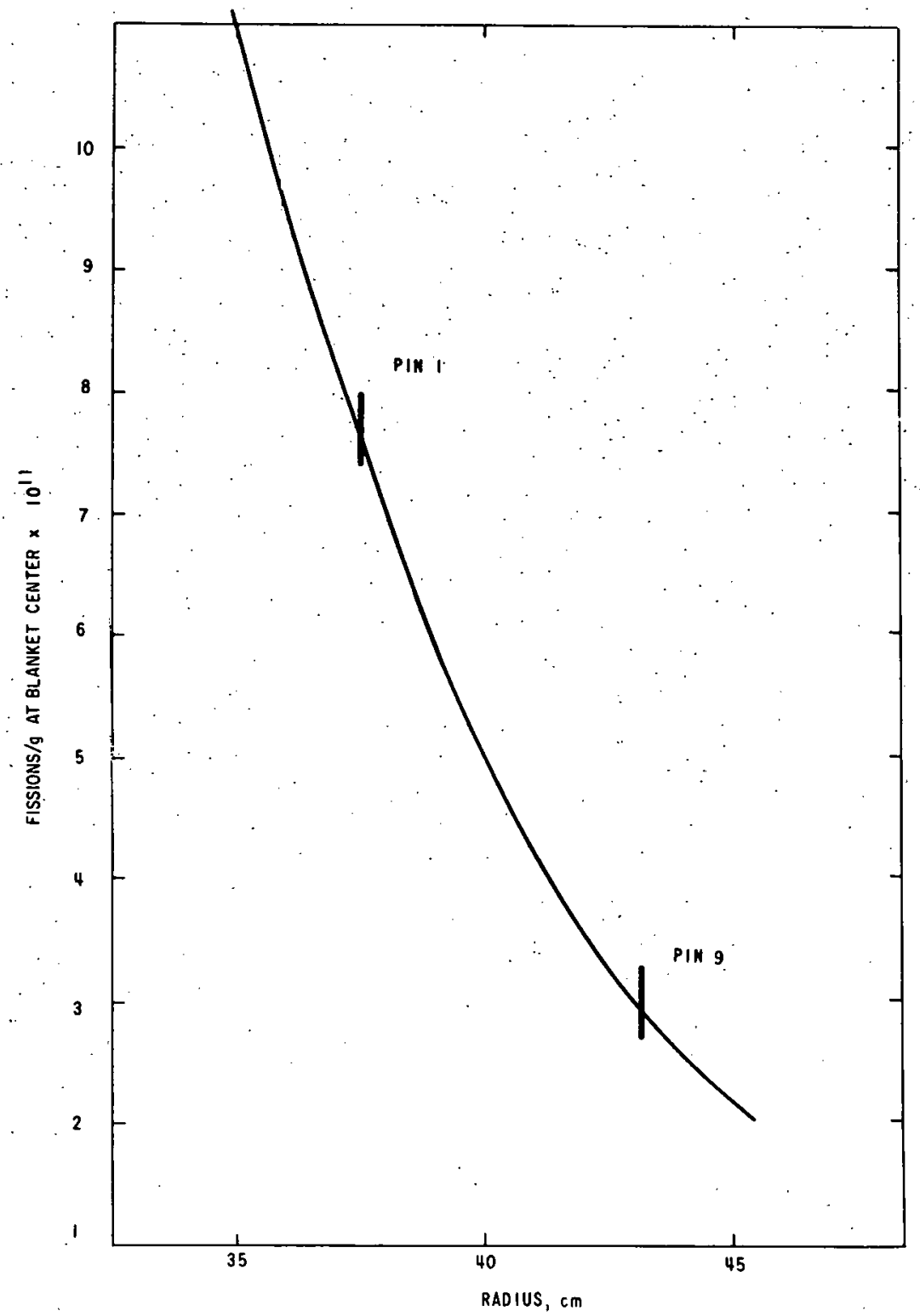

ID-103-K-5807 Rev. 1

Fig. 38. Fission Distribution in Row 9 for ${ }^{235} \mathrm{U},{ }^{238} \mathrm{U}$, and ${ }^{239} \mathrm{Pu}$ 
An inspection of the results given in Table XVI makes it clear that whereas temperatures at any given elevation decrease radially across Row 7 , the gradient is reversed in Row 8. Such behavior contrasts strongly with that in operations prior to Run 25, when the temperature gradients across all core and blanket subassemblies decreased with increasing radius. Such results suggested a bowing model in which Row-7 subassemblies tended to bow inward at the center, while Row 8 subassemblies bowed outward at the center. In effect the reverse bowing attitudes assumed the form of a pair of closed parentheses, thus (). The development of a physical model based on reversed bowing effects is discussed in detail in Section IX.

\section{B. Bowing Calculations}

The possibility of subassembly bowing and the effects of buwing phenomena on reactivity were considered in the original Hazards Summary Report. ${ }^{33,34}$ Despite an unusually large amount of attention directed to bowing phenomena as a consequence of the Run-25 power-coefficient decrease, nothing developed that would suggest any serious revision of the earlier concepts of subassembly bowing. Since the basic bowing model is still considered acceptable, a review of those features which contribute to an understanding of the more-complex bowing attitudes experienced during Run 25 is worthwhile. The following constitutes a brief summary of the early concepts. On occasion, actual quotations will be given.

"All subassemblies are positioned and supported in the reactor by their lower adapters, the ends of which pass through holes in the upper plate of the support grid and engage in axially aligned holes in the lower plate. The portion of the adapter which rests on the upper plaie lias the shape of a truncated sphere; the upper edge of the plate hole, on which the adapter rests, is chamfered conically. This arrangement provides a continuous line contact for subassembly support. It has been established experimentally that lateral movement of the upper part of the subassembly (or the lower part of the adapter) is accompanied by pivoting of the subassembly about this area of contact; that is, lateral movement of the subassembly in the region of contact with the upper plate does not occur unless a very large force is applied..... Consequently, application of lateral force in or above the region of the core section produces only a pivoting of the subassembly until the lower end of the adapter closes the lower plate hole clearance ( 0.0042 in. radially) and, thereafter results in binding of the subassembly. Lateral movement of the top end is unrestricted up to nominal displacement of 0.030 in. when contact with the adjacent subassembly is made; if the adjacent subassembly also undergoes displacement, restriction is not effected until after correspondingly greater displacement."

Temperature gradients exist across all subassemblies by virtue of the following facts: (1) Heat generation within a given subassembly is nonuniform radially, and (2) heat may flow in or out of a given subassembly to 
adjacent subassemblies. For the original core (i.e., with the conventional uranium blanket), the sense of all temperature gradients was such that resulting subassembly bowing phenomena were manifested by a convex curvature as viewed from the core center. In other words, a given subassembly bowed such that the upper and lower ends tended to move outward while the midsection tended to move inward.

The axial shape of the temperature profile is such that the temperature differential increases approximately linearly from $0^{\circ} \mathrm{F}$ at the bottom of the core to a maximum at the top. From this point, the temperature differential is assumed to decrease back to $0^{\circ} \mathrm{F}$ within a distance of 9 in. The decrease results from coolant mixing during passage through the upper gap and the lower portion of the upper blanket.

At low power (i.e., for a small temperature differential), the lower portion of the core section starts to bow radially outward, thus increasing the core radius. As the temperature differential increases (i.e., as power increases), the amount of outward displacement also increases until the top of the subassembly contacts the top of the adjacent outlying subassembly. As subassemblies become increasingly engaged at the upper ends, additional power increases are manifested by an inward radial movement of the core sections. At the same time, subassemblies proceed to pivot, which causes the lower ends of the adapters to move outward until clearances are closed between the pole pieces and the lower-grid-plate holes. At this point, two constraints are realized; one at the top and the other at the extreme lower end. Under these conditinns, an additional puwer increase is manifested by an inward movement of the core section until the clearance between adjacent spacer pads is closed. Such a phenomenon is characterized by a decrease in core radius. An additional increase in the temperature differential across a given subassembly does not produce additional inward movement (assuming the absence of compressional effects). In fact, when all clearances between spacer pads are closed, an additional power increase results in an overall radial-expansion component that tends to increase the core radius.

In brief, the manifestations of a power increase from hot critical to operating power on the effective core radius are an initial increase in the radius, a transition period in which inward movements compete with outward, and finally an increase in the radius. Logically, such power-sensitive changes would be reflected by a decrease in the magnitude of the differential power coefficient in the midpower region. As previously indicated (see Fig. 1), such changes were frequently noted in pre-Run-25 power-coefficient data.

Although the earlier concepts of subassembly bowing are still considered valid, the basic bowing considered in the original Hazards Summary Report ${ }^{33}$ was considered to be too general for direct application to the Run-25 problem. For example, the original bowing calculations were carried out 
without the benefit of computer programs and considered bowing in the outermost row only. Furthermore, the original calculations involved rather arbitrarily imposed conditions of restraint by neighboring subassemblies.

Recognizing the limitations of earlier results, but working within the framework of the qualitative model, Bump: $6 ; .7$ developed a digitalcomputer program (BOW-II) that treated bowing phenomena on a morerealistic basis. As input, the BOW program accepts the axial distribution of the temperature differential across inboard and outboard subassembly flats and evaluates the unrestrained thermal deflections for each row of subassemblies. Then, while accounting for limited-pivot supports at the lower ends and assumed obstruction locations at the upper ends, the variations in radial subassembly positions with axial locations are determined. The data reflect the superposition of the unrestrained thermal deflections upon the stress-induced deflcctions due to the externally imposed end restraints. If interference is detected between subassemblies at the spacer pads, additional deflections are assigned to the subassemblies to remove the interferences. The additional deflections are treated as second-order effects. Finally, if the net load, due to the end and spacer-pad restraints on any subassembly, is found to be incompatible with the loads on adjacent subassemblies, the upper-end obstruction locations are gradually moved during iterative calculations in directions that eventually produce quasiequilibrium. During this process, spacer-pad dimensions are varied to account for both thermal-expansion effects and elastic deformation.

Figures 39 and 40 summarize the results of BOW calculations carried out with the assumptions given above. As an illustration of preRun-25 behavior, Fig. 39 shows the unrestrained lielmal=bowing deflections for Runs 17-24. From an inspection of these results, it may be seen that the subassemblies in all rows bow in a manner which tends to displace the upper ends outward. The first influence of restraint is reached in Row 7. Whereas, in the absence of restraint, the upper ends of Row- 7 subassemblies would move 0.210 in. and the upper ends of Row-8 subassemblies would move 0.150 in., they cannot do so because the upper ends of Row- 9 subassemblies impose restraint on Row- 8 subassemblies, which, in turn, limit the upper movement of Row-7 subassemblies.

Figure 40 shows the bowing phenomena during Run 25. In this case, the situation is considerably different because of the reversed bowing attitude in Row 8. If unrestrained, the tops of Row- 8 subassemblies would bow $0.150 \mathrm{in}$. inward. However, because the tops of all inboard subassemblies (in Rows 2-7) tend to bow outward, the consequence of the opposing actions is an effective barrier at Row- 7 radial positions that reduces the freedom of upper-end movement for all inboard subassemblies.

Following the completion of the studies that resulted in the data given in Figs. 39 and 40, Bump improved the original BOW program to: 


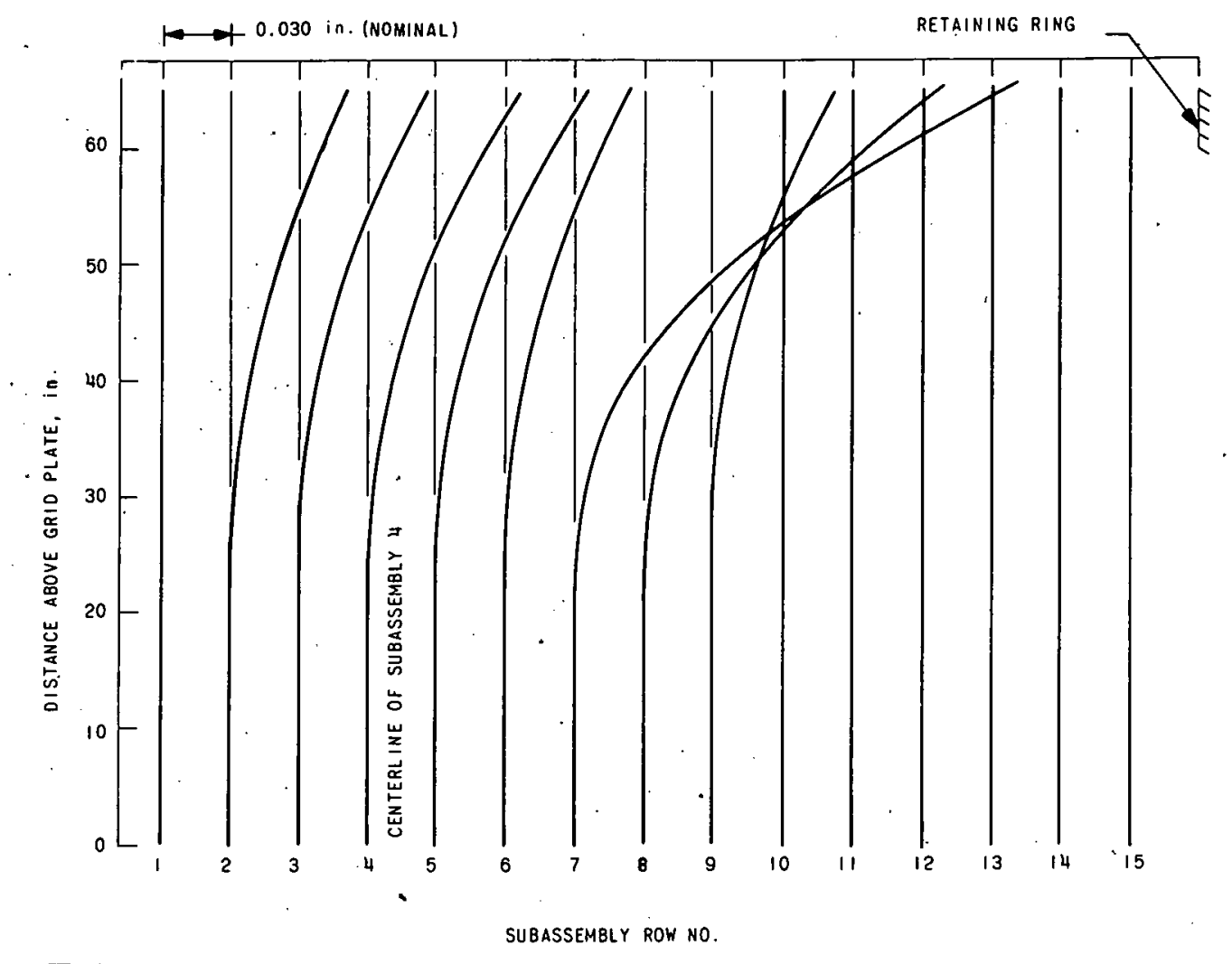

ID-103-K-5808 Rev. 1

Fig. 39. Unrestrained Thermal-bowing Deflections for Runs 17-24; 45-MWt Power

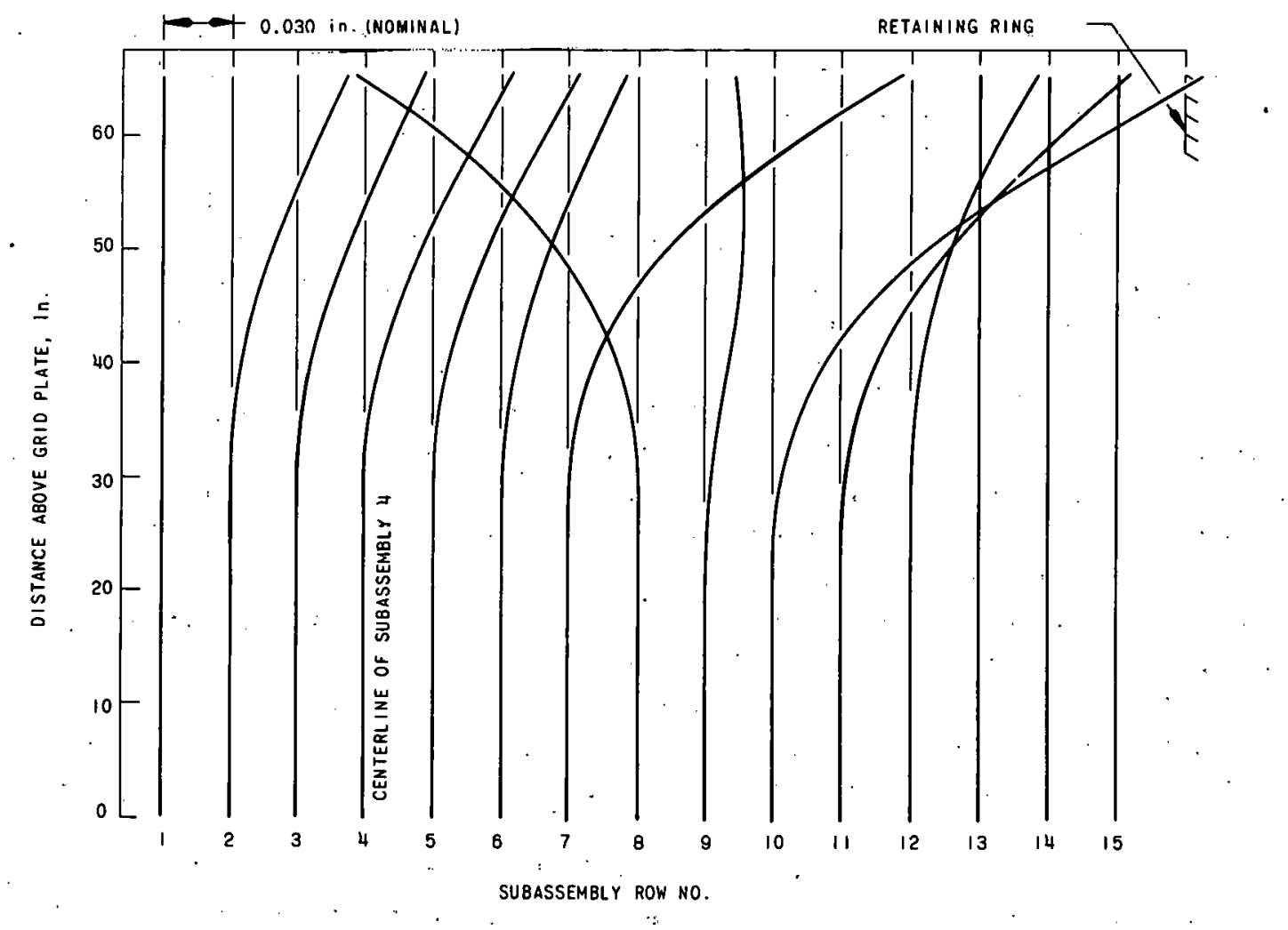

ID-103-K-5809 Rev. 1

Fig. 40. Unrestrained Thermal-bowing Deflections for Run 25: 45-MWt Power 
(1) provide for additional modes of restraint, and (2) equilibrate spacerpad loads by the appropriate movement of pads during successive iterations. Although the improved version changed the magnitudes of upper-end deflections somewhat, the data given in Figs. 39 and 40 are still sufficiently reliable for illustrative purposes.

Using the results of Bump's work, Persiani ${ }^{9,10}$ translated the physical displacement of subassemblies into associated reactivity effects. In

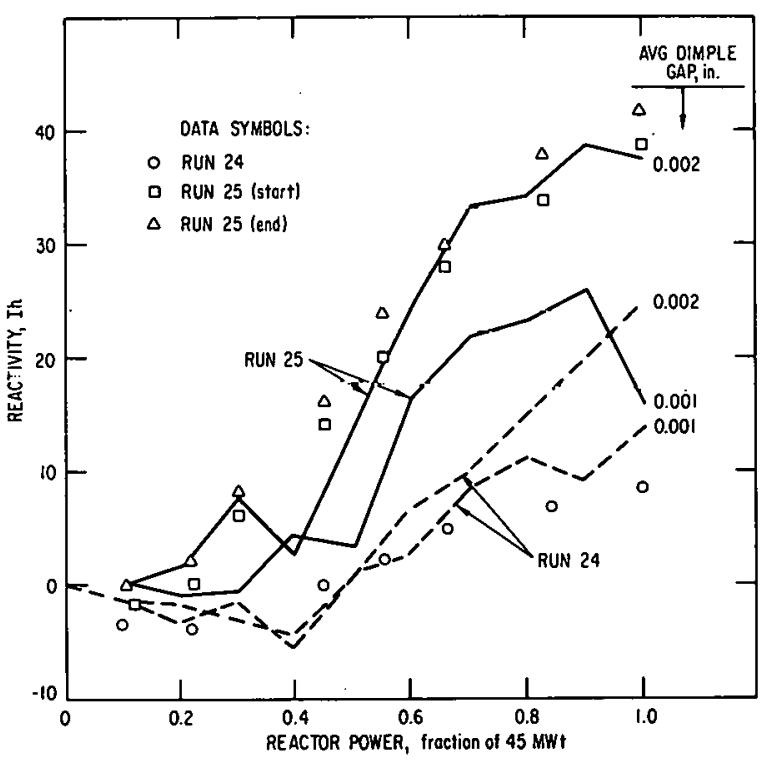

$113-1808$

Fig. 41. Comparison of Calculated (lines) and Experimentally Based (data points) Nonlinear Reactivity Feedbacks for Runs 24 and 25 this portion of the work, reactivity coefficients (i.e., the change in reactivity with change in core radius, or $\Delta \mathrm{k} / \Delta \mathrm{r}$ ) deduced by Persiani et al. ${ }^{9-15}$ were used. Additional refinements were incorporated by considering subas serrbly binding stiffnesses, subassembly squashing stiffnesses, nominal pad clearances, and subássembly zero-power leane.

A measure of Persiani's success in calculating the effects of subassembly displacement on reactivity may be inferred from a consideration of Fig. 41, in which the calculated results are compared with experimental. In the figure, only the nonlinear portions of the feedback have been considered. Experimental data points were established by subtracting estimates

for the linear components from experimental values, and the calculated data points were established from reactivity coefficients $(\Delta k / \Delta r)$ and the calculated physical displacements of subassemblies in Rows $6,7,8$, and 9.

The influence of spacer-pad clearances on the magnitude of the nonlinear feedback component is shown to be significant. If a 0.002 -in. clearance is assumed for Run 25, an excellent agreement is effected between experimental and calculated results. The assumption of a 0.001-in. clearance, however, leads to a nonlinear component that is too small to explain the changes in the Run-25 power coefficient. For Run 24, on the other hand, the assumption of a 0.001 -in. rather than a 0.002 -in. clearance leads to a satisfactory agreement. These results not only illustrate the effect of small changes in spacer-pad clearance on feedback, but strongly suggest that extra clearance was available during Run 25.

To explain the increase in available clearances in Run 25, Bump compared loads (forces) on the spacer pads for typical Run-24 and Run-25 conditions and concluded that the loads imposed by bowing phenomena during 
Run 25 were sufficiently large to cause enough elastic and inelastic deformation to be sensed by the system as an effective increase in spacer-pad clearances. In support of this conclusion, Persiani cited the results of work by Smith and Mitchell ${ }^{8}$ who found that dimensions across the spacer pads of subassemblies discharged from Runs 25 and 26 had decreased, on the average, approximately 0.0012 in. A review of this work is given in Section VIII.C.

The results of Bump's and Persiani's work strongly supported the contention that the effect of the stainless steel reflector was manifested by reversed bowing phenomena (in Row 8), which tended to decrease the magnitude of normal negative feedback components by limiting blossoming effects at the upper ends of subassemblies and by increasing the magnitude of normal positive feedback components associated with the inward movement of subassemblies at midplane.

C. Déformation of Subassemblies during Runs 25 and 26

All subassemblies discharged from Runs 25 and 26 were examined in the Fuel Cycle Facility (FCF) for evidence of deformation. ${ }^{8}$ Three types of measurements were made: for straightness, twist, and dimensional changes across opposite sets of spacer pads.

Seventeen driver subassemblies and six control rods were discharged at the end of Run 25. Straightness measurements of each revealed that in only two instances was there any evidence of deformation. Even in these two instances, the extent of deformation was less than the 0.080 -in. permissible deviation. Only one subassembly showed any evidence of twist, and even for this case, the $0.9^{\circ}$ of twist was less than the nominal specification of $1^{\circ}$.

Of the 51 individual dimensional measurements made across the spacer pads of the 17 driver subassemblies discharged from Run 25, 34 indicated a decrease, four indicated no change, and only 13 indicated an increase. Furthermore, the total decrease amounted to 0.099 in. and the total increase amounted to 0.039 in. Accordingly, the average algebraic change was -0.0012 in. per flat.

Twist and straightness measurements were not made of subassemblies discharged from Run 26 because no evidence of change had been indicated by the Run- 25 results. Dimensional measurements across the spacer pads of subassemblies discharged from Run 26 showed much the same pattern as that for subassemblies discharged from Run 25. Of a total of 96 measurements of 32 discharged driver assemblies, 54 registered a decrease, nine no change, and 33 registered increases. The total decrease amounted to $0.206 \mathrm{in.}$, and the total increase amounted to $0.090 \mathrm{in}$. The average algebraic change per flat was found to be (coincidentally) -0.0012 in. 
To establish the effects of "heat-soaking" on the deformation of subassemblies, two experiments were conducted. In one, careful measurements were made across the flats of a special subassembly (X900) used in a study of the effects of sodium immersion and water washing. The subassembly was soaked for 15 days in $700^{\circ} \mathrm{F}$ sodium in the storage basket during Run 26 . The dimensions across the spacer pads were remeasured following discharge. For all flats, a net increase of 0.003 in. was noted.

In another series of tests, three hex sections containing spacer pads were heated in a furnace for $3 \mathrm{hr}$ at $900^{\circ} \mathrm{F}$ and then air cooled. Measurements across the spacer pads indicated that the average increase across the nine sets of flats was 0.002 in. In no case was a decrease noted. These results and those given above indicate that stress relief through heating is manifested by dimensional increases and imply that the decreases in spacerpad dimensions noted for Runs 25 and 26 subassemblies are very likely real. In fact, it is reasonable to assume that the degree of compressional effects across some of the flats might have been masked by stress relief under the high-temperature conditions.

D. Effects of Changes in Core Radius on Reactivity

As discussed in Section VIII.B, formulation and verification of a satisfactory physical model for the Run-25 feedback and power coefficient involved the following phases: calculation of the axial distribution of temperature gradients across all subassemblies in Rows $1-8$, calculation of subassembly displacement by bowing phenomena, and translation of the displacement into reactivity feedback effects. In effect, the displacement of subassemblies, regardless of the mechanism involved, may be treated as a problem in which the volume fractions for all constituents vary with a change in core radius. The results of such calculations have been described in detail by Made11 ${ }^{15,20}$ for a variety of EBR-II core configurations and compositions. Pertinent results are summarized in Table XVII.

TABLE XVII. Expansion and Compaction Reactivity Coefficients (Ih/mil)

\begin{tabular}{llcll}
\hline & \multicolumn{2}{c}{ Expansion } & & \multicolumn{2}{c}{ Compaction } \\
\cline { 2 - 3 } No. & Core & Blanket/Reflector & Core & Blanket/Reflector \\
\hline 16 & 3.1 & 0.1 & 2.7 & 0.1 \\
24 & 2.7 & 0.1 & 2.6 & 0.1 \\
25 & 2.6 & $0.4^{*}$ & 2.5 & $0.04^{* *}$ \\
26 & 2.5 & $0.4^{*}$ & 2.6 & $0.03^{* *}$ \\
\hline
\end{tabular}

*For movements in the stainless steel reflector.

**For movements in the uranium blanket outside the stainless steel reflector. 
E. Separation of Nonlinear Feedback Effects

Fundamentally, Bump's work on subassembly bowing phenomena demonstrated that credible bowing attitudes and associated forces could account for enough changes in nonlinear positive and negative feedback components to explain qualitatively and quantitatively the decrease noted in the power coefficient. To test the validity of the bowing model, and to assist in refining the model, Bump ${ }^{6,7}$ and Persiani $9,10,13,14$ calculated the power-dependent shape of the nonlinear feedback from subassembly movements and radial reactivity coefficients and compared the results with those deduced from actual experimental determinations:

In particular the power-dependent feedback function may be divided into two components, one linear with respect to power and the other strongly dependent on constraints and deformational attitudes that change nonlinearly as power increases: The magnitude of the linear portion is dictated by feedback effects originating from the expansion of fuel, sodium, and structural materials. Each of these effects is more or less susceptible to mathematical evaluation. Their sum may be subtracted from experimental values to arrive at the power-dependent nonlinear component. As indicated in Section VIII.B and Fig. 41, Bump was able to demonstrate a reasonable and acceptable agreement between calculated and experimental results.

The separation of nonlinear feedback effects is discussed in detail by Madell. ${ }^{15}$ Basically, the work involved the calculation and summing of all linear feedback effects and the subtraction of the total linear effect from experimental values. The results of two-dimensional transport-theory calculations for the Run-24 and Run-25 core configurations are summarized in Table XVIII.

TABLE XVIII. Calculated Power-coefficient Components for Runs 24 and 25

\begin{tabular}{|c|c|c|c|}
\hline \multirow[b]{3}{*}{ Feedback Sourcc } & \multicolumn{3}{|c|}{ Reactivity Change (Ih/MWt) } \\
\hline & \multicolumn{2}{|c|}{ Calculated } & \multirow{2}{*}{$\begin{array}{l}\text { Experimentäl } \\
\text { Run } 25\end{array}$} \\
\hline & Run 24 & Run 25 & \\
\hline $\begin{array}{l}\text { Sodium in the core, upper } \\
\text { reflector, and blankett }\end{array}$ & -0.91 & -0.86 & \\
\hline Fuel expansion & -0.53 & -0.44 & -0.65 \\
\hline Linear component & -1.44 & -1.30 & \\
\hline $\begin{array}{l}\text { Structure, stainless steel in } \\
\text { the core, and expansion of } \\
\text { the radial blanket }\end{array}$ & -1.37 & -1.20 & \\
\hline $\begin{array}{l}\text { Total power coefficient } \\
\text { Is othermal temperature }\end{array}$ & -2.81 & -2.50 & \\
\hline coefficient $\left(\mathrm{Ih} /{ }^{\circ} \mathrm{F}\right)$ & -1.01 & -1.15 & -1.04 \\
\hline
\end{tabular}


The calculations indicate a slight difference in the fuel-expansion coefficient between Runs 24 and 25. The slightly higher value in Run 24 reflects the effects of a system characterized by a higher neutron-leakage rate. Although the calculated values of the fuel-expansion component were lower than the value established experimentally, the experimental value of $-0.65 \mathrm{Ih} / \mathrm{MW}$ was used in subsequent efforts to separate linear and nonlinear feedback effects.

F. Constant $-\Delta T$ Experiments

In establishing values for the feedback associated with fuel expansion, experimental information was used. Such information was. obtained through constant $\Delta \mathrm{T}$ experiments, which involve the measurement of the reactivity difference associated with a change in power while keeping the ratio of power to coolant flow constant. Since the coolant temperature differential across the core is constant under these conditions, those feedback processes that are sensitive to coolant temperature variations do not change. Fuel temperatures, however, are sensitive to the power/flow ratio. Hence, a measurement of the reactivity difference between two levels of power (with the same power/flow ratio) reflects the effects of temperature differences in the fuel under the two sets of conditions. Necessary for the translation of actual experimental results into a fuel-expansion component of the power coefficient are the following: (1) measurement of the reactivity change associated with the power change under constant- $\Delta \mathrm{T}$ conditions, and (2) knowledge of fuel temperature under the conditions of the experiment. The firstiof these was established from the position of a carefully calibrated regulating rod. The second was established by HECTIC-II calculations that gave fuel and coolant temperatures for fuel material in Rows $1-6$ under various power and flow conditions. The results of these calculations are summarized in Table XIX.

The fuel-expansion component of the power coefficient was established from the relation

$$
(\Delta \mathrm{k} / \Delta \mathrm{P})_{\text {fuel }}=\frac{\Delta \mathrm{k}}{\Delta \mathrm{T}_{1}} \times \frac{\Delta \mathrm{T}_{2}}{\Delta \mathrm{P}}
$$

where $\Delta \mathrm{T}_{1}$ is the difference between average fuel temperatures at two different levels of power, but with the power/flow ratio held constant; $\Delta \mathrm{k}$ is the associated reactivity change, established from differences in regulating rod positions; $\Delta \mathrm{P}$ is the difference in power; and $\Delta \mathrm{T}_{2}$ is the difference between average fuel temperatures at the two different levels of power, both under full-flow conditions. The sum of the fuel component obtained in this manner and components for sodium and structural expansions is the total linear feedback. Subtraction of this feedback from experimental values gives the nonlinear component used by Bump and Persiani in comparing calculated and experimental results. 
TABLE XIX. Average Fuel and Coolant Temperatures as a Function of Reactor Power and Flow

\begin{tabular}{|c|c|c|c|c|c|}
\hline Row & 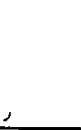 & $\begin{array}{l}\text { Reactor } \\
\text { Power } \\
\text { (MWt) }\end{array}$ & $\%$ Flow & $\begin{array}{c}\text { Avg Fuel } \\
\text { Temperature } \\
\left({ }^{\circ} \mathrm{F}\right)\end{array}$ & $\begin{array}{c}\text { Avg Coolant } \\
\text { Temperature } \\
\left.\text { ( }{ }^{\circ} \mathrm{F}\right)\end{array}$ \\
\hline \multirow[t]{6}{*}{1} & . & 41.5 & 100 & 897 & 767 \\
\hline & · & 22.5 & 100 & 807 & 736 \\
\hline & & 22.5 & 90 & 812 & 740 \\
\hline & & 22.5 & 75 & 821 & 748 \\
\hline & & 22.5 & 60 & 835 & 760 \\
\hline & & 22.5 & 54 & 843 & 768 \\
\hline \multirow[t]{6}{*}{2} & & 41.5 & 100 & 895 & 766 \\
\hline & & 22.5 & 100 & 805 & 736 \\
\hline & & 22.5 & 90 & 810 & 740 \\
\hline & & 22.5 & 75 & 820 & 748 \\
\hline & & 22.5 & 60 & 833 & 760 \\
\hline & & 22.5 & 54 & 841 & 767 \\
\hline \multirow[t]{5}{*}{3} & & 41.5 & 100 & 896 & 772 \\
\hline & & 22.5 & 100 & 806 & 739 \\
\hline & & 22.5 & 90 & 811 & 743 \\
\hline & & 22.5 & 75 & 821 & 752 \\
\hline & & 22.5 & 60 & 837 & 765 \\
\hline . & & 22.5 & 54 & 845 & 772 \\
\hline \multirow[t]{6}{*}{4} & & 41.5 & 100 & 905 & 786 \\
\hline & & 22.5 & 100 & 811 & 746 \\
\hline & & 22.5 & 90 & 817 & 752 \\
\hline & & 22.5 & 75 & 829 & 762 \\
\hline & & 22.5 & 60 & 846 & 778 \\
\hline & & . 22.5 & 54 & 856 & 786 \\
\hline \multirow[t]{6}{*}{5} & & 41.5 & 100 & 902 & 794 \\
\hline & & 22.5 & 100 & 809 & 750 \\
\hline & & 22.5 & 90 & 815 & 756. \\
\hline & & 22.5 & 75 & 828 & 76.7 \\
\hline & & 22.5 & 60 & 847 & 784 \\
\hline & & 22.5 & 54 & 857 & 794 \\
\hline \multirow[t]{6}{*}{6} & & 41.5 & 100 & 881 & 786 \\
\hline & & 22.5 & 100 & 798 & 747 \\
\hline & & 22.5 & 90 & 804 & 752 \\
\hline & & 22.5 & 75 & 816 & 762 \\
\hline & & 22.5 & 60 & 833 & 778 \\
\hline & & 22.5 & 54 & 843 & 787 \\
\hline
\end{tabular}

Throughout Runs 25 through 29, many constant- $\triangle \mathrm{T}$ experiments were conducted. Although the measurements made during Runs 25 and 26 were sufficient for an evaluation of the fuel-expansion component of the power coefficient, additional periodic measurements were made in an attempt to demonstrate the relative constancy of the fuel-expansion component. The results of constant $-\Delta T$ experiments are summarized and discussed separately by Long. ${ }^{17,25}$.

\section{G. Flow-coefficient Measurements}

By holding power constant and reducing the flow, the temperature differential across the opposite flats of a given subassembly increases. The reactivity change associated with a flow decrease consists of two major components. One, associated with fuel-expansion effects, is linear 
and negative. The other, associated with subassembly bowing phenomena, is nonlinear and consists of competing positive and negative components.

TABLE XX. Reactivity Changes under Constant-power and Reduced-flow Conditions*

\begin{tabular}{rcc}
\hline & \multicolumn{2}{c}{$\begin{array}{c}\text { Change in Reactivity } \\
\text { from } 100 \%\end{array}$} \\
\cline { 2 - 3 } \% Flow & Run 25 & Run 26A \\
\hline 100 & Reference & Reference \\
95 & - & 1.31 \\
90 & 2.7 & 3.2 \\
75 & 6.5 & 4.5 \\
60 & 4.3 & 4.1 \\
54 & 3.5 & 0.6 \\
\hline
\end{tabular}

*Power is $22.5 \mathrm{MWL}$.

and the negative effects predominate. reduced-flow effects is given by Long. ${ }^{17,25}$

H. The Effects of Core Size and Composition on Power Coefficient

Soon after the discovery of the weakened power coefficient, attention was directed to the effects of core size and composition on the power coefficient. Because Run 25 was characterized by a large core outline and a larger number of experimental subassemblies than in preceding runs, a tendency existed to attribute part of the decrease in power coefficient to dilution of the core and increasing of its size. In fact, an indication that the power coefficient was indeed affected by core size and composition was clearly indicated by a review of previous power-coefficient and coresize data. As an illustration, 0-45-MWt PRD values for 14 runs between Runs 3 and 24 are plotted as a function of core size in Fig. 42. All of the data points have been corrected for the effects of control-rod expansion. In defining core size, all subassemblies either fully or partially loaded with either Mark-I or Mark-IA fuel are included in the core. All 14 control and safety rods and all experiments within the first six rows are also included.

Figure 42 shows a trend towards lower PRD values as the core size increased. It also shows that the trend was not chronological. On several occasions between Runs 3 and 24, the core size was decreased, with the result that the associated PRD value increased. From this observation, it was difficult to escape the conclusions that the PRD did indeed decrease as core size increased and that no historical trend toward lower PRD values existed. 


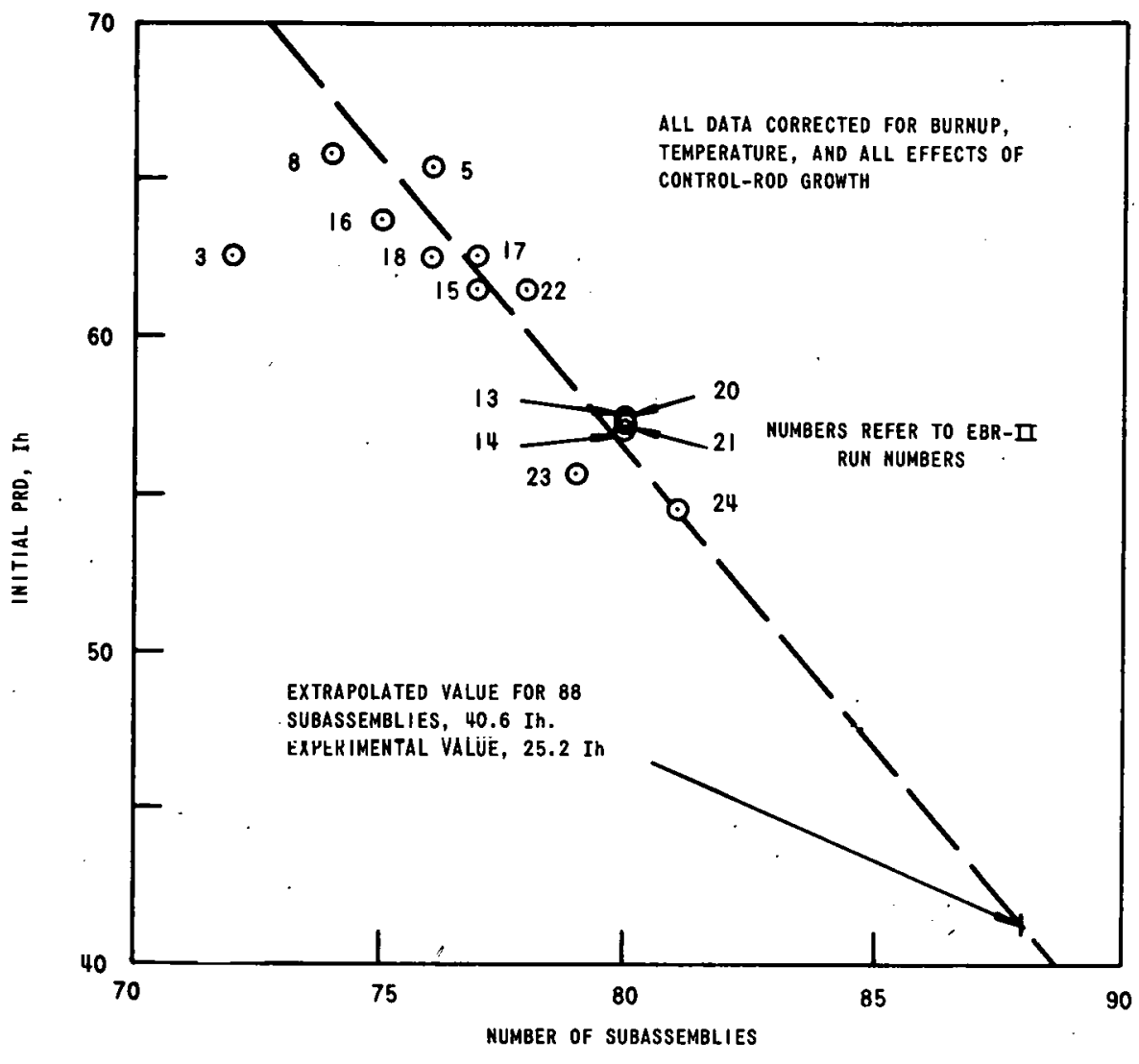

ID $-103-\mathrm{K}-5810$ Rev. 1

Fig. 42. Effect of Size of Hypothetical EBR-Il Core on PRD

On the other hand, the fact that other changes in core size and configuration were implemented during Runs 15 through 25 complicates any simple interpretation. For example, the number of experimental irradiation subassemblies varied considerably. Subassemblies containing stainless steel upper and lower reflectors were gradually introduced, primarily in Runs 18-20, and the changeover from Mark-I to Mark-IA fuel took place largely between Runs 15 and 19. Nevertheless, an inspection of the data in Fig. 42 reveals that the trend of earlier runs is approximately consistent with that of later runs, indicating that the changes in fuel and reflector materials had little effect on the power coefficient.

A best-fit straight line drawn through the various data points leads to a value of -1.7 Ih per subassembly added at the edge of the core. It follows that if the trend continued up to and including Run 24, a simple extrapolation of the data would indicate a PRD (without control-rod expansion) of approximately $41 \mathrm{Ih}$. The difference between this value and the corresponding value for Run 24 (55 Ih) is $14 \mathrm{Ih}$, approximately one-half of the decrease noted at the beginning of Run 25 .

Encouraged by what appeared to be a partial explanation for the decrease in the power coefficient, substantial effort was devoted to computing 
the power coefficient for various core sizes and configurations. Since the results of these computations have been given in detail by Madell ${ }^{20}$ and Blomberg, ${ }^{18,19}$ only the significance of their conclusions will be cited. Essentially, both investigators, each of whom used an independent approach, found that the changes implemented between Runs 24 and 25 could not account for the change noted in the power coefficient. Accordingly, it was concluded that the historical trend towards lower PRD values could not be attributed to compositional and configurational changes.

Attention was directed in Section VII.C to a trend in the opposite direction during Runs 27, 28, and 29. The significance of the earlier trend, in Runs 3-24, and that noted in Runs 27-29 will be discussed in Section IX.

\section{Rod-drop Studies}

As discussed in Section III, the failure of the Mark-IIA oscillator rod during the later portion of Run 24 in December 1966 and the inability to fabricate a replacement during Run 25 prevented definitive analyses of the reactivity feedback in the frequency domain. As a consequence, the stability-monitoring program throughout Run 25 was based primarily on measurements of the static power coefficient.

Although all available evidence indicated that the reduction in the overall power coefficient was the result of changes in delayed feedback components; no information existed which could be used as conclusive evidence that prompt feedback effects had not changed and were not undergoing change. Accordingly, interest intensified in developing a method that could be used to detect changes in the prompt power-coefficient component.

The method considered most promising was that based on a timebased evaluation of the feedback recovery following the steep-ramp removal of reactivity. As indicated in Section II, such a method was undergoing development before the Run- 25 power-coefficient difficulties became apparent.

Basically the method involved removing approximately 12 Ih of reactivity over a total time interval of approximately 280 milliseconds by scramming a standard control rod filled with stainless steel rods. The power output before, during, and for approximately two minutes after the drop was then transcribed into digital form with a NAVCOR analog-todigital converter, which fed directly to an IBM-1620 digital computer. The NAVCOR unit is equipped to handle from one to six channels of analog input, all of which can be digitalized under the control of the computer and an external clock signal. After one to six channels of data are fed to the computer, the converter is disconnected, and the program is turned over for computational use. On completion of the computational cycle, the clock reconnects. the converter to the computer. 
In addition to converting the signal from the ion chamber, the NAVCOR also converts into digital form a rod-position signal actuated by a potentiometer mounted on the drop rod and an initiating signal associated with the actual dropping of the rod. The actual rod drop occurs at a predetermined time after the initiation signal, usually one second. The initiation signal is inter rogated by the computer at each timing interval (from the clock) to determine its polarity. If the signal is negative, data are discarded. At the receipt of the first positive signal, the rod-position and ion-chamber signals are stored for each timing interval until the preselected number of points have been stored in the computer. The computer then transfers the stored data to magnetic tape for future reduction with a CDC-1604 computer. Essentially, the data consist of rod position and power level as a function of time.

The next step consists of an evaluation of the reactivity in the system as a function of time, using the inverse kinetics expressions and the period-calibrated worth of the drop rod, the latter as a measure of the reactivity removal. While later experience indicated the fallibility of this approach, the results during Run 25 were nevertheless useful in demonstrating the relative constancy of the prompt-power coefficient component.

Typical illustrations of rod-drop data taken during Run 25 are given in Figs. 43-48. A power trace taken under 22.5-MW full-flow conditions on May 17 is shown in Fig. 43. To illustrate the shape of the power trace at a longer wait time, the trace is displayed on two scales, one (B) from 0 to 22 seconds and the other (A) from 0 to 110 seconds. A similar expansion in the arbitrary power scale may be noted. Apparent from the data given in Fig. 43 is the existence of a high-frequency oscillation (about $10 \mathrm{cps}$ ), which is superimposed on the power trace. Such oscillations have long been observed and are believed to be the result of a coherency in the flutter of individual subassemblies as clearance systems become increasingly ordered. ${ }^{42}$

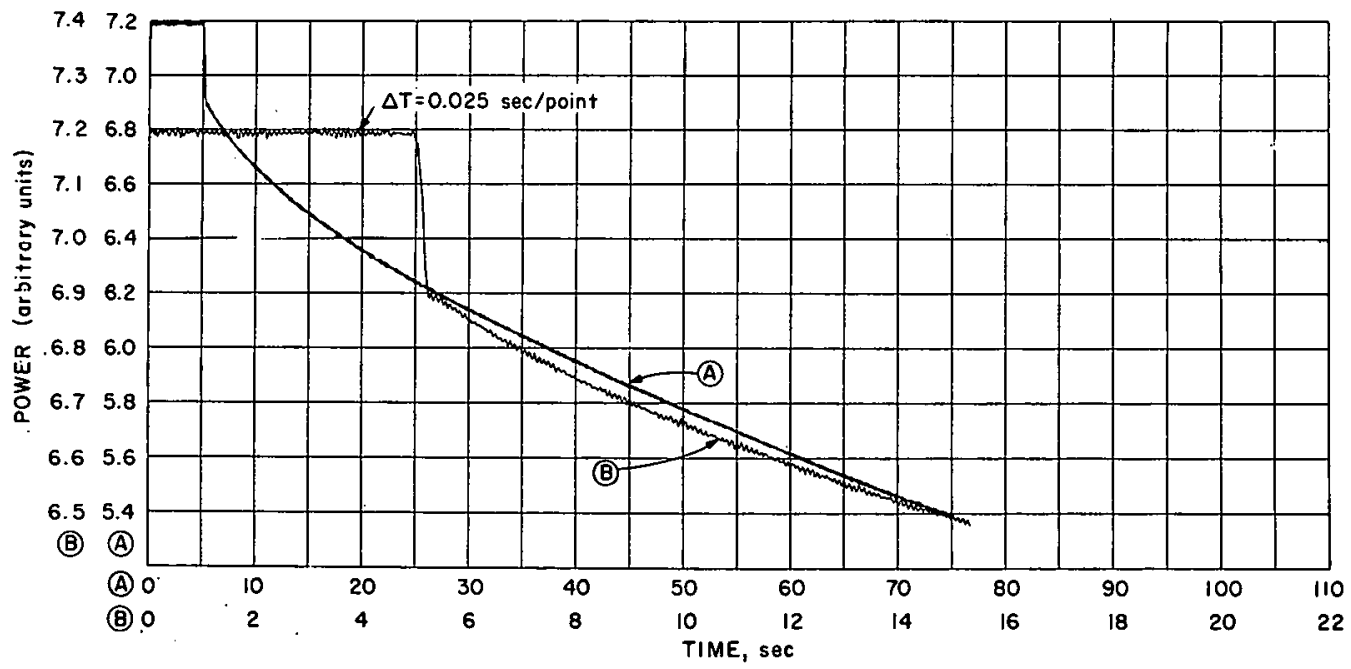

ID $-103-\mathrm{K}-5811$ Rev. 1

Fig. 43. Power Trace Following Rod Drop on May 17, 1967; 22.5-MWt Full-flow Conditions 
The results of time-dependent reactivity calculations are illustrated for various conditions of power and flow in Fig. 44. Immediately after the drop, the reactivity recovers rapidly for a period of approximately one second and then more slowly as the influence of more-delayed feedback effects predominates. Such behavior confirms that the prompt feedback (i.e.; that associated with fuel-expansion effects) is strongly negative. The influence of positive effects would be reflected either by a flattening of the reactivitytime trace or by an actual reversal of slope. For example, while the feedback recovery appears to increase with time for $41.5 \mathrm{MWt}, 100 \%$ power and flow, a decrease may be noted in the data for $22.5 \mathrm{MWt}, 100 \%$ power and flow. Such behavior confirms that at $22.5 \mathrm{MWt}$ and $75 \%$ flow, delayed positive power-coefficient components are either partially cancelling delayed negative components or that the magnitudes of delayed negative components are being weakened. Both of these possibilities are consistent with versions of the inverse bowing model.

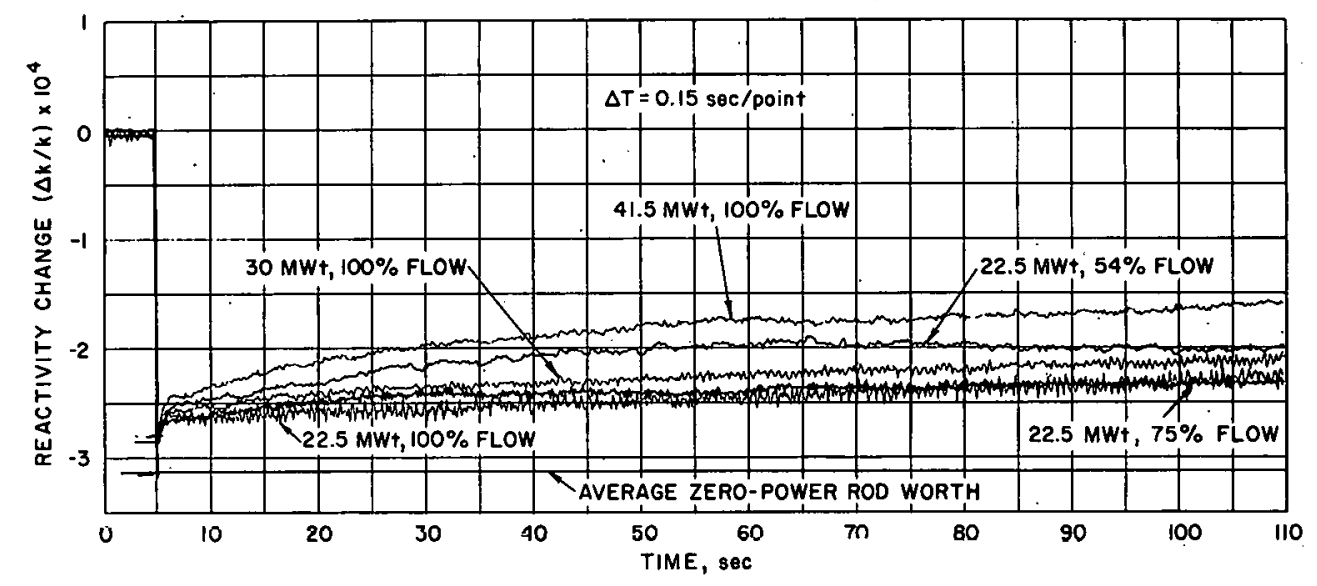

ID-103-K-5812 Rev. 1

Fig. 44. Reactivity Recovery under Various Conditions of Power and Flow; May 17, 1967

The results of a similar treatment of rod-drop data taken under $500-\mathrm{kWt}$ (zeropower) conditions are given in Fig. 45. (The two traces shown in the figure were actually the same, but have been intentionally offset for display.) Since feedback effects at this level of power are essentially nonexistent, the reactivity-time trace after the drop is described by a straight line with zero slope. The zero-time intercept with the reactivity axis defines the reactivity worth of the drop rod. The fact that no reactivity recovery is indicated confirms the adequacy of the delayed neutron parameters used in the inverse kinetics program.

The reactivity-recovery data may be presented in a different form by subtracting the zero-power reactivity data in Fig. 45 from those in Fig. 44. The result gives the reactivity fed back to the system as a function of time. Such results are illustrated in Fig. 46. The "spike" in the reactivity-recovery curve at the time of drop is the result of an inability (at the time) to synchronize the drop times for the various runs. 


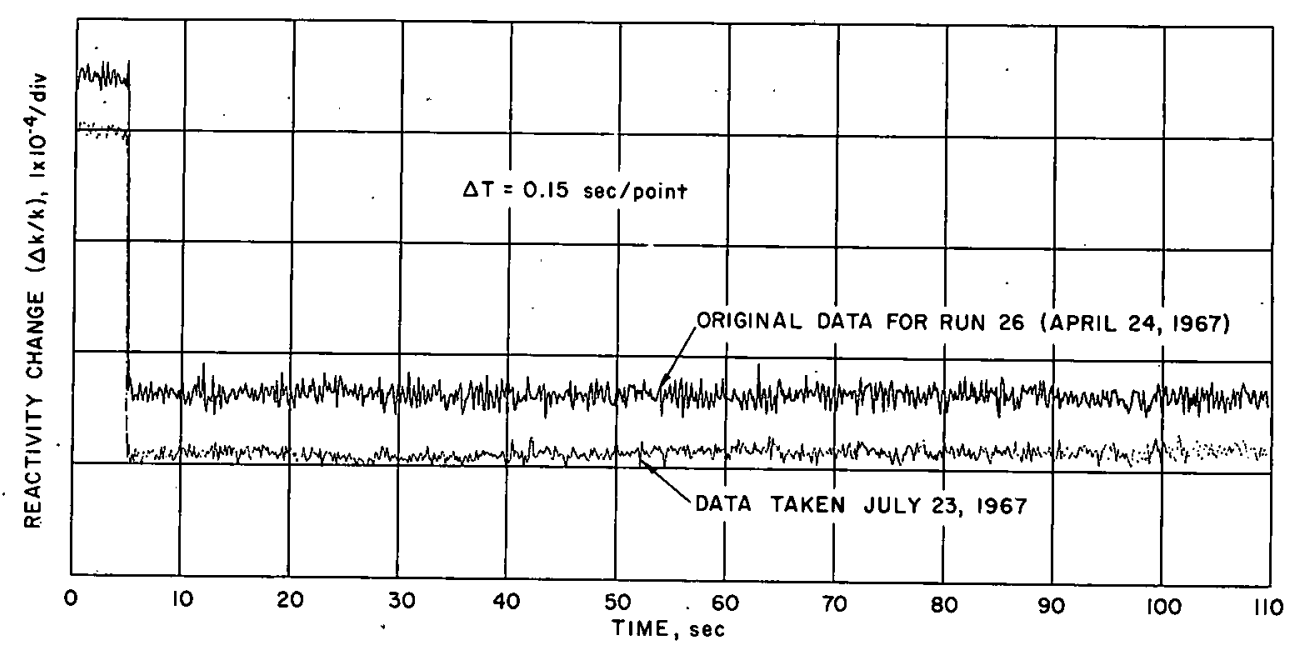

ID-103-K-5813 Rev. 1

Fig. 45. Reactivity Recovery at 500-kW Power

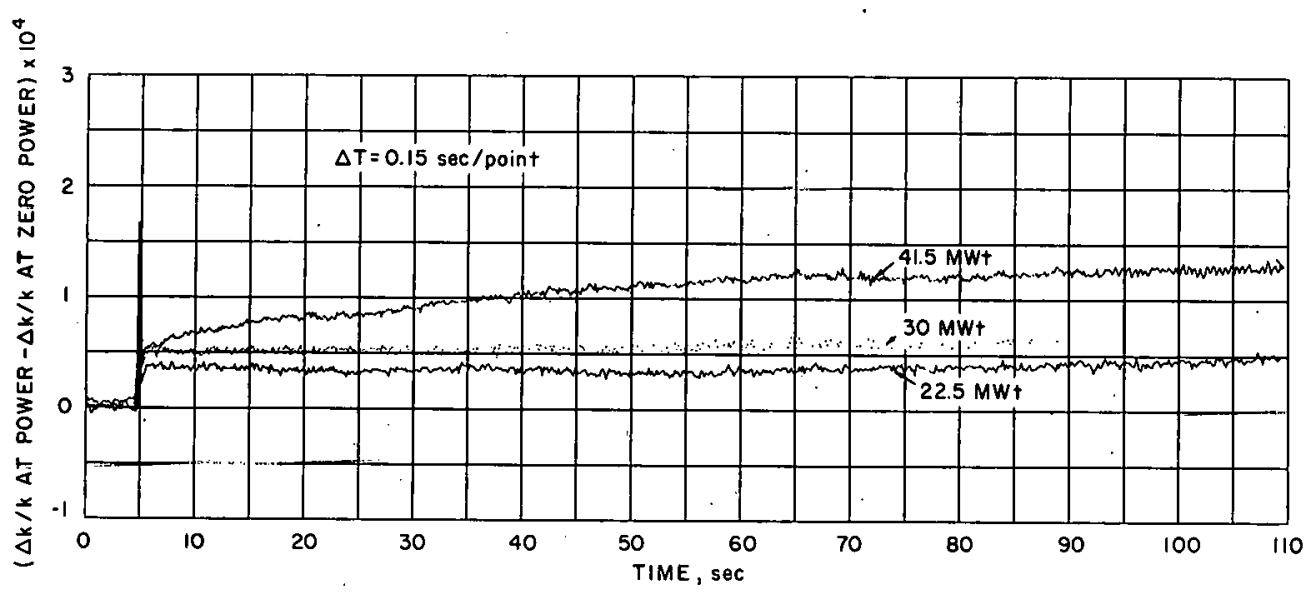

DD-103-K -5814 Rev. 1

Fig. 46. Reactivity Feedback to System as a Function of Time; Full-flow Conditions

Similar data for operation under a variety of power and flow conditions are illustrated in Figs. 47 and 48. Again, evidence of a strong competition between delayed positive and negative power coefficient components may be found in the lower-power data (20-22.5 MWt).

As discussed on pg. 88, primary interest was focused on the prompt reactivity feedback component; any deterioration of that component would have serious safety implications. Fortunately, the rod-drop technique, while not fully perfected in Run 25, was sufficiently developed to permit periodic measurements of the magnitude of the prompt component, using the percentage reactivity recovery at a fixed time (usually one second) as a figure of merit. Comparisons of feedback data taken near the beginning and the end of Run 25 are given for 30 and $41.5 \mathrm{MWt}$ in Figs. 49 and 50, respectively. While not immediately apparent because of the compressed time scale, little perceptible change was noted in the prompt feedback during Run 25. At wait times longer than 10 seconds, significant differences 
may be noted. Such changes were, however, identified with differences in the positions at which the control rods were banked during the run, as described in Section III.F.

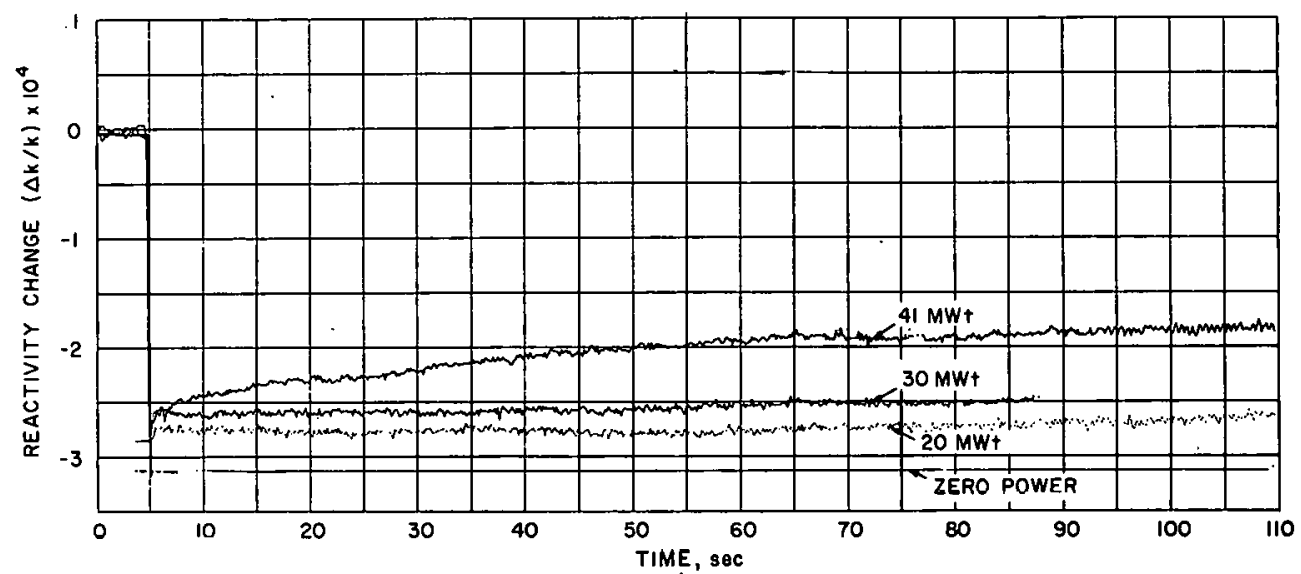

ID-103-K-5815 Rev. 1

Fïg. 47. Reactivity Recovery undor Full-flow Conditions: July 23, 1967

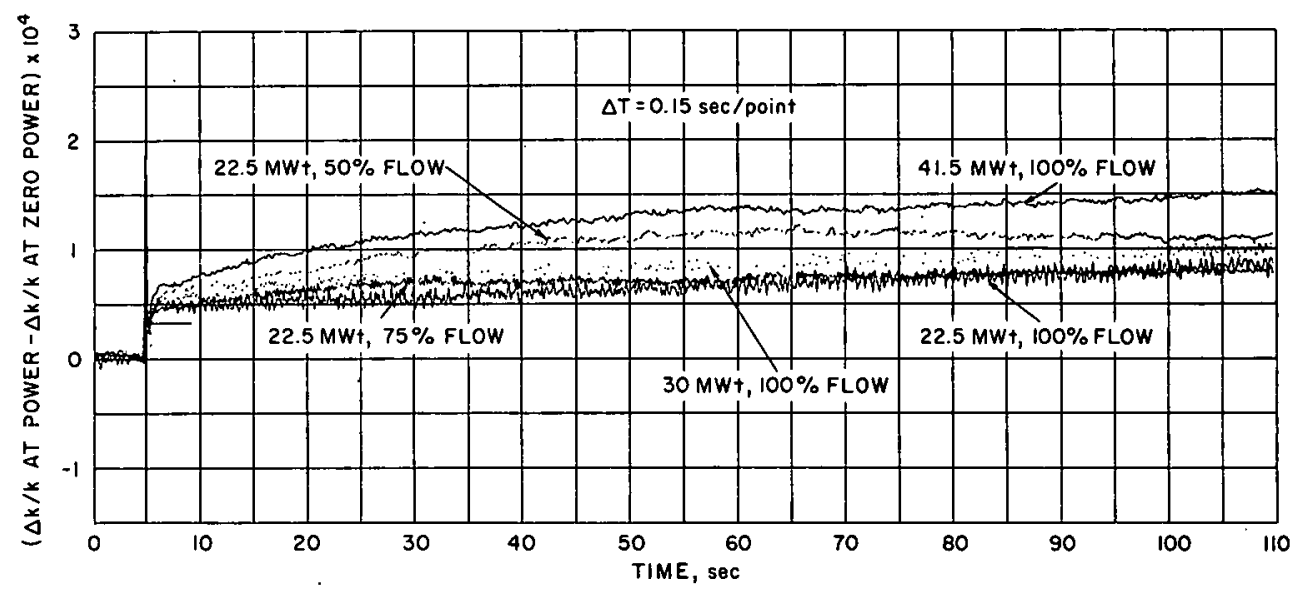

ID-103-K-5816 Rev. 1

Fig. 48. Reactivity Feedback to System as a Function of Time; Various Conditions of Power and Flow

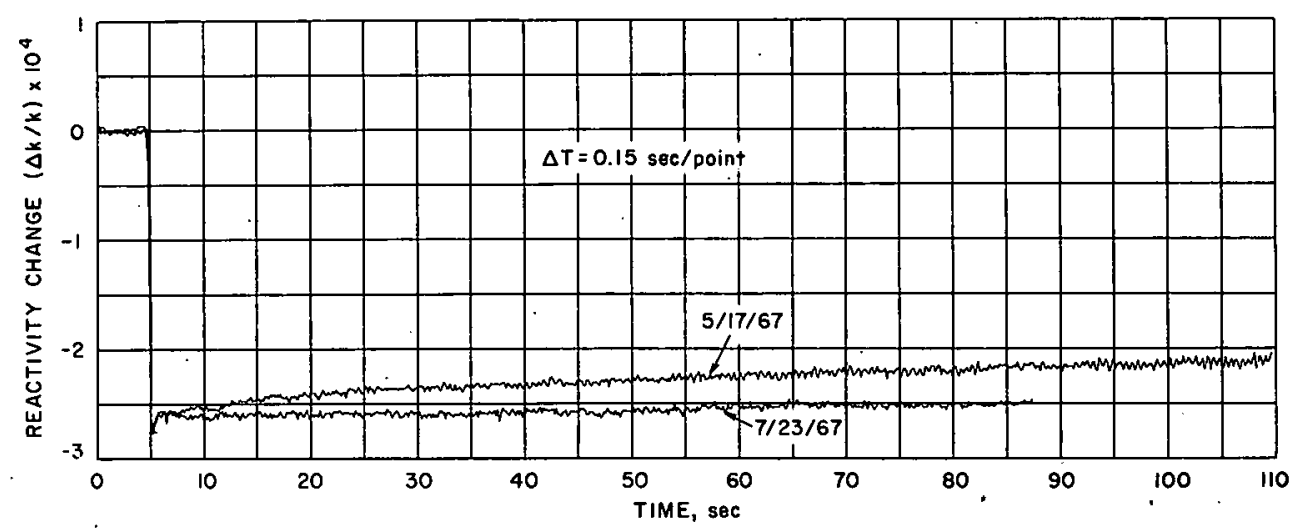

ID-103-K-5817 Rev. 1

Fig. 49. Comparison of Reactivity Recoveries Measured at $30 \mathrm{MWt}$ and $100 \%$ Flow on May 17 and July 23, 1967 


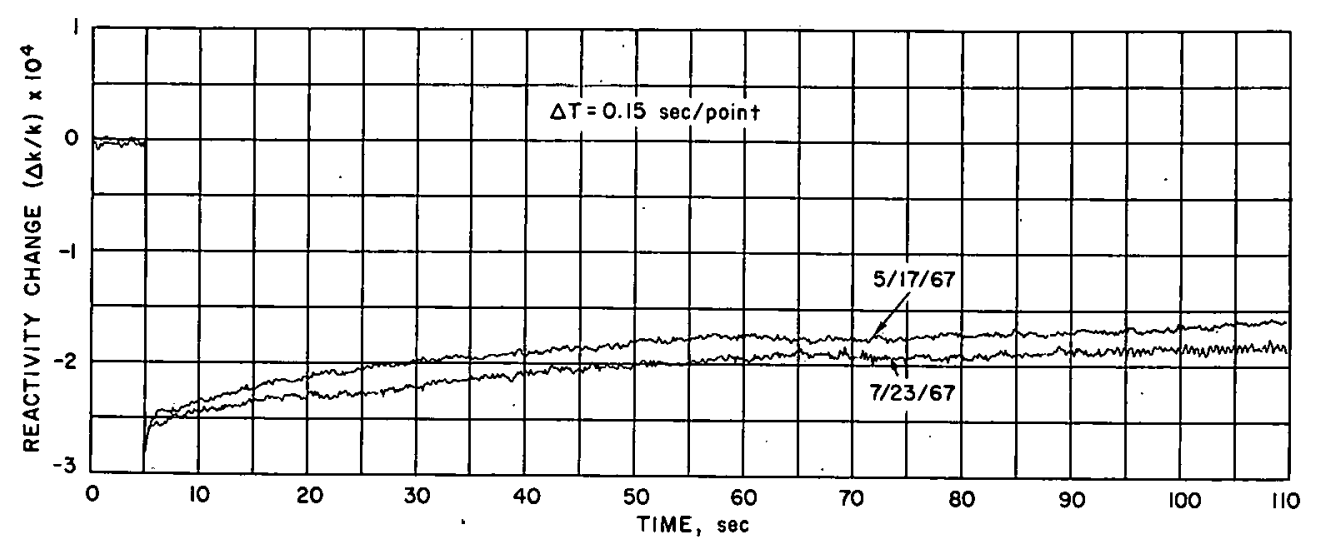

ID-103-K-5818 Rev. 1

Fig. 50. Comparison of Reactivity Recoveries Measured at 41.5 MWt and 100\% Flow on May 17 and July 23, 1967

Although information provided by the rod-drop method during Run 25 was limited to a more or less qualitative application, efforts made near the end of Run 25 to improve the reliability of the method were sufficiently successful to permit the information to be used in a quantitative manner. A comprehensive description of the apparatus, a discussion of methodology, limitations of the method, and the results obtained during Runs 25 and 26 have been previously given by Hyndman and Nichols on. ${ }^{28}$ In addition, a complete summary of all rod-drop data taken during Runs 25-29 has been published in catalog form by Engen and Hyndman. ${ }^{29}$

For convenience, three typical sets of rod-drop data taken during Run 26B (during which the oscillator rod was operational) are given in Figs. 51 through 53 . In all cases, the reactivity recovery during the

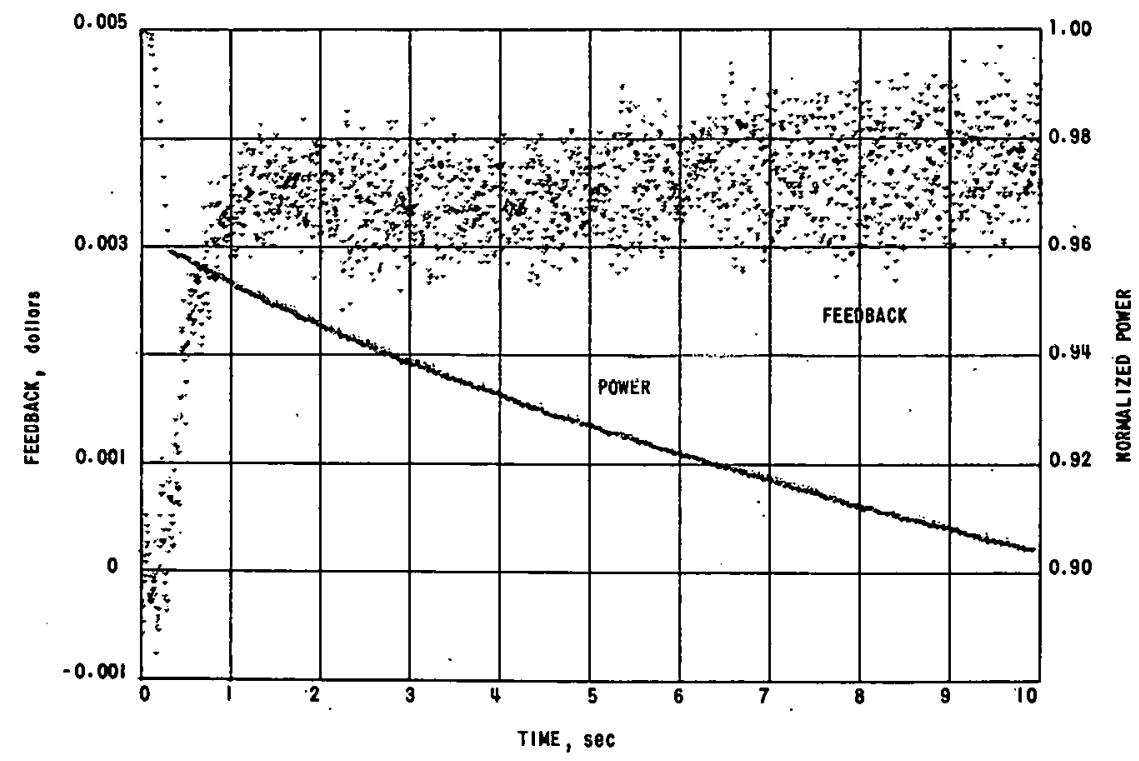

ID $-103-\mathrm{K}-5120$ Rev. 1

Fig. 51. Results of Rod-drop Experiments at 22.5 MWt during Run 26A 


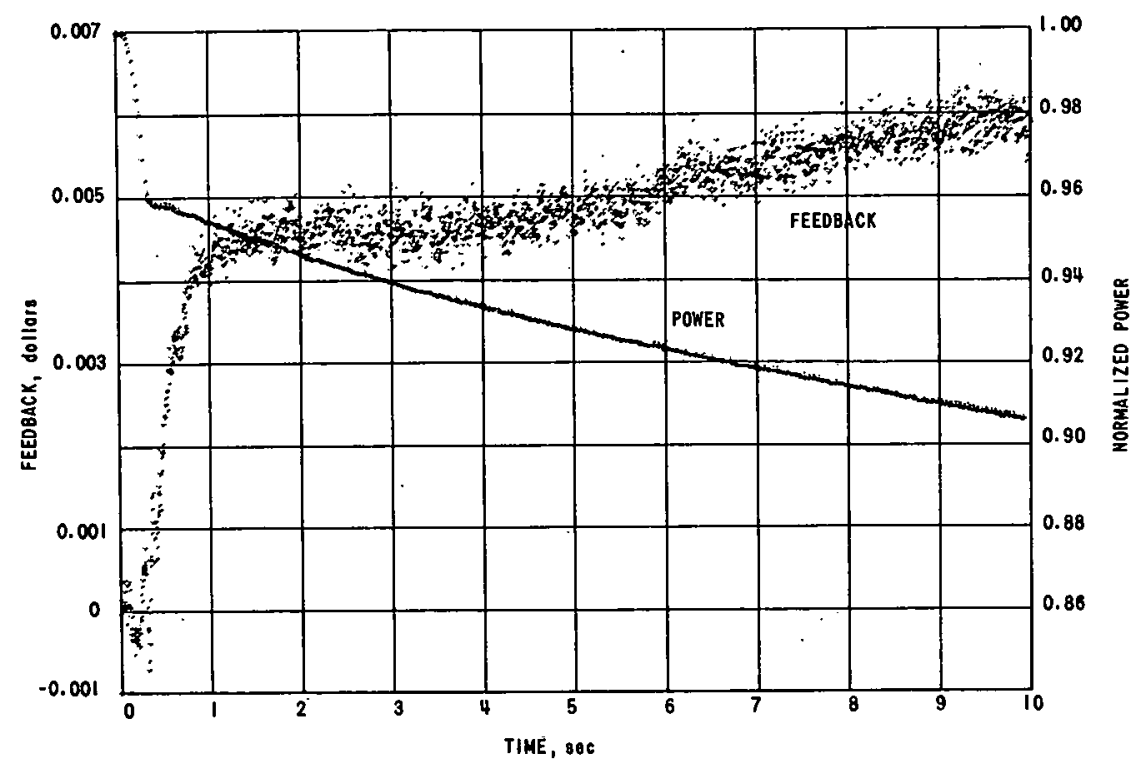

ID-103-K-5121 Rev. 1

Fig. 52. Results of Rod-drop Experiments al $30.0 \mathrm{NWt}$ during P.un $26 \mathrm{R}$

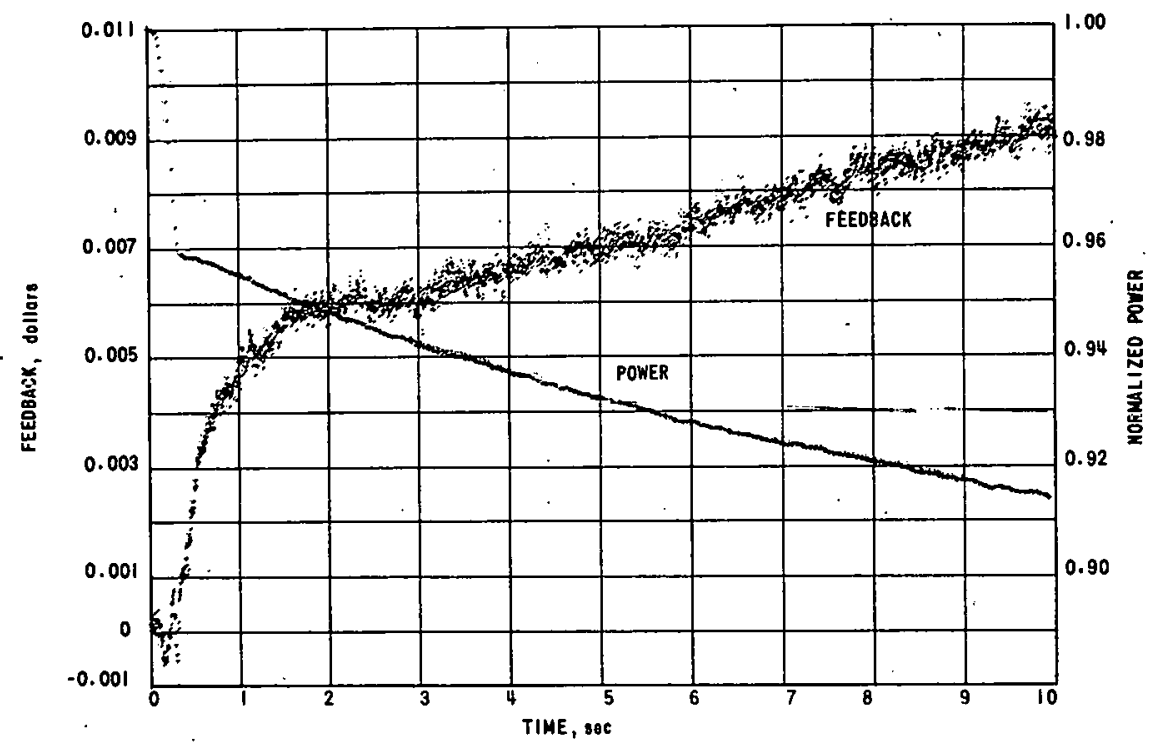

ID $-103-\mathrm{K}-5122 \mathrm{Kev} .1$

Fig. 53. Results of Rod-drop Experiments at 41.4 MWt during Run 26B

first second after the drop is prompt, strongly negative, and dictated almost entirely by density changes in the fuel material. Corresponding transfer-function data for similar conditions are given in Section VIII.J. The interpretation of both rod-drop and transfer-function data in terms of a mathematical model is discussed in Section VIII. M, and the significance of the model is discussed in Section IX. 


\section{J. Transfer-function Measurements}

The failure of the original rotary-type oscillator rod at the end of Run 24 and the long lead time necessary for a replacement prevented measurements of the transfer function during Run 25. In September 1967 a replacement was made available. Although Run 25 had been terminated earlier, precautions had been taken to preserve the Run- 25 configurations and composition. Essentially the only differences between the loadings for Runs 25 and 26 were the replacement of spent driver fuel and the removal of experimental subassembly XOll. Because the core had been disturbed as little as possible, we assumed that transfer-function and rod-drop information obtained for the Run-26 configuration would be typical of that for Run 25.

Since the completion of previous transfer-function measurements in December 1966 (Run 24), important changes had been made in the method of data reduction. In the earlier method, the amplitude and phase of the transfer function were deduced from two Fourier integrals that were evaluated from an integration of analog signals. ${ }^{31}$ The inability to eliminate small gain changes in the existing amplifiers prompted the development of a more powerful, more reliable, and faster on line digital method. Since a detailed discussion of the digital equipment is given elsewhere, ${ }^{26,27}$ only general features will be discussed here.

The oscillator rod installed before the startup of Rin $26 \mathrm{~B}$ consisted essentially of a $\mathrm{B}_{4}{ }^{10} \mathrm{C}$-loadcd tube, which, through rotary motion, periodically moved $\mathrm{B}_{4}{ }^{10} \mathrm{C}$ toward and away from the center of the reactor. An identical tube filled with $\mathrm{Al}_{2} \mathrm{O}_{3}$ was used as a counterweight to reduce vibrational effects at higher frequencies. The rod, mounted in a special thimble, replaced a standard control rod and guide thimble.

A synchronous motor coupled through a variable-speed gear box was used to drive the rod over a frequency range variable from 0.001 to approximately $10 \mathrm{rps}$. A tendency toward resonant vibration at $9 \mathrm{rps}$ in effect limited the operation of the rod to $8.8 \mathrm{rps}$.

The on line Fourier analysis is based on three signals. One is the amplified alternating component of the flux, and the other two are received from sine and cosine potentiometers mounted on the shaft of the variablespeed driver unit. All three signals are transmitted to a station approximately $300 \mathrm{ft}$ from the reactor building where the signals are conditioned, amplified, and transmitted an additional $300 \mathrm{ft}$ to the computer room. Here the signals are converted to digital form and Fourier-analyzed by an IBM-1620 computer that has been programmed to resolve the phases and amplitudes of the transfer function and of the feedback function. The reliability and accuracy of the technique has been assessed by comparing 
experimental values of the zero-power transfer function with values calculated from the delayed neutron parameters. The results of the assessment indicate an accuracy of $\pm 0.25 \%$ in amplitude and $\pm 0.23^{\circ}$ in phase (at zero power).

Unfortunately, bowing problems that plagued the use of the previous rotary oscillator rod in Run 24 were not entirely eliminated. At the lower speeds and at higher levels of power, bowing effects cause the rod to rub against the thimble. (A discussion of bowing phenomena and their effects on the accuracy of the transfer-function information has been given by Hyndman and Nicholson. ${ }^{28}$ ) Despite such limitations, enough information resulted from the studies to permit the formulation of a physical and mathematical feedback model that has been found to be acceptably consistent with the results of rod-drop measurements and other experimentally observed phenomena. The resulting feedback functions for $22.5-, 30$, and 41.4-MWt operating conditions are given in Figs. 54 through 56, respectively.

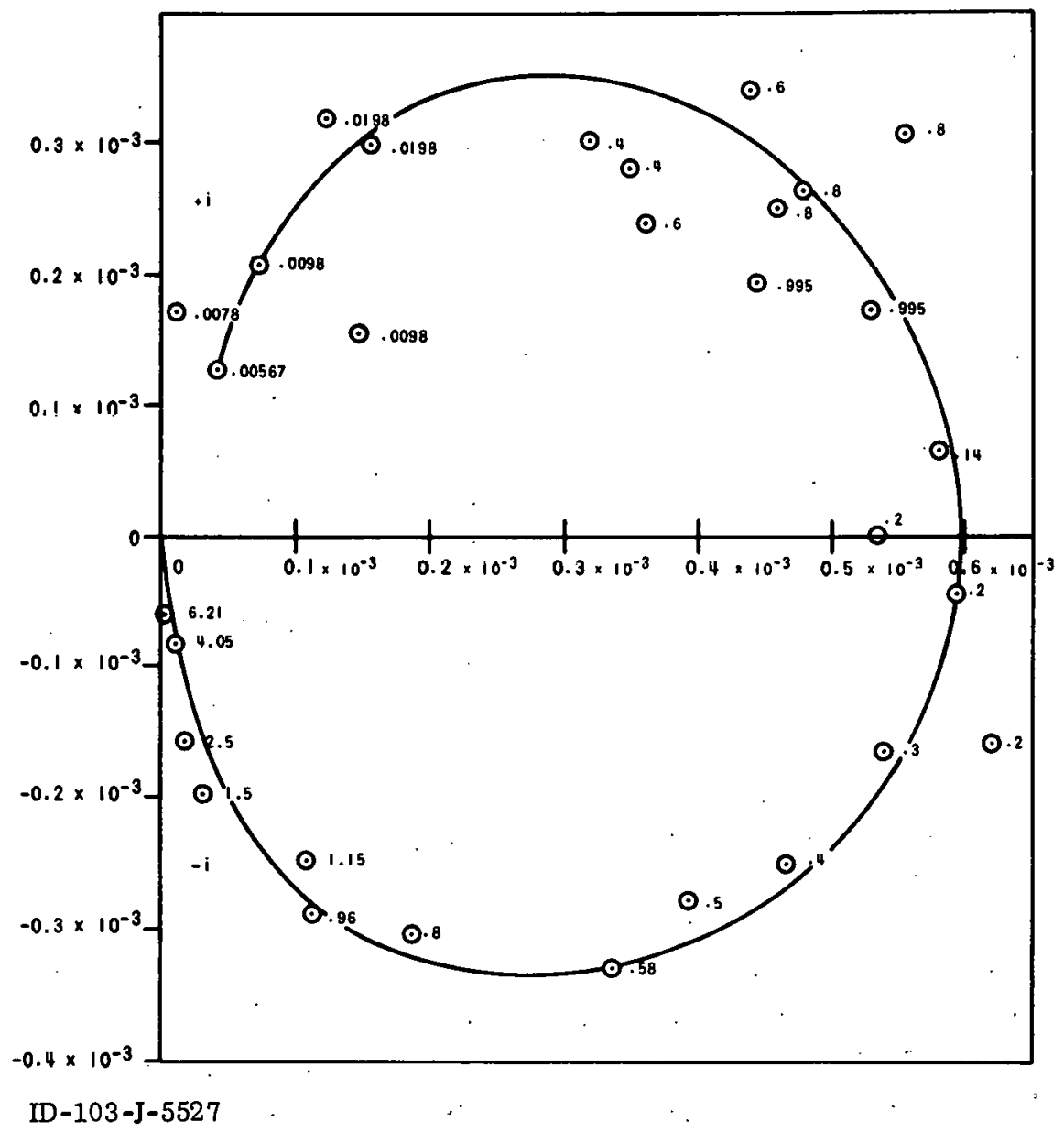

Fig. 54. Feedback as Determined from Oscillator-rod Data Obtained at $22.5 \mathrm{MWt}$ on October 23, 1967, during Run 26B; Rod-bank Position, 11.5 in. 


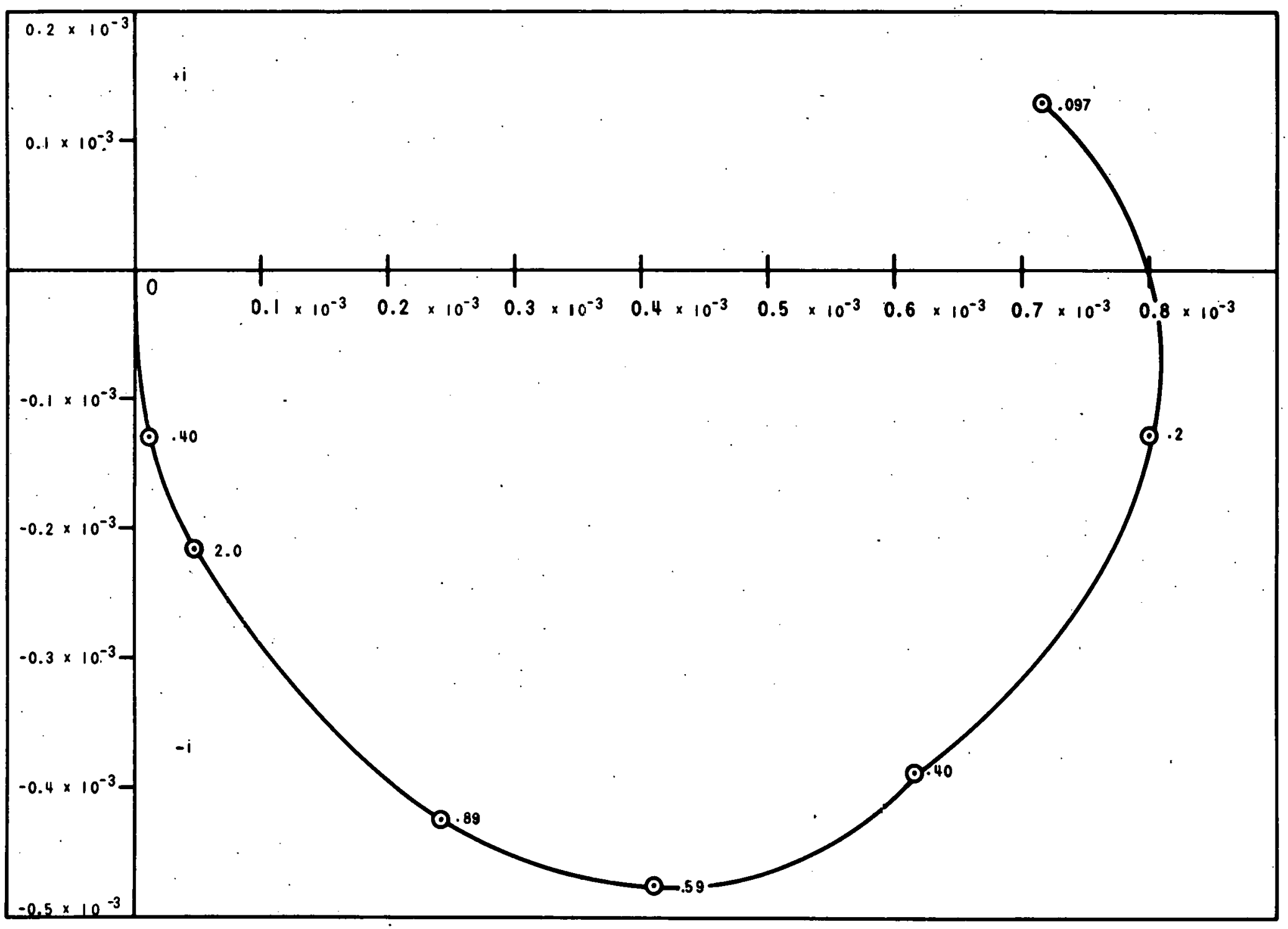

DD $-103-\mathrm{J}-5525$

Fig. 55. Feedback as Determined from Oscillator-rod Data Obtained at 30 MUt on October 18, 1967, during Run 26B; Rod-bank Position, 11.0 in.

$\stackrel{0}{2}$ 
$\infty$

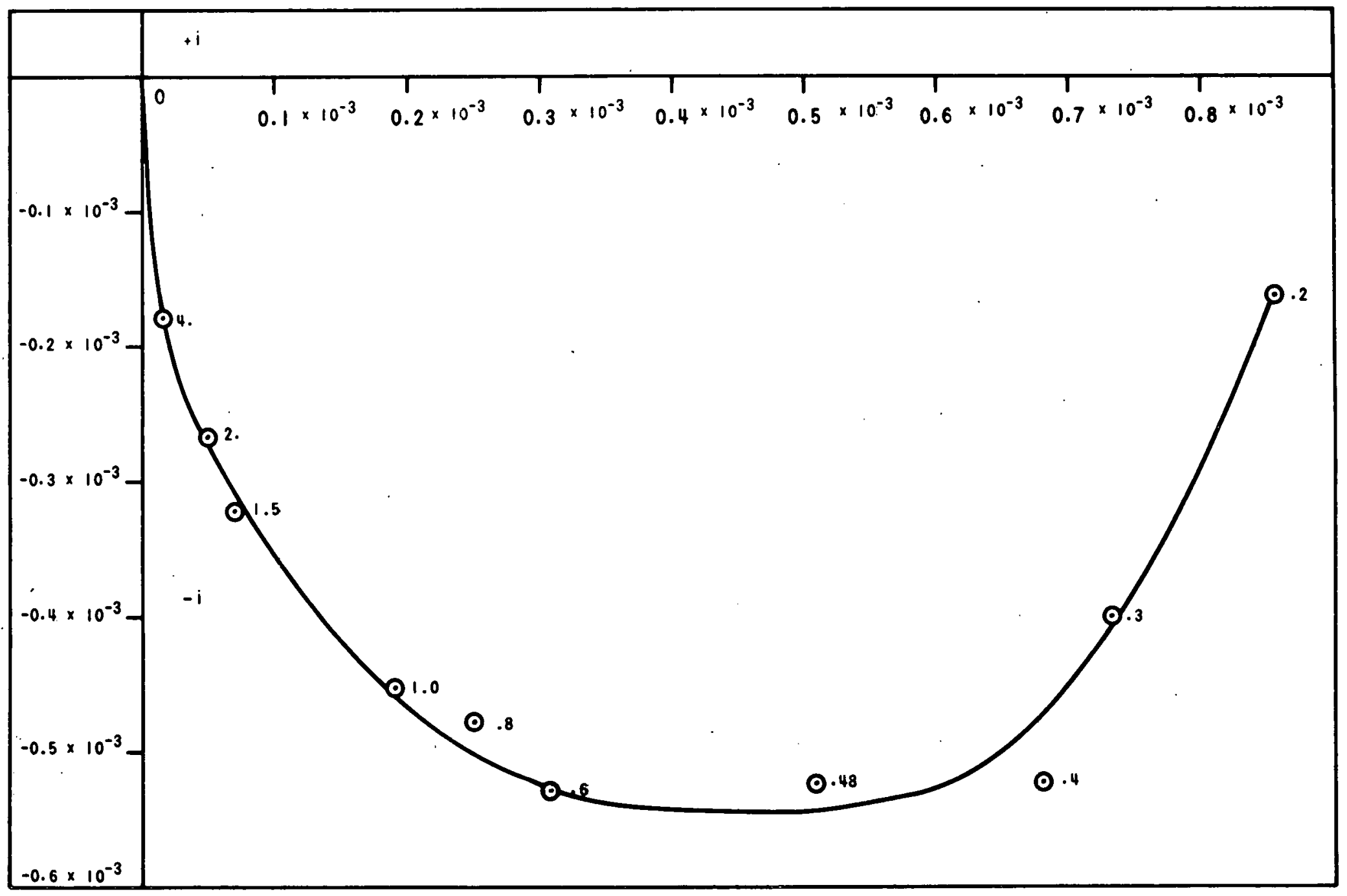

$$
\text { ID }-103-\mathrm{J}-5526
$$

Fig. 56. Feedback as Determined from Oscillator-rod Data Obtained at 41.5 MW on October 18, 1967, during Run 26B; Rod-bank Position, 11.0 in. 
K. Trapezoidal Reactivity-insertion Technique

During the earlier portions of Run 25, the capability of the rod-drop method to yield useful kinetics information had not been established. Accordingly, parallel efforts were devoted to studies of other techniques that indicated reasonable promise. One such technique involved the excitation of the system by the alternate in and out movement of a control rod over a fixed distance of approximately 0.2 in. in the linear region of the reactivityworth-position curve. A simple understanding of the mechanics of the method may be obtained from a consideration of Fig. 57, which illustrates the time behavior of the power and reactivity changes.

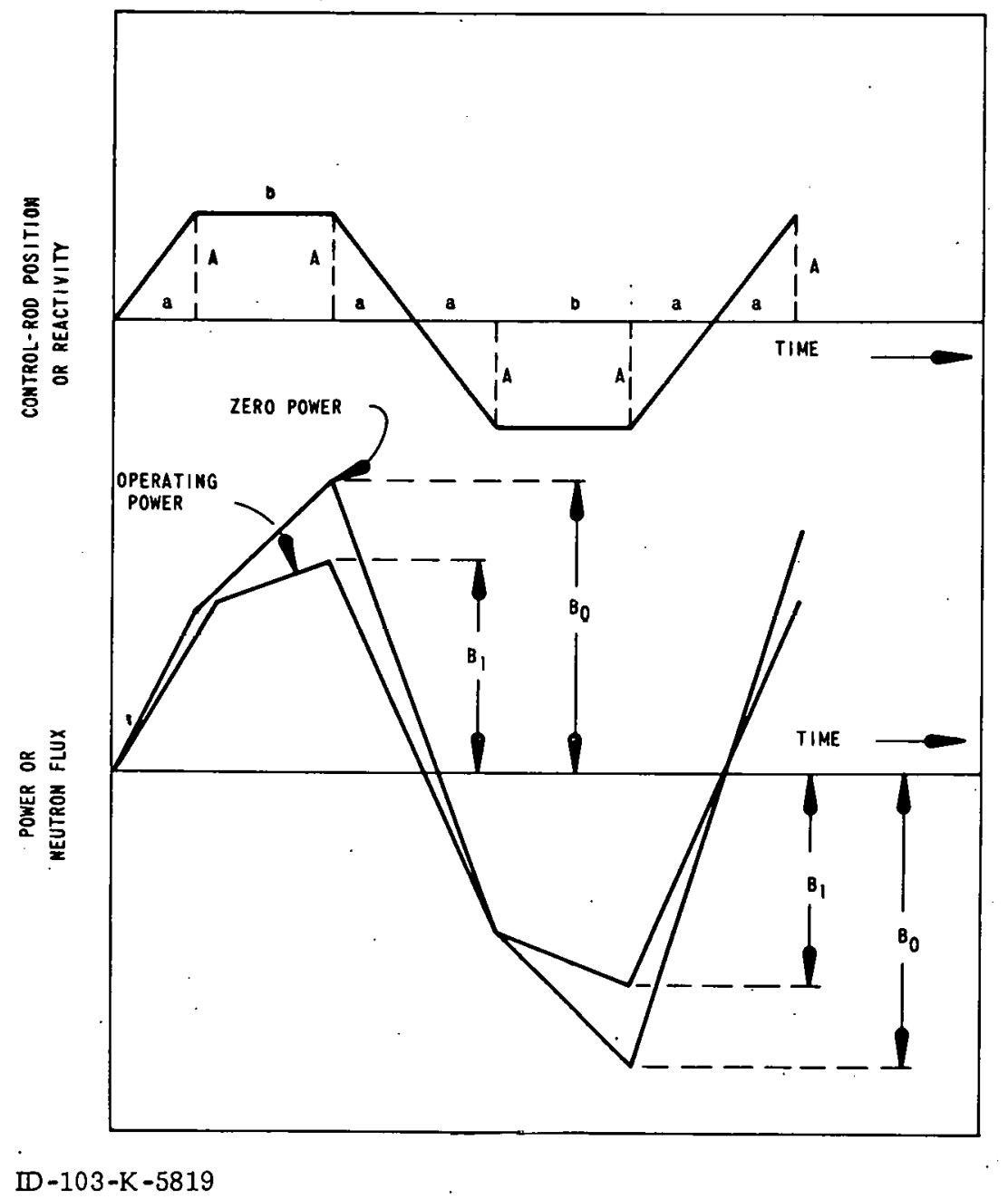

Fig. 57. Response of Power to Trapezoidal Reactivity Change

The control rod is programmed to move in such a way that reactivity $A$ is either inserted or withdrawn over a fixed distance corresponding to the insertion time a. At the end of time interval a, the insertion stops and the power is allowed to rise for a period of time $b$. At the end of time interval $b$, the rod is withdrawn for a period of time $2 \mathrm{a}$, after which the 
power is allowed to decrease for another time interval b. Two parameters are constant. The total distance through which a control rod moves is fixed, and assuming an invariant drive speed, the total reactivity change $2 \mathrm{~A}$ and the driving time $2 \mathrm{a}$ are fixed. Two parameters vary. One, the power, is a continuous function of time, and the other, the wait time $b$, is varied parametrically between series of runs.

The physical interpretation of the power-time trace of Fig. 57 requires an understanding of delayed-neutron kinetics and the time-based effects of the various power-coefficient components. Consider the idealized (simplified) power-time trace of Fig. 57 for the zero-power condition. During the initial insertion from mid-control-rod position, the power rises sharply. When the rod stops adding reactivity at the end of time interval a, the flux transient dies rapidly, and the power trace follows a course dictated by the stable reactor period. At the end of interval $b$, the control rod is moved out for a time interval $2 \mathrm{a}$. The power drops sharply during the withdrawal. At the end of the withdrawal and after negative transient effects have died, the power decreases at a slower rate. The reinsertion of reactivity over time interval a completes the cycle. Obviously, the parameter $\mathrm{B}_{0}$ (the half-amplitude of the power oscillation) depends strongly on the wait time $b$, since if $b$ is infinitely long, $B_{0}$ goes to infinity. It follows that $B_{0}$ approaches a minimum value as b approaches zero.

The effects of feedback on the time-dependent power trace are also illustrated in Fig. 57. In this particular illustration, two feedback components are considered, one essentially prompt and the other relatively delayed. This situation, in a general sense, characterizes the feedback of EBR-II.

The effects of the prompt feedback are immediately apparent from Fig. 57. The prompt feedback, acting along a shorter time base than the ramp addition, effectively cancels a portion of the input. Physically, this means that the power increase resulting from the ramp addition is manifested immediately through axial fuel expansion, which acts to reduce the magnitude of the reactivity insertion. The power increase proceeds, accordingly, along a somewhat decreased slope. At the end of time interval $a$, when the ramp addition stops, transients die out and the actual path traced by the power depends on a small additional axial fuel expansion, expansion of the coolant and structure, and the delayed-neutron kinetics.

The effects of the delayed neutrons tend to increase the power while the effects of feedback tend to decrease it. The result is a power trace significantly lower in amplitude than for the case in which feedback is absent (i.e., the zero-power situation). The extent of difference between the two traces reflects the effects of feedback. The more feedback, the greater the difference, and vice versa. (The effects of a prompt positive powercoefficient component would be reflected during the ramp input by a power trace having a slope steeper than that for zero power because the feedback essentially augments the ramp.) 
Measurements of the peak-to-peak amplitude for the two alternating components (i.e., for zero power and operating power) may be used as reference points for the feedback at any given time. Any significant change in the magnitude of the net power coefficient would be revealed by a subsequent set of similar measurements.

Alternately, another criterion of feedback change could be extracted from the same data. This extraction involves a machine evaluation of the geometric areas bounded by the respective zero-power and operating-power traces. Area evaluations of data taken during the ramp insertion and the wait time would indicate possible changes in the prompt and delayed powercoefficient components, respectively.

Although a moderate amount of effort was devoted to the development and actual testing of the method, little useful information was gained. In the first place, the relatively slow $r$ ate at which reactivity could be inserted or withdrawn placed severe limitations on information relevant to prompt feedback effects. In the second place, concern was expressed for the possibility of excessive wear on the rack-and-pinion control-rod drive system. Finally, the promise indicated by the results of parallel efforts with the rod-drop method discouraged the intcnsive effort needed for implementation.

L. Monitoring of Subassembly Outlet Temperatures

The outlet temperatures of some core and blanket subassemblies are measured with thermocouples located approximately 0.250 in. above the outlet portion of the upper adapter. The thermocouples are enclosed in stainless steel tubes that are fixed to the holddown fingers at their lower ends. Such an arrangement makes possible the replacement of a faulty thermocouple. Of a total of 25 thermocouples, 19 are located above subassemblies occupying positions within Rows 1-6. The other six are located above blanket subassemblies in positions $16 \mathrm{E} 9,12 \mathrm{E} 6,9 \mathrm{E} 4,7 \mathrm{~A} 3,7 \mathrm{D} 4$, and $7 \mathrm{~F} 4$.

Figure 58 illustrates the location of core thermocouples (by dots) and the orientation of individual thermocouples with respect to the upper adapters. Four of the core thermocouples, those located above subassemblies in positions $5 \mathrm{~A} 4,4 \mathrm{Fl} ; 3 \mathrm{El}$, and $4 \mathrm{El}$, are connected with the scram system. Any temperature variance sensed by any one of these thermocouples that exceeds $10 \%$ of the normal temperature differential across the subassembly will result in an automatic scram. The outputs of all four scram thermocouples are fed continuously to a 50-point scanner that permits an on-demand reading at any time.

The outputs of the other 21 core and blanket thermocouples are fed to a Beckman automatic data logger, which scans and prints out actual subassembly outlet temperatures every 30 minutes. In the event of an indicated temperature reading of $10^{\circ} \mathrm{F}$ above the normal, an audible alarm is sounded and the indicated reading is printed out in red ink on an electric typewriter. 


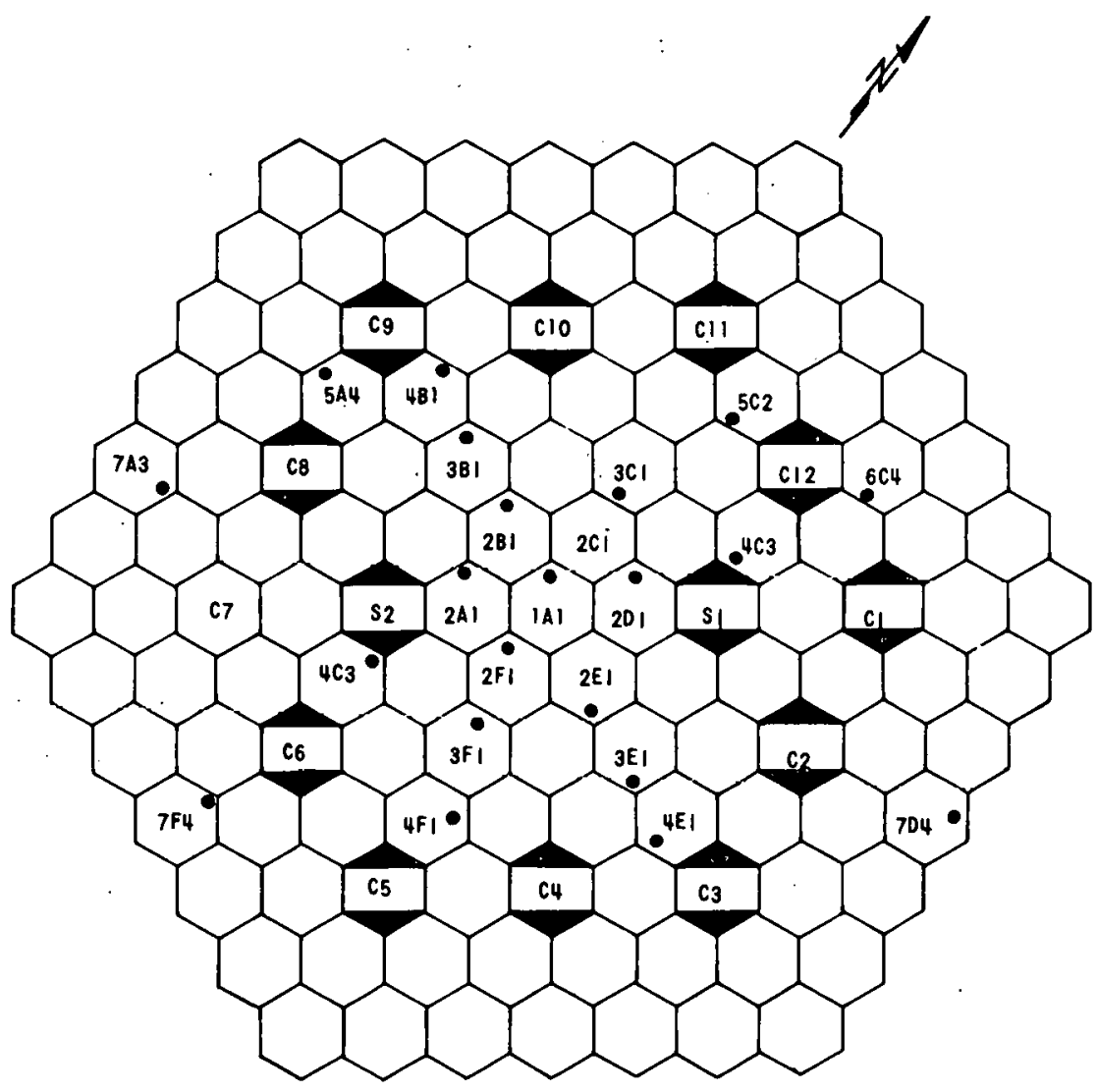

ID $-103-\mathrm{K}-5820$

Fig. 58. Thermocouple Locations in EBR-II

Sct points for the scram thermocouples are set in the following manner. At critical, the set points are those for the previous $r$ un. When a power level of $20 \mathrm{MWt}$ is reached, each of the four thermocouple-outputs is read. These values are then used to estimate the temperature differential $(\Delta T)$ across the four scram subassemblies at operational power. The scram limits are then set for a $10 \%$ increase above the estimated $\Delta \mathrm{T}$ value. Upon reaching operating power, the individual set points are readjusted in accordance with the actual readings and the off-normal criterion of $10 \%$.

As an added precaution, all thermocouple readings were plotted as a function of power level during all Run-25 startups. In all but a few instances, the temperature differential across a given subassembly varied linearly with power. In some cases, however, deviations from a straightline dependence were noted. In those cases for which the temperature differential at power exceeded the anticipated value, the origin of the dis crepancy was traced to an inflow of heat from neighboring subassemblies that ran hotter because of their loadings. Discrepancies in the other direction were traced to the loss of heat through radial conduction to colder neighboring subassemblies. 
Only one other anomalous situation was noted. The actual outlet temperatures for subassemblies in positions $12 \mathrm{E} 6$ and $16 \mathrm{E} 9$ in general ran hotter than the calculated outlet temperatures. The origin of this discrepancy was attributed to crossflow effects (i.e., the thermocouples in these positions were sensing the temperature of hotter sodium that was flowing outward from the center of the plenum to the discharge pipe).

\section{Synthesis of a Feedback Model}

In formulating a mathematical model for the feedback, the ultimate achievement is a detailed, yet understandable, model that explains all experimentally observed kinetic phenomena for all conditions of power, coolant flow rate, and temperature. In practice, the strong nonlinearities associated with subassembly bowing and the dependence of the power coefficient on indeterminate clearance systems effectively eliminates from consideration the formulation of a truly unified model for the feedback as a function of frequency, power, temperature, and coolant flow rate. With the information available, the best that can be attained is a mathematical expression, or model, that considers the magnitudes and time dependencies of special physical processes for a limited range of power and coolant flow conditions. Insofar as understanding the Run-25 feedback is concerned, such a model is considered sufficient because each term in the model may be identified with some specific thermal-mechanical-reactivity feedback process in the system.

Attempts have been made by Nichols on and Hyndman ${ }^{28}$ to interpret feedback effects from rod-drop and transfer-function data taken during Run $26 \mathrm{~B}$ in terms of a relatively simple model. Essentially, the approach involved fitting feedback functions from transfer-function and rod-drop data to models in the frequency and time domains, respectively. Then, through a series of trial-and-error iterations, both sets of data were forced to give a consistent feedback model. After applying small corrections for bowing effects in the oscillator rod and for changes in the worth of the drop rod as a function of power, two specific models were generated. One (Model A) gave the best fit in the time domain, and the other (Model B) gave the best fit in the frequency domain. Illustrations of the time- and frequency-dependent behavior of both models at $22.5 \mathrm{MWt}$ in Run $26 \mathrm{~B}$ are given in Figs. 59 and 60, respectively. [In Fig. 60, $(\Delta \mathrm{k} / \mathrm{k}) /(\Delta \mathrm{P} / \mathrm{P})=$ unit reactivity change per unit power change.]

Although no single model could be found that was consistent with both sets of data, the marked similarities of the two models indicate that the overall feedback consists of four and possibly five major components, two of which are relatively prompt and negative and two of which are strongly delayed and positive. The existence of a third, relatively delayed 
negative component is also indicated from the rod-drop data. In defining individual terms of the feedback models, a positive amplitude indicates a negative feedback, and a negative amplitude a positive feedback.

The physical processes associated with the two "promptest" terms of Model A have been attributed by Nicholson and Hyndman to the expansion of fuel and coolant. The two positive terms of Model A are identified with delayed subassembly-bowing phenomena in Rows 6 and 7 and in Row 8 , and the delayed negative term is attributed, in part, to the expansion of control-rod shafts.

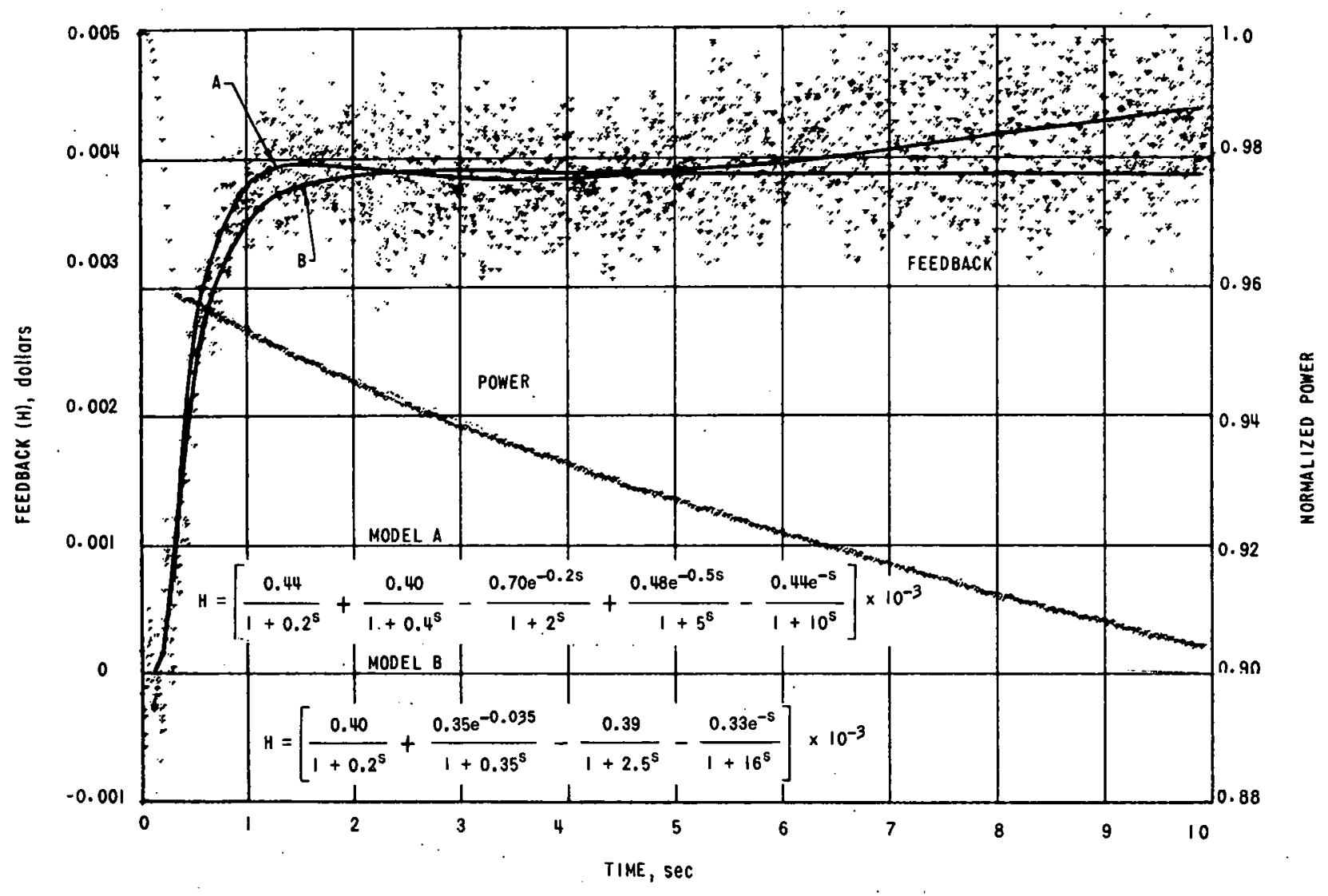

ID-103-K -5131 Rev. 1

Fig. 59. Fit of Mathematical Feedback Models to Data from Rod-drop Experiment at 22.5 MWt in Run 26B 


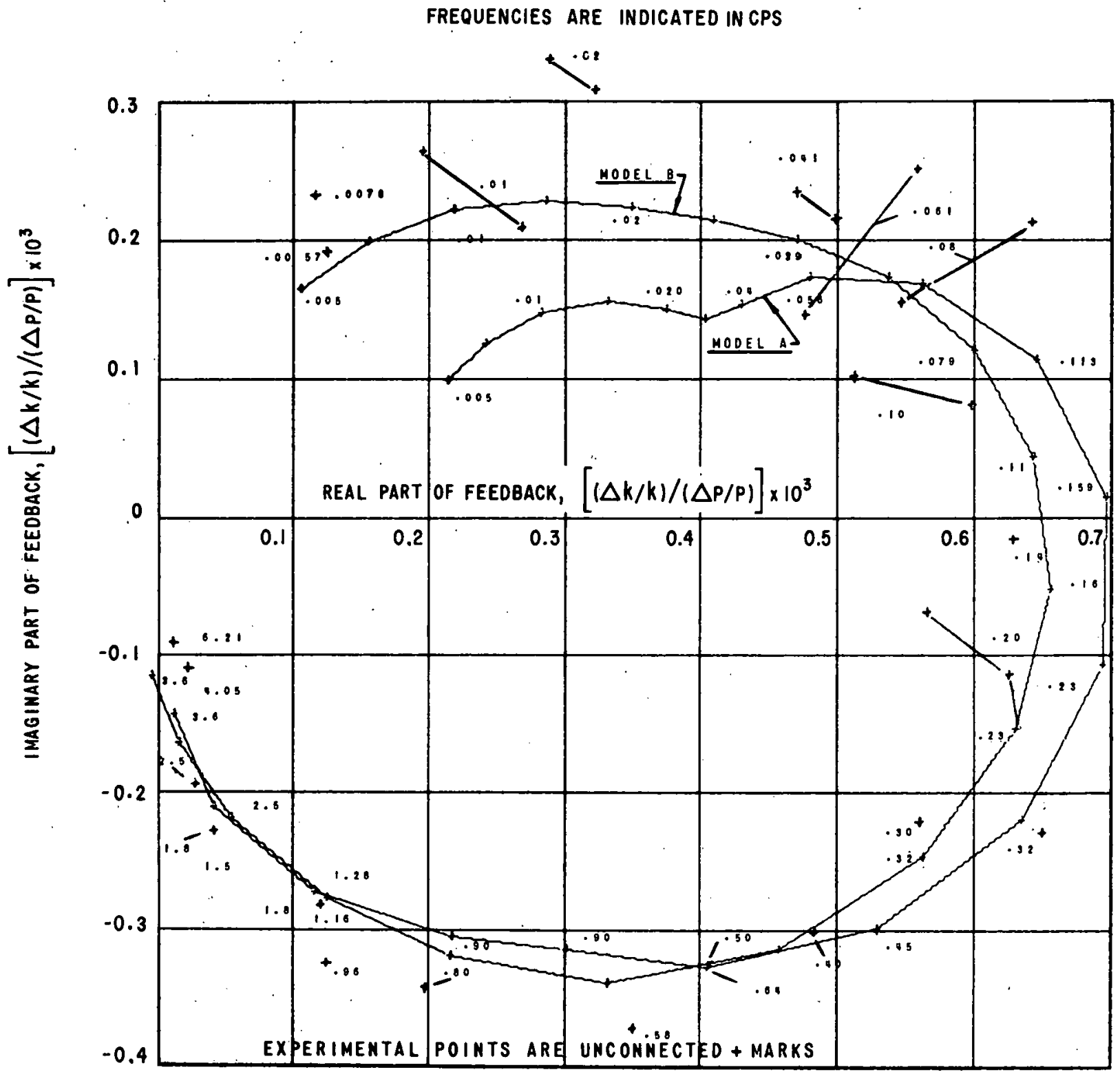

D-103-K-5138 Rev. 1

Fig. 60. Fit of Mathematical Models to Nyquist Plot of Oscillator Feedback Function at $22.5 \mathrm{MWt}$ in Run $26 \mathrm{~B}$ 


\section{PHYSICAL FEEDBACK MODEL}

In this section, an attempt will be made to explain why the power coefficient changed upon the installation of the stainless steel reflector and to show how the explanation is consistent with the results of specific experiments and observations.

\section{A. The Effects of Subassembly Bowing}

Up to and including Run 24, the effect of a power increase was reflected by an increase in the temperature differential across a given subassembly and a consequent increase in the tendency for the subassembly to bow outward at the top. Since all temperature differentials were in the same direction, the ultimate consequence of a power increase was a flowering of the core at the top. Such an effect tended to increase the core radius and to reduce the reactivity of the system. Eventually, the tops of subassemblies would engage and, by so doing, would decrease the extent of flowering with an additional power increase. Equally important was the tendency for subassemblies to bow inward under increased power conditions once their tops were fully engaged. The two effects were reflected in the power coefficient by a decrease in the negative (flowering) component and an increase in the positive (inward bowing) component. Such effects have always been present in EBR-II, but up until Run 25 the competition between positive and negative components was such that the negative always predominated. More freedom was available at the tops of subassemblies to permit the flowering attitude.

The installation of the stainless steel reflector before the Run-25 startup caused a marked change in the temperature gradient acrus $s$ the Row -8 subassemblies. While temperature gradients across Row- 7 subassemblies were normal, the increased power generation in Row-9 (uranium) subassemblies, resulting from an increased neutron and gamma transmission in Rows 7 and 8 , caused the outboard.faces of Row- 8 subassemblies to run hotter than the inboard faces. The reversal in the temperature gradient across Row 8 was manifested by a bowing attitude opposite to that in all inboard subassemblies. In effect, bowing phenomena in Rows 7 and 8 resembled the form of a pair of closed parentheses, thus ( ), and had the effect of a closed spring which tended to expand as the power increased. Expansion restricted the outward movement of the tops of inboard subassemblies and forced inboard subassemblies inward at midplane. Furthermore, as Bump has shown, forces were sufficient to cause the elastic deformation of spacer pads, thereby accentuating the extent of inward subassembly movement.

Evidence that spacer pads were very likely being elastically and inelastically indented was indicated from examinations of discharged subassemblies. As described by Smith and Mitchell, the average dimensional change across a given set of flats was a decrease of 0.0012 in. Such results clearly indicated the existence of elastic and inelastic deformational effects. 
As indicated from the many.illustrations of power-coefficient data in Sections III through VII, the effect of increasing power on the PRD depended strongly on the actual power level. At low power $(0-15 \mathrm{MWt})$, the PRD was relatively unaffected by the reflector change, and the differential power coefficient was strongly negative: Such behavior reflects the effects of core blossoming superimposed on the normal linear and strongly negative effects of fuel and coolant expansion. In the midpower range (15-30 MWt), subassembly tops came under restraint, causing the normal negative flowering component to decrease and the inward-bowing component to increase. The combined effects were strong enough to compete successfully with the unchanged linear negative-feedback processes. At higher levels of power (30-45 MWt), the system became ordered in two major areas: at the top, and at midplane as spacer-pad clearances became closed. Additional power increases in this power range were reflected by an overall outward movement of the core both at midplane and at the top. Such movements resulted in an increase in core radius, and the associated decrease in reactivily was superimposed on the normal linear negative effects.

B. Consistency of the Model with Experimental Information

The physical model described above is consistent with the mathematical model derived by Hyndman and Nicholson from rod-drop and transfer-function data. From analyses of many sets of feedback data in both the time and frequency domains, Hyndman and Nicholson identified the normal negative feedback effects (i.e., expansion of fuel, conlant, and control-rod shafts) and two positive effects. One of the positive effects is moderately delayed and presumably associated with bowing phenomena in Rows 6 and 7 , and the other is strongly delayed and associated with reversed bowing effects in Row 8 .

As the results of attempts to scale the overall feedback as a linear function of power, Hyndman and Nichols on found that whereas the feedback from fuel and coolant expansion was a linear multiple of power, the feedback from bowing was strongly nonlinear. Again such results are consistent with the physical and mathematical models since the importance of nonlinear bowing phenomena in the midpower region is clearly predicted.

The experimental verification of a consistent and strongly negative prompt power-coefficient component is also consistent with both the physical and mathematical models because both models predict strong negative feedbacks from both fuel and coolant expansion.

Additional verification that the power coefficient associated with fuel expansion remained strong throughout the residence of the stainless steel reflector was provided by the results of the constant- $\Delta T$ experiments 
described by Long and Madell. Although small variations in the fuel component of the power coefficient were occasionally noted, no significant or potentially serious change was indicated.

C. Other Power-coefficient Anomalies

In view of the results of an unusually large computational and experimental effort, there seems little doubt that the principal origin of the reduction of the power coefficient in Run 25 involved reversed temperature gradients in the stainless steel subassemblies in Rows 7 and 8 . The simple model based on this reversal, however, does not explain other peculiarities noted in the power coefficient during the time the stainless steel reflector was installed. At least two such peculiarities may be cited. One was the marked deterioration noted in the power coefficient near the end of Run 26, and the other the persistent trend toward higher PRD values throughout Runs 27, 28, and 29.

The fact that $P R D$ values tended to decrease with burnup (or running time) is not considered an anomaly or peculiarity. As illustrated in Figs. 9 and 10, when corrections were applied for the effects of expansion of control-rod shafts, no discernible difference could be found between the initial and final PRD behaviors in Run 25.

\section{Deterioration of the Power Coefficient during Run 26}

In Run 26, marked differences between initial and final PRD behaviors were noted which could not be reconciled with the banked-controlrod effecl. Common to all measurements that indicated a decrease in the PRD was a marked tendency for the reactivity balance to drift, as discussed in Sections IV.C and IV.D. Typical behavior was the continuous insertion of reactivity over a period of hours when operating in the midpower region, followed by a continuous removal of reactivity after sustained operation at $45 \mathrm{MWt}$. In effect, the insertion of reactivity while conducting powercoefficient measurements in the midpower region led to the impression that the power coefficient was weakening. In retrospect, it seems clear that if corrections for the gradual increase in reactivity could have been applied no anomaly would have been noted during Run 26.

The origin of the pronounced reactivity drift noted during Run 26 is obscure and has not been unambiguously identified. On the other hand, a substantial amount of evidence indicates that reactivity drifts were associated with the bent control-rod thimble in position 5C4. As cited in Section V, two recorded difficulties were experienced with fuel transfers in this location: one on January 17, 1967, and a more-serious indication on September 20, 1967 (during Run 26). It:is now postulated that the major damage to the thimble occurred on September 20 and that the crimping of the 
thimble created an extensive gap between an indeterminate number of core and reflector subassemblies. Such a gap would have significantly altered the clearance situations throughout the core. Assuming that a gap did result from the damage to the 5C4 thimble, it seems reasonable to believe that strong changes would occur in the power coefficient. For example, subassemblies in locations outboard from the gap would have more freedom to bow inward at midplane and thereby increase the reactivity of the system. On the other hand, the effects of an overall radial expansion of subassemblies inboard from the gap would not be sensed as a contiguous expansion by subassemblies in locations on the other side of the gap.

The fact that reactivity tended to increase in the midpower region is believed to be the natural consequence of strong compressive forces exerted at midplane elevation by reversed bowing effects in the reflector. Increased clearances were afforded by the gap, and the forces built up in the reflector tended to move subassemblies inward to fill the gap. The fact that such movements took place over a period of hours is not considered unusual since it is conceivable that the movement consisted of an intermittent slippage of individual subassemblies, one at a time.

With the reactor operating at $45 \mathrm{MWt}$, a reversal in movements was noted. Since inward bowing motions were essentially saturated, the predominant manifestation of subassembly expansion was a net movement outward. In this instance, outward forces caused the intermittent slippage of individual subassemblies either into the gap or across the gap into clearances opened in outlying rows during operation in the midpower region.

\section{Reactivity Anomaly on January 29, 1968}

During the approach to criticality for Run 27 on January 29, 1968, it was noted that the system was more reactive than expected. Even after intensive efforts to evaluate the associated reactivity effect for eachloading change, the system was approximately 56 Ih more reactive than the results of calculations indicated. At that time, the reactivity gain was tentatively attributed to core-rearrangement effects associated with the removal and replacement of the damaged control-rod guide thimble prior to Run- 27 startup.

The removal of the damaged control-rod guide thimble eliminated.the postulated gap. Subassemblies lying outboard.from the gap were very likely under compressive forces, and when the gap was eliminated a net inward movement of subassemblies resulted. While no attempt was made to correlate inward movement with the 56-Ih reactivity gain, the fact that a 1 -mil change in core radius results in a 3 -Ih reactivity gain suggests that closure of the gap could have caused a fairly large reactivity gain. 


\section{The Increase in PRD during Runs 27 through 29}

As indicated in Sections VI and VII and illustrated in Figs. 35 and 36, a definite trend toward increasing power-coefficient values was noted throughout Runs 27 through 29. In fact, the indicated increase between the Run-27A and Run-29A startups was approximately 7.1 Ih. Since both cores were essentially the same, the increases cannot be attributed to configurational and compositional changes. Again it is reasonable to postulate that at least a portion of the gradual increase noted in the PRD throughout this period (approximately five months) was associated with the closing of the gap. In other words, the elimination of the gap before the Run-27A startup caused a step increase of $56 \mathrm{Ih}$, and subsequent fuelhandling operations, which rearranged clearances, caused an additional 7.1 Ih increase. On the other hand, the gradual increase might also have been the result of the increasing use of cold-line fuel during this period. Such effects are discussed in the following section.

\section{Long-term Changes in Fowcr Coofficient}

During the period between July 1964 and December 1966, a long-term tendency towards lower PRD values is evident. An illustration of this effect is given in Fig. 42. At one time it was believed that the decrease was the consequence of increasing the core outline and decreasing the average concentration of fissile material in the core. This supposition seemed reasonable since the specific worth of fuel material at the edge of a larger, more-dilute core should be smaller than the corresponding worth with a smaller, more-concentrated metal-fueled core. On the other hand, the results of intensive calculational efforts by Persiani, Madell, and Blomberg were consistent in their indication that the gradual decrease in PRD from July 1964 to December 1966 could not be reconciled with changes in core composition and configuration.

An impressive demonstration of the insignificance of the effects of core size and composition on PRD was experienced during Run 28 when $P R D$ values for a reference core containing no fueled experiments, were compared with PRD values for a core containing experiments in Rows 6 and 7 and a core containing experiments in Rows 4 through 7 . The difference in PRD values between the reference (no experiment) core and the core with a full complement of experiments was 2 Ih (increase). Accordingly, it must be concluded that the effects of core configuration and composition on the power coefficient are small and that the gradual decrease noted over the period from July 1964 to December 1966 must have involved some other effect. Similarly, it must be concluded that the gradual increase in PRD noted between January 1968 and July 1968 could not be the result of compositional or configurational changes. 
Although conjectural at this time, it is conceivable that the origin of the trend towards smaller PRD values between July 1964 and December 1966 might have been associated with the use of recycled fuel. For example, the continuous accumulation of nonvolatile fission products in the fuel during this period might have affected the power coefficient through a gradual reduction of the linear expansion coefficient of the fuel material. Part or all of the indicated recovery throughout Runs 27-29 presumably could have been the result of using less recycled fuel and more cold-line (fresh) fuel during this period. Cold-line fuel was first used during Run 27D when three subassemblies containing it were added. During Run 28, ten subassemblies of cold-line fuel were installed, and at the start of Run 29A, seven of the 71 driver subassemblies in the reactor were made up of cold-line material. Unfortunately, studies of the effects of fuel recycling on the linear-expansion properties of fuel material have not been conducted; therefore, it is impossible to conclude whether or not the recycling of fuel decreases its expansion coefficient. Hopefully, measurements may be conducted on historical and cold-line fuel samples to resolve this important possibility. 


\section{THE EFFECT OF REINSTALLING A URANIUM REFLECTOR ON THE POWER COEFFICIENT}

As discussed in Section VII, the stainless steel reflector was replaced with conventional depleted-uranium subassemblies during Run 29. The replacement was carried out in two stages: first, the replacement of Row 7, and then the replacement of Row 8. The replacement in Row 7 resulted in a 5.6-Ih increase in the PRD relative to the Run-29A reference, and the replacement in Row 8 resulted in an additional 29.0 - Ih increase. From an inspection of Fig. 35, which gives power-coefficient data for Runs 24, 25, and 29, it may be concluded that the reinstallation of uranium subassemblies in Rows 7 and 8 eliminated the flattening of the power coefficient in the midpower region and actually increased the PRD relative to that in Run 25.

Since the restoration of the uranium blanket during Run 29, no evidence of power-coefficient flattening in the midpower region has been noted. Accordingly, it may be concluded that the installation of the stainless steel reflector in Run 25 caused the power-coefficient decrease and that its replacement in Run 29 returned the system to its normal behavior. 


\section{REFERENCES}

1. R. R. Smith, T. R. Bump, R. A. Cushman, R. W. Hyndman, F. S. Kirn, W. B. Loewenstein, J. K. Long, J. T. Madell, and P. J. Persiani, Recent Operation Experience with EBR-II, paper to be presented at the British Nuclear Energy Society Int. Conf. on the Physics of Fast Reactor Operation and Design, London, England, June 1969.

2. F. S. Kirn, J. K. Long, and R. R. Smith, Effect of the Stainless Steel Reflector on the Power Coefficient of EBR-II, Trans. Am. Nucl. Soc. 10(2), 648 (Nov 1967).

3. R. A. Cushman, The Effect of Radial Heat Transfer on the Temperature Distribution in EBR-II Stainless Steel Reflector Subassemblies, Trans. Am. Nucl. Soc. 10(2), 66 (Nov 1967).

4. R. A. Cushman, EBR-II Reactor Heat Transfer: Experience with an Operating Liquid Metal Fast Breeder Reactor, Heat Transfer, Philadelphia, AIChE Symposium Series 65(\$2), (1969).

5. R. A. Cushman, Thermal-hydraulic Analysis of the EBR-II Stainless Steel Reflector, ANL-7536 (to be published).

6. T. R. Bump, BOW-II - A Code for Calculating Deflections of Closely Spaced Parallel Beams, Each with Limited Pivotal Support at One End', Possible Beom Interactions at the other End and at one Intermediate Position, and Arbitrary Temperature Distribution, ANL-7528 (to be published).

7. T. R. Bump, Effect of Reactor Temperatures on Bowing of EBR-II Subassemblies, Trans. Am. Nucl. Soc. 10(2), 661 (Nov 1967).

8. R. R. Smith and D. L. Mitchel1, Post-irradiation Properties of Subassemblies Discharged from Runs 25 and 26 in EBR-II, ANL-7538 (to be: published).

9. P. J. Perșiani, T. R. Bump, R. A. Cushman, J。K. Long, and D. A. Kucera, Analysis of the Variation in the EBR-II Power Coefficient due to. Blanket Change, Trans. Am. Nucl. Soc. 11(1), 282 (June 1968).

10. P. J. Persiani, J. Kallfelz, F. S. Kirn, J. K. Long, and R. R. Smith, EBR-II Power Coefficient Variations during Operational Run 26, Trans. Am. Nuc1. Soc. 11(1), 281 (June 1968).

11. J. T. Made11, "Investigation of the Temperature Coefficient of EBR-II Run 25," in Reactor Physics Division Annual Report, July 1, 1966 to. June 30, 1967, ANL-7310.

12. R。 E. Jarka and J. T. Made11, "Further Investigation of the Jinear Components of the Power Coefficient of EBR-II," in Reactor Physics Division Annual Report, July 1, 1967 to June 30, 1968, ANL-7410.

13. P. J. Persiani, J. Kallfelz, F. S. Kirn, J. K. Long, and R. R. Smith, "EBR-II Power Coefficient Variations during Operational Run 26," in Reactar Physics Division Annual Report, July 1, 1967 to June 30, 1968, ANL-7410.

14. P. J. Persiani, R. A. Cushman, J. K. Long, and D. Kucera, "Analysis of the Variation in the EBR-II Power Coefficient due to Blanket Changes," in Reactor Physics Division Annual Report, July 1, 1967 to June 30, 1968, ANL-7410。 
15. J. T. Madell and R. E. Jarka, Investigation of the Constant Components of the Power Coefficient of EBR-II, ANL-7539 (to be published).

16. J. K。 Long and F。 S。 Kirn, Effect of Reduced-flow Conditions on the Power Coefficient of EBR-II, Trans. Am. Nucl。Soc. 11(1), 280 (June 1968).

17. J. K. Long, Analysis of the Static Power Coefficient of EBR-II with Reduced Coolant Flow, Nucl. Appl。6, 116 (Feb 1969).

18. P.E. Blomberg, A Synthesis Method for Calculating Temperature, Power, and.Bowing Reactivity Coefficients of Fast Reactors, Trans. Am. Nucl. Soc. 11(1), 208 (June 1968).

19. P. E. Blomberg, An Analytical Method for Determining the Temperature and Power Reactivity of Fast Power Reactors, ANL-7466 (to be pub1ished).

20. J. To Made11, Development of a Neutron Model for EBR-II, ANL-7540 (to be published)。

21. J. 'I'. Madell, "Some Effects of Fe, Mo, and Ni Reflector Placed between the Core and Blanket of EBR-II," in Reactor Physics. Division Annual Report, July 1, 1966 to June 30, 1967, ANL-7310.

22. J, T. Madel1, "Multigroup Cross-section Sets for Neutronic Calculations of EBR-II," in Reactor Physics Division. Annual Report, July 1, 1966 to June 30, 1967, ANL-7310。

23. D。 Kucera and J. T. Madell, "Analysis and Development of Neutron Cross-sections for. EBR-II Studies," in Reactor Physics Division Annual Report July 1, 1967 to June 30, 1968, ANL-7410.

24. R. E. Jarka and Jo T. Madell, "Investigation of Regional Representations of the Core of EBR-II," Reactor Physics Division Annual Report, July 1, 1967 to June. 30, 1968, ANL-7410.

25. J. K. Long, A Documentation of EBR-II Criticality Data for the Period during Which a Stainless Steel Reflector Was Installed, ANL-7541 (to be published)。

26. R. W. Hyndman; M. R. Tuck, and F. S. Kirn, On-line Tronsfer Function Analysis of EBR-II, Trans. Am. Nucl. Soc. 10(2), 696 (Nov 1967).

27. R. W. Hyndman and M. R. Tuck, An On-line Method of Transfer Function Analysis in EBR-II, Nucl。Appl。6, 137-141 (Feb 1969).

28. R. W. Hyndman and R. B. Nicholson, The EBR-II Feedback Function, ANL-7476 (July 1968).

29. I. A. Engen and R。W. Hyndman, A Catalog of Rod-drop and Transfer Function Data, Runs 25-30A, ANL-7542 (to be published).

30. J. A, DeShong, Dynamic Analysis of Liquid-metal-cooled Fast Power Reactors, ANL-7529 (Jan 1969).

31. R. R。Smith, R。 D, DeForest, F. Just, and F. S。 Kirn, EBR-II Dynamics, Trans. Am。Nucl。Soc, 8(2), 478 (Nov 1965).

32. F. S. Kirn, R. W. Hyndman, R. R. Smith, and H. Kuroi, Monitoring Reactor Kinetics in EBR-II, Trans. Am. Nucl. Soc. 8(2), 602 (Nov 1965). 
33. L. J. Koch, H。 O. Monson, D. Okrent, M. Levenson, W. R. Simmons, J. R. Humphreys, J. Haugsnes, V. Z。 Jankus, and W. B. Loewenstein, Hazard Sumary Report, Experimental Breeder Reactor-II (EBR-II), ANL-5719 (May 1957).

34. L. J. Koch, W. B. Loewenstein, and H. O. Monson, Addendum to Hazard Summary Report, Experimental Breeder Reactor-II. (EBR-II), ANL-5719 (Addendum), (June 1962).

35. R. R. Smith, C. B. Doe, and F. S. Kirn, The Application of Cover Gas Monitoring in the Recent EBR-II Fission Product Release, Trans. Am. Nucl. Soc. 10(2), 634 (Nov 1967).

36. R. R. Smith et al., Locating and Identifying the Source of the May 24, 1967, Fission-product Release in EBR-II, ANL-7543 (to be published)。

37. R. R. Smith and C. B. Doe, Fuel Element Failure Detection in EBR-II, Trans. Am. Nucl. Soc. 8(2), 602 (Nov 1965).

38. R. R. Smith and C. B. Doe, Cladding Failure Simulation Tests in EBR-II, ANL-7067 (Dec . 1966).

39. E. R. Ebersole and R. Villarreal, Diagnostic Radiochemistry Following the Recent EBR-II Fission Product Release, Trans. Am. Nuc1. Soc. 10(2), 634 (Nov 1967).

40. W. B. Loewenstein, "EBR-II Physics," in Reactor Physics Division Annual Report, July 1, 1963, to June 30, 1964, ANL-7010.

41. R。 R. Smith, E. R. Ebersole, and F. W. Thalgott, Experience with a Gas-type Failure in an EBR-II Driver Fuel Element, Trans. Am. Nucl. Soc. $11(1), 279$ (June 1968)。

42. R. W. Hyndman, F. S. Kirn, and R. R. Smith, EBR-II Solf-excited Oscoilzations, Trans. Am. Nucl. Soc. 8(2), 590 (Nov 1965). 